Zachary Gallant

Katharina F. Gallant

\title{
Brauner Boden
}

Ein jüdischer Blick

auf die deutsche Aufarbeitung

der NS-Zeit

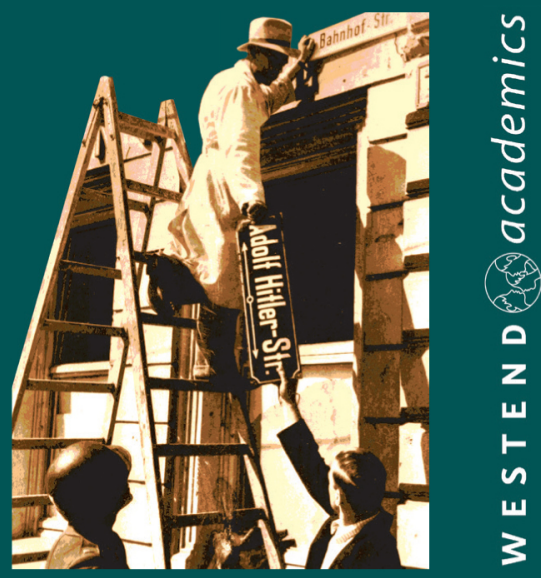




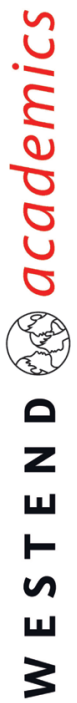





\section{ZACHARY GALLANT}

KATHARINA F. GALLANT

\section{Brauner Boden}

Ein jüdischer Blick auf die deutsche Aufarbeitung der NS-Zeit 
Veröffentlicht mit Unterstützung der Muslim Jewish Alliance
und Juma e.V. im Rahmen der EU-geförderten
Muslim Jewish Coalition for Combatting Hatred

Mehr über unsere Autoren und Bücher:

www.westendacademics.com

Die Deutsche Nationalbibliothek verzeichnet diese Publikation in der Deutschen Nationalbibliografie; detaillierte bibliografische Daten sind im Internet über http://dnb.d-nb.de abrufbar.

Dieses Werk ist lizenziert unter der Creative Commons Lizenz: CC BY-NC-ND 3.0; diese Lizenz erlaubt die private Nutzung, gestattet aber keine Bearbeitung und keine kommerzielle Nutzung. Weitere Informationen finden Sie unter: https://creativecommons.org/ licenses/by-nc-nd/3.0

DOI: https://doi.org/10.53291/NQTZ6935

ISBN 978-3-949925-01-6

(C) Westend Verlag GmbH, Frankfurt am Main 2022

Umschlaggestaltung: Westend Verlag, Frankfurt am Main

Printed in Germany 
קדצ יפדור Zachary Gallant ist Mitbegründer der Organisation (Rodfei Tzedek), die sich zum Ziel gesetzt hat, unter in Europa lebenden Jüdinnen und Juden das Zugehörigkeitsgefühl zu Europa wieder zu stärken. Gallant ist Leiter des vom Bundesamt für Migration und Flüchtlinge geförderten interkulturellen und interreligiösen Verständigungsprojekts „Values are One“ der Stiftung Weltethos. Außerdem ist er Organisator mehrerer großer Projekte für Geflüchtete und interkulturellen Dialog. Eines dieser Projekte wird in der Kleinstadt Unkel umgesetzt und zählte $2019 \mathrm{zu}$ den Gewinnern des deutschen Integrationspreises. Gallant hat einen Masterabschluss in internationalen Studien und sammelte als Fulbright-Stipendiat für Post-Konflikt-Wiederaufbau umfangreiche Forschungserfahrung in Ost- und Südosteuropa. $\mathrm{Zu}$ seinen Interessens- und Forschungsschwerpunkten zählen Intervention in und Wiederaufbau nach Konflikten sowie die Auswirkungen von Armut und organisiertem Verbrechen auf die Zivilgesellschaft in verschiedenen regionalen Kontexten.

Dr. Katharina F. Gallant forscht als Ethnologin und Psychologin zu Interkulturalität und interethnischen Konflikten und legt dabei den Fokus auf die soziale Rolle der jüdischen und der muslimischen Gemeinschaft im sogenannten westlichen Kulturraum, auf die politische Repräsentation von indigenen und afroamerikanischen Minderheiten in Nord- und Lateinamerika sowie im afrikanischen Kontext auf ethnische Konflikte in der Sahel-Region und ihren Zusammenhang mit Ernährungsunsicherheit, unzureichender Governance und Infektionskrankheiten. Zudem war sie von 2019 bis 2021 Mitglied des Unkeler Stadtrates. 



\section{Inhalt}

Dankeswort ................. ix

Anmerkung zur Aufarbeitung der Vergangenheit eine Zukunft geben . . . . . . . . . 1

Henkels Persilschein: Aufarbeitung in einer deutschen Kleinstadt. . . . . . . . . . . . . . . . . 11 Ausgangssituation . . . . . . . . . . . . . . . 11 Aufarbeitung und das deutsche Unternehmertum . . . 13 Henkel - ein Familienunternehmen in der NS-Zeit. . . 21 Henkel - eine Familie in Unkel und ihre Profite aus der NS-Zeit . . . . . . . . . . . . . . . . . . 30 „Nie wieder" - ein lokales Paradoxon . . . . . . . . . .43 Ausblick zur Aufarbeitung im deutschen Unternehmertum . . . . . . . . . . . . . . . . . . . .46

Gedenken als Freifahrtsschein: Unzulänglichkeiten der Aufarbeitung. . . . . . . . . . . . . . . . 53 Geschichte des lokalen Kontexts . . . . . . . . . . . . .53 Gedenkveranstaltung - zur Rhetorik der Aufarbeitung . . 58 Stadtbild - die Architektur des Gedenkens. . . . . . . . . 62 Judenfreie Aufarbeitung? . . . . . . . . . . . . . . . . . . 74 Ausblick zur internationalen Bedeutung der deutschen Aufarbeitung. . . . . . . . . . . . . . . . 91 Abschließende Betrachtungen zur

NS-Durchdrungenheit . . . . . . . . . . . . . . . 101 



\section{Dankeswort}

U nser außerordentlicher Dank gilt Prof. Dr. Peter Hayes, dessen Arbeiten über die Verstrickungen von Unternehmen in die Shoah und die Kriegsverbrechen des nationalsozialistischen Regimes, insbesondere derer von I. G. Farben und Degussa, einen wegweisenden Impuls für dieses Buch darstellen. Besonderer Dank gebührt Hayes zudem für die unterstützenden Anregungen, die er uns bereits zu Beginn unserer Recherchearbeit zuteilwerden ließ.

Überaus dankbar sind wir auch Barbara Bartel für zahlreiche Gespräche über die Aufarbeitungskultur der rheinischen Kleinstadt Unkel, ihre Erfolge ebenso wie ihre Herausforderungen und zukünftige Aufgaben. In ähnlicher Weise sind wir auch Klaus-Henning Rosen zu besonderem Dank verpflichtet für seine hilfreichen Ratschläge, aber auch für seine eigenen Recherchen über jüdisches Leben in Unkels Nachbargemeinde Rheinbreitbach sowie seinen außerordentlichen Einsatz für die Aufarbeitung von Rheinbreitbachs Verstrickungen mit dem nationalsozialistischen Regime. Es ist Rosens Verdienst, dass im Juni 2021 die ersten Stolpersteine in Rheinbreitbach verlegt werden konnten. Dank gebührt auch Roland Thelen und Karsten Fehr dafür, dass die Stolpersteinverlegung unter ihrer politischen Federführung erfolgte. Fehr hatte sich in den vergangenen 
Jahren durch seinen besonderen Einsatz für eine gelebte Willkommenskultur und eine politische Repräsentation von Menschen verschiedener nationaler Hintergründe hervorgetan. $\mathrm{Zu}$ dieser Integration der Diversität im alltäglichen Miteinander passte jüngst auch das Erinnern an drei der ermordeten Jüdinnen von Rheinbreitbach im Rahmen der Stolpersteinverlegung.

Des Weiteren unterstützte uns Holly Huffnagel vom Amerikanisch-Jüdischen Komitee (American Jewish Committee) beim Verfassen des vorliegenden Buches, indem sie die bis heute andauernde Gefahr des Antisemitismus auf nationaler und internationaler Ebene hervorhob. Celia Gomez von der jüdischen Auswanderungshilfsorganisation Hebrew Immigrant Aid Society (HIAS Europe) sowie Maurice Kirschbaum, ehemaliger Sprecher der europäischen Union jüdischer Studierender (European Union of Jewish Students) sowie der Internationalen Vereinigung jüdischer Anwälte und Juristen (International Association of Jewish Lawyers and Jurists) beim UN-Menschenrechtsrat, betonten durch ihre Anmerkungen die internationale Relevanz dieses Buches. Eine große Bereicherung waren auch die Anregungen der Rabbinerin Rebecca Lillian sowie die Kommentare des Politikwissenschaftlers und Publizisten Dr. Max Czollek zur jüdischen Perspektive aufdas Thema der deutschen Aufarbeitung. Ihnen allen sind wir zu großem Dank verpflichtet.

Schließlich gilt unser besonderer Dank Dr. Constanze Klein für ihr außergewöhnliches sprachliches Fingerspitzengefühl bei der redaktionellen Überarbeitung dieses Buches. Abschließend besonders hervorheben möchten wir auch die beispielhafte Solidarität, mit der die Muslim Jewish Alliance und insbesondere Dennis Sadik Kirschbaum von JUMA e.V. (JUMA - jung, muslimisch, aktiv) die Veröffentlichung des vorliegenden Buches im Rahmen des EU-geförderten Projekts „Muslim Jewish Coalition for Combating Hatred“ $(\mathrm{MJCCH})$ gefördert haben. 


\section{Anmerkung zur Aufarbeitung - der Vergangenheit eine Zukunft geben}

$\mathrm{V}$ or mehr als 60 Jahren hielt der Philosoph und Soziologe Theodor W. Adorno vor dem Koordinierungsrat für Christlich-Jüdische Zusammenarbeit einen Vortrag mit dem Titel „Was bedeutet: Aufarbeitung der Vergangenheit“. Wenige Monate später wurde dieser als Beitrag im Hessischen Rundfunk gesendet und erreichte dadurch ein breites Publikum. In seinem Vortrag kritisierte Adorno nachdrücklich die damals gängige deutsche Aufarbeitungspraxis der Zeit des Nationalsozialismus. Sie versäume, „daß man das Vergangene im Ernst verarbeite, seinen Bann breche durch helles Bewußtsein". ${ }^{1}$ Hinter dem Begriff der Aufarbeitung verstecke sich, so Adorno weiter, das deutsche Bedürfnis, der Erinnerung zu entkommen und die Vergangenheit hinter sich zu lassen. ${ }^{2}$

1 Theodor W. Adorno, Was bedeutet. Aufarbeitung der Vergangenheit, in: Theodor W. Adorno (Gerd Kadelbach, Hrsg.), Erziehung zur Mündigkeit. Vorträge und Gespräche mit Helmut Becker 1959 bis 1969. Berlin (1959) 2013, E-Book-Ausgabe.

2 Vgl. ebd. 
Angesichts des Erstarkens rechtsextremer Gesinnungen und in einer Zeit, in der leicht verfügbare Informationen schnell als unstrittige Fakten hingenommen werden, ist es unabdingbar, den Stand der Aufarbeitung der Zeit des Nationalsozialismus in Deutschland erneut kritisch zu hinterfragen. Dieser Aufgabe widmet sich dieses Buch und legt dabei den Fokus auf das deutsche Unternehmertum, da auf diesem Feld die Aufarbeitung bis heute nur sehr zögerlich erfolgt. Am Beispiel des Familienunternehmens Henkel beleuchtet der erste Teil dieses Buches zunächst die Verstrickungen des Henkel-Unternehmens mit dem nationalsozialistischen Regime, der Enteignung europäischer Jüdinnen und Juden und der Shoah. ${ }^{3}$ Im nächsten Schritt wird die Bedeutung der Henkel-Familie als Wohltäter einer rheinischen Kleinstadt diskutiert. Als Sponsor öffentlicher Räume und Förderer des öffentlichen Lebens gestaltet die Henkel-Familie dort bereits in der dritten Generation das Stadtbild und prägt kulturelle Veranstaltungen. In einem weiteren Schritt stellt das Buch die historisch gewachsene Abhängigkeit der Kleinstadt von der Wohltäterfamilie dem Selbstverständnis der Kleinstadt als Wahlzuhause des früheren Bundeskanzlers Willy Brandt gegenüber. Dabei fällt die Diskrepanz zwischen der nationalsozialistischen Belastung des Henkel-Familienunternehmens einerseits und Willy Brandt als Sinnbild des Antifaschismus und des Aufarbeitungsprozesses andererseits unweigerlich ins Auge. Abschließend wird die Frage aufgeworfen, wie aus heutiger Sicht Unternehmen, Politikerinnen und Politiker sowie die breite Öffentlichkeit im Sinne der Aufarbeitung

3 Dieses Buch verwendet bewusst den Begriff ,Shoah ' anstelle von ,Holocaust", um zu betonen, dass der deutsche Völkermord an der jüdischen Gemeinschaft keineswegs ein Akt der Opferdarbietung war (der Begriff Holocaust impliziert ein Brandopfer), sondern eine absolute ,Katastrophe‘, wie der hebräische Begriff, Shoah“ übersetzt lautet. Aufgrund dieses maßgeblichen Unterschiedes in der Bedeutung und Konnotation wird auch in Paraphrasierungen auf den Terminus, Shoah` zurückgegriffen. 
verantwortungsbewusst mit dem Erbe Deutschlands aus der Zeit des Nationalsozialismus, insbesondere mit den Profiten der Arisierungen, umgehen könnten. Zentral ist dabei, die Aufarbeitung nicht als einmalig zu erreichendes Ziel anzusehen, sondern sie als fortwährenden Prozess zu begreifen. Dieser verlangt nicht zuletzt im Hinblick auf die Rolle deutscher Unternehmen während der Zeit des Nationalsozialismus, dass begünstigte Individuen ebenso wie politische Institutionen und Einrichtungen des öffentlichen Lebens stets die Ursprünge der ihnen zugedachten Gelder kritisch hinterfragen. Die hier formulierten Empfehlungen schließen sowohl den lokalen Kontext vergleichbarer Kleinstädte als auch die gesamtdeutsche Ebene mit ein und verweisen zugleich auf die Bedeutung des deutschen Aufarbeitungsprozesses im internationalen Kontext.

Die Notwendigkeit der Aufarbeitung des Nationalsozialismus bezieht sich nicht allein auf das deutsche Unternehmertum. Soll Aufarbeitung gelingen und authentisch sein, muss sie als fester Bestandteil der nationalen Identität alle Dimensionen des Lebens durchdringen. Dabei versteht sich von selbst, dass die Aufarbeitung weit über die Ebene der rhetorischen Absichtserklärung und Distanzierung von den Gräueltaten der Vergangenheit hinausgehen muss. Worten müssen Taten folgen - Taten müssen die Worte im Hier und Jetzt verankern als Fundament, das dem nationalen Diskurs Bestand gibt, als Eichung des ethischen Kompasses einer Gesellschaft.

Während im ersten Teil dieses Buches das Unternehmen Henkel im Vordergrund steht, widmet sich der zweite Teil einer kritischen Reflexion der deutschen Gedenkkultur, insofern als diese die offiziell vertretene Haltung zur eigenen Vergangenheit und nationalsozialistischen Belastung widerspiegelt. Erneut wird das Beispiel der rheinischen Kleinstadt genutzt, um den historischen Kontext der 
kulturellen Diversität einerseits und den Repressalien der Zeit des Nationalsozialismus bis hin zum Völkermord andererseits zu skizzieren sowie darauffolgend den gegenwärtigen Umgang mit der Vergangenheit auf rhetorischer und praktischer Ebene zu charakterisieren. Letztere bezieht die architektonische Dimension als Manifestation der deutschen Aufarbeitung im Stadtbild mit ein. Ausgehend von diesen weitgehend lokal illustrierten Ausführungen widmet sich dieser zweite Teil des Buches auch der Frage, welche Rolle Jüdinnen und Juden bei der deutschen Aufarbeitung der Zeit des Nationalsozialismus spielen. Das Kapitel „Judenfreie Aufarbeitung?" diskutiert, wie Jüdinnen und Juden im deutschen Umgang mit der nationalsozialistischen Vergangenheit auf die Rolle der Opfer der Shoah reduziert werden, ohne selbst als handelnde Subjekte Gehör zu finden. $\mathrm{Zu}$ diesen Ausführungen gehört auch die kritische Frage, welche Auswirkung die Objektifizierung der jüdischen Bevölkerung für die empfundene Aufrichtigkeit der Aufarbeitung hat, nicht zuletzt angesichts ihrer mangelhaften Umsetzung durch das deutsche Unternehmertum und der aus arisiertem Eigentum gewonnenen Profite, die bis heute Wirtschaft und Gesellschaft durchdringen.

Ebenso wie die Shoah nicht auf das Gebiet des heutigen Deutschlands beschränkt war, sollte auch ihre Aufarbeitung nicht lokal begrenzt gedacht werden. Entsprechend schließt dieser zweite Teil des Buches mit einem Ausblick zur internationalen Bedeutung der deutschen Aufarbeitung. Angestoßen von den Siegermächten, allen voran den USA, wurde die Aufarbeitung der nationalsozialistischen Verbrechen Teil der deutschen Wirklichkeit. Die Verpflichtung, sich der eigenen Vergangenheit zu stellen, obliegt Deutschland selbst und sollte entsprechend als unumgänglicher Bestandteil seiner nationalen Identität angesehen werden. Inwiefern die deutsche Aufarbeitung dadurch eine Vorreiterrolle im internationalen 
Vergleich einzunehmen vermag, ist Gegenstand der abschlieBenden Diskussion.

Ohne den folgenden Kapiteln vorgreifen zu wollen, sei an dieser Stelle auf zwei grundsätzliche Überlegungen hingewiesen: Den Stand der deutschen Aufarbeitung der Zeit des Nationalsozialismus kritisch zu reflektieren, birgt das Risiko, dass die getroffenen Aussagen missverstanden oder instrumentalisiert werden. Um dem vorzubeugen, sei festgehalten: Die deutsche Aufarbeitung verdient Lob angesichts ihres Bemühens, das „Nie wieder“ fest in der Gesellschaft zu verankern. Nichtsdestotrotz wird am Beispiel des Mikrokosmos einer rheinischen Kleinstadt schnell deutlich werden, dass die deutsche Aufarbeitung unvollständig ist und eine Fortsetzung des angestoßenen Prozesses erfordert, die in Ausmaß und Intensität die bisherigen Bemühungen übersteigt. Der Fall besagter Kleinstadt ist exemplarisch für die Situation in vielen deutschen Kleinstädten und verweist auf systemimmanente Unzulänglichkeiten, die auch in Großstädten, im regionalen und nationalen Kontext eine Rolle spielen. Auf dieser systemischen Ebene lassen sich zudem Parallelen zu Aufarbeitungsbemühungen in anderen nationalen Kontexten ziehen, etwa zum Genozid der autochthonen Bevölkerung des amerikanischen Doppelkontinents oder zur Kolonialisierung Afrikas. Auch hier steht eine Rückerstattung ,europäisierten“ Eigentums aus, während die systematische Benachteiligung der Entrechteten andauert. ${ }^{4}$

4 Eine Untersuchung zu den Spätfolgen der Kolonialisierung für die weitere Entwicklung der betroffenen Länder und das Wohlergehen ihrer Bevölkerung kommt zu dem Ergebnis, dass die Etablierung von sich bereichernden (extraktiven) Institutionen durch die Kolonialmächte bis in die Gegenwart mit einem niedrigeren Pro-Kopf-Einkommen einhergehen im Vergleich zu jenen Ländern, in denen die Kolonialmächte dauerhaft Fuß fassen wollten. Vgl. Daron Acemoglu/Simon Johnson/James Robinson, The colonial origins of comparative development. An empirical investigation, in: 
Die Kenntnis des internationalen Kontexts hinsichtlich des schwierigen Ringens vieler systematisch diskriminierter und marginalisierter Bevölkerungsgruppen um das Wiedererlangen ihrer Rechte und die Wiedergutmachung für das ihnen zugefügte Leid (zum Beispiel \#BlackLivesMatterBewegung) begründet nicht zuletzt die Sorge der Historikerin und Antisemitismusexpertin Holly Huffnagel, die in diesem Buch vertretene kritische jüdische Perspektive auf die deutsche Aufarbeitung könnte antisemitische Reaktionen hervorrufen. ${ }^{5}$ Ein Blick auf die Anfänge der Aufarbeitung der Zeit des Nationalsozialismus zeigt, dass ihre Sorge auch im deutschen Kontext kaum von der Hand zu weisen ist: Tatsächlich stünde eine solche Antisemitismus schürende Rezeption sogar in der Tradition des historischen „Vorbildes“ der Auseinandersetzung mit den Gräueltaten des nationalsozialistischen Unrechtsregimes kurz nach der Gründung der Bundesrepublik. Um die deutsche Haltung zur Frage der Rückerstattung arisierten Eigentums nach Ende des nationalsozialistischen Regimes zusammenzufassen, verweist etwa der Historiker Constantin Goschler auf die zutiefst zynische und erschreckend antisemitisch klingende Aussage des damaligen hessischen Finanzministers Werner Hilpert in der Süddeutschen Zeitung vom 31. Januar 1950. Angesichts der Höhe der fälligen Rückerstattungen von 37 Milliarden DM habe Hilpert konstatiert: „Wenn wir diese Summe aufzubringen hätten, müssten wir alle den Gashahn aufdrehen."

American Economic Review 91 (2001), S. 1369-1401; http://www.jstor.org/ stable/2677930?origin=JSTOR-pdf.

5 Dem Autor und der Autorin ist es wichtig hervorzuheben, dass sie in sieben Jahren keinerlei offenen Antisemitismus in Unkel erlebt haben.

6 Zitiert nach Constantin Goschler, Die Auseinandersetzung um die Rückerstattung „arisierten“ jüdischen Eigentums nach 1945, in: Ursula Büttner (Hrsg.), Die Deutsche Judenverfolgung im Dritten Reich, Frankfurt am Main 2003, S. 361-380, hier S. 361. 
Dem offiziellen politischen Diskurs zufolge wurde zwar eine sogenannte Wiedergutmachung angestrebt, Worte wie die von Hilpert erzählen jedoch eine andere Geschichte. Sie zeugen von einem nur eingeschränkten „Vermögen“7 - oder gar einem eng begrenzten Bedürfnis oder Interesse - der jungen Bundesrepublik, sich die ethischen Grundzüge des menschlichen Miteinanders zu eigen zu machen. Versöhnung wurde angestrebt, jedoch wohl eher eine Versöhnung Deutschlands mit den Siegermächten als eine tatsächliche Aussöhnung mit der jüdischen Schicksalsgemeinschaft. Rückerstattungen sollten dieser Art der Versöhnung nicht im Wege stehen, weshalb sich etwa Ludwig Kastl, damaliger Präsident des Wirtschaftsbeirates beim Bayrischen Wirtschaftsministerium, besorgt gezeigt habe und argumentiert habe, Rückerstattungsansprüche könnten aufgrund eines damit assoziierten Eingreifens in deutsche Besitzstrukturen antisemitisches Gedankengut fördern. ${ }^{8}$ Kastl, der von den Nationalsozialisten als „Nicht-Arier“ eingestuft ${ }^{9}$ und bereits 1933 zum Rücktritt von seinem Posten als geschäftsführen-

7 Es ist wichtig hervorzuheben, dass Hilpert kein Verfechter des Nationalsozialismus war, sondern ganz im Gegenteil in der frühen NS-Zeit als Fürsprecher der jüdischen Bevölkerung wirkte. Noch am Tage des deutschen Einmarsches in Polen wurde er als Gegner des NS-Unrechtsregimes verhaftet und ins KZ Buchenwald gebracht, wo er das Grauen der Shoah über fünfeinhalb Jahre hinweg tagtäglich miterlebte. Vgl. Walter Mühlhausen, Werner Hilpert (1897-1957), in: Heidenreich, Bernd/Mühlhausen, Walter (Hrsg.), Einheit und Freiheit. Hessische Persönlichkeiten und der Weg zur Bundesrepublik Deutschland, Wiesbaden 2000, S. 245-272. - Wenn sich ausgerechnet Hilpert zur Frage der Rückerstattungen zynisch auf den Massenmord an der jüdischen Bevölkerung bezieht, so ist dies kein Antisemitismus, sondern zeugt wohl eher von einer zutiefst desillusionierten Einschätzung der deutschen Bevölkerung, deren Judenhass sich mit Kriegsende nicht aufgelöst hatte, sondern nicht zuletzt in (wirtschaftlichen) Machtstrukturen weiter vor sich hin schwelte.

8 Vgl. Goschler, Auseinandersetzung um die Rückerstattung, in Büttner (Hrsg.), Judenverfolgung.

9 Vgl. Peter Langer, Paul Reusch und die Gleichschaltung der „Münchner Neusten Nachrichten“ 1933, in: Vierteljahreshefte für Zeitgeschichte 53 (2005), Heft 2., S. 203-240, hier S. 214. 
des Präsidiumsmitglied des Reichsverbands der Deutschen Industrie gezwungen worden war ${ }^{10}$ mag nicht zuletzt aufgrund seiner persönlichen Erfahrung besorgt über ein Wiederaufflammen des Antisemitismus gewesen sein. Nichtsdestotrotz resultieren solche Argumentationsstränge absurderweise in einer prospektiven Schuldzuweisung ausgerechnet an die jüdischen Opfer, als ob deren berechtigte Ansprüche auf Entschädigung Antisemitismus entfachen würden. Um eine Degradierung jener zu verhindern, die von dem nationalsozialistischen Regime profitiert hatten, wurden die Rückerstattungsansprüche der Opfer zum Konfliktgegenstand. Dass dieser auch heute nicht gänzlich aus dem Wege geräumt ist, wird das Beispiel der rheinischen Kleinstadt zeigen unter Verweis auf tiefere, systemimmanente Unzulänglichkeiten der deutschen Aufarbeitung der Zeit des Nationalsozialismus sowie auf eine gewisse Unsicherheit, wie mit dem Wissen um die Gräueltaten des nationalsozialistischen Regimes und der damit verbundenen Scham umzugehen sei.

Schließlich ist dem Autor und der Autorin bewusst, dass durch die Infragestellung des Status quo der Aufarbeitung die Erwartung geweckt werden könnte, auch eine Lösung des Problems präsentiert zu bekommen. In vorliegendem Buch werden wir dieser Erwartungshaltung nur im Kleinen entsprechen, da die Skizzierung einer umfassenderen, auf der Ebene des politischen und gesellschaftlichen Systems ansetzenden Lösung für eine spätere Veröffentlichung geplant ist. Während die Forderung nach Lösungen nachvollziehbar ist, kann es lohnend sein, auch diese Erwartungshaltung selbst infrage zu stellen. Wie der Kommunikationswissenschaftler und Journalist Warren Berger in seinem preisgekrönten

10 Vgl. Udo Wengst, Der Reichsverband der Deutschen Industrie in den ersten Monaten des Dritten Reiches. Ein Beitrag zum Verhältnis von Großindustrie und Nationalsozialismus, in: Vierteljahreshefte für Zeitgeschichte 28 (1980), Heft 1., S. 94-110. 
Buch Die Kunst des klugen Fragens unter Berufung auf den Innovationswissenschaftler der Harvard University und Empfänger des MacArthur Genius Award Paul Bottino erläutert:

„Wer herausfordernde Fragen stellt, wird sich vermutlich [...] daran gewöhnen müssen, die klassische AntiHerausforderer-Frage gestellt zu bekommen: Okay, du Genie, wie würdest du es besser machen? Diese Frage beruht auf der interessanten Annahme, dass man sofort eine Alternative parat haben muss, wenn man einen bestehenden Zustand in Frage stellt. Es ist jedoch wichtig, Warumund Was-wäre-wenn-Fragen auch dann zu stellen, wenn man die Wie-Frage noch nicht beantworten kann. Die Entwicklung einer besseren Alternative kann ein langer Prozess sein, aber er muss irgendwo beginnen, und dieser Ausgangspunkt ist häufig die Infragestellung des Status quo." ${ }^{11}$

Nachfolgende Betrachtung ist sicherlich als Beginn einer solchen längerfristigen Lösungssuche zu werten. Entsprechend geht es vor allem darum, den Status quo zu identifizieren anhand jener Daten, die verfügbar sind und sich wie Puzzleteile zu einem Bild zusammensetzen lassen. ${ }^{12}$ Zweifellos

11 Warren Berger, Die Kunst des klugen Fragens (Helmut Dierlamm, Übers.), Berlin 2014, E-Book-Ausgabe [Hervorhebungen im Original].

12 Dieses Buch basiert vorwiegend auf einer Auswertung schriftlicher Quellen (zum Beispiel streichen frühen zeitgeschichtlichen Studien zur Rolle des deutschen Unternehmertums für die nationalsozialistische Wirtschaft sowie den wenigen geschichtswissenschaftlichen Untersuchungen, die insbesondere in den vergangenen 20 Jahren zur Rolle des Henkel-Unternehmens und assoziierter Unternehmen in der Zeit des Nationalsozialismus erschienen sind) sowie auf Daten, die der Autor und die Autorin durch Interviews, informelle Gespräche und teilnehmende Beobachtung in der Kleinstadt Unkel sammeln konnten. Durch den Rückgriff auf Gedächtnisprotokolle eigens für diese Untersuchung erhobener Daten ist nicht auszuschließen, dass im Falle von Zitaten geringfügige - nicht-sinnentstellende - Abweichungen von dem Wortlaut bestehen, wie dieser seitens der Informantinnen und Informanten mündlich geäußert wurde und heute erinnert wird. Die Wiedergabe aller Informationen erfolgte nach bestem Wissen und Gewissen. 
ist dieses Bild unfertig - einige Teile sind noch nicht an der richtigen Stelle platziert, andere sind in diesem Augenblick nicht einmal aufzufinden. Nichtsdestotrotz erlaubt auch diese erste Analyse bereits, den Stand der Aufarbeitung der Zeit des Nationalsozialismus zu bewerten und ausgehend von der derzeit möglichen Charakterisierung des Status quo auf einige best practices im Umgang mit den sichtbar werdenden Unzulänglichkeiten hinzuweisen.

Den moralischen Imperativ für dieses Infragestellen des derzeitigen Umgangs mit dem Aufarbeitungsauftrag an Deutschland hat wiederum Adorno formuliert. Bliebe eine ernsthafte Aufarbeitung der Shoah aus, würde dies bedeuten: „Die Ermordeten sollen noch um das einzige betrogen werden, was unsere Ohnmacht ihnen schenken kann, das Gedächtnis." ${ }^{13}$ Hinzuzufügen ist die Sorge um die Zukunft nicht nur der jüdischen Bevölkerung, sondern auch die aller anderen denkbaren Gruppierungen: „Morgen kann eine andere Gruppe drankommen als die Juden, etwa die Alten [...] oder die Intellektuellen, oder einfach abweichende Gruppen." ${ }^{14}$

13 Adorno, Was bedeutet, in: Adorno (Kadelbach, Hrsg.), Erziehung zur Mündigkeit.

14 Theodor W. Adorno, Erziehung nach Auschwitz, in: Theodor W. Adorno (Gerd Kadelbach, Hrsg.), Erziehung zur Mündigkeit. Vorträge und Gespräche mit Helmut Becker 1959 bis 1969, Berlin (1966) 2013. 


\section{Henkels Persilschein: Aufarbeitung in einer deutschen Kleinstadt}

\section{Ausgangssituation}

in Mäzen, der durch seine Großzügigkeit in einer
beschaulichen Kleinstadt sehr zur Belebung von Kunst, Kultur und öffentlichen Plätzen beigetragen hat, äußert den Wunsch, dass ein nach seinem Großvater benannter Park zu Ehren seiner Mutter umbenannt werde. Bereits der Großvater ist der Kleinstadt als Gönner verbunden gewesen und auch die Mutter hat durch Schenkungen zum Wohlergehen der Stadt und der lokalen Kirche beigetragen. Der Stadtrat entscheidet einstimmig zugunsten der Namensänderung; verbunden damit wird eine Großspende zur Verschönerung des Parkes angenommen. Dieser Vorgang in Unkel am Rhein, so der Name der Kleinstadt, ist mitnichten ungewöhnlich. Gerade in Zeiten knapper Gelder sind viele Kommunen auf das Wohlwollen von Mäzeninnen und Mäzenen angewiesen, um das öffentliche Leben zu finanzieren.

Was diese Anekdote gesamtgesellschaftlich und überregional relevant macht, ist ihre geschichtliche Einbettung: Deutschland hat im vergangenen halben Jahrhundert weltweit 
den Ruf erworben, im Bemühen um eine Aufarbeitung der eigenen Vergangenheit ehrlich mit seiner Geschichte umzugehen. Geschichtswissenschaftliche Analysen untersuchten, wie es zu dem nationalsozialistischen Unrechtsregime kommen konnte. Unweigerlich verknüpft sind diese Untersuchungen mit der Frage nach der Schuld an den Gräueltaten des Regimes. ${ }^{15}$ Allzu oft jedoch wird die Aufarbeitung auf den Umgang mit der Vergangenheit beschränkt, anstatt auch die Auswirkungen des Unrechtsregimes auf die heutige Zeit kritisch zu reflektieren. Dabei geht es nicht allein um Personen, die sich durch eine besondere Regimetreue und aktive Mittäterschaft hervorgetan hätten; vielmehr bedeutet eine ehrliche Auseinandersetzung mit der deutschen Geschichte auch, die Spuren der aus der Zeit des Nationalsozialismus stammenden Profite nachzuzeichnen und ihre Auswirkung auf die gesellschaftlichen Strukturen der heutigen Zeit zu erläutern.

Hierzu gehört auch, die Aufarbeitung der Zeit des Nationalsozialismus auf das deutsche Unternehmertum und die Institution des Mäzenatentums zu beziehen. Dabei sei vorweggenommen, dass die im Folgenden am Beispiel einer rheinischen Kleinstadt erläuterte Langzeitwirkung von in der Zeit des Nationalsozialismus begründeten Profiten auf das soziale Miteinander als Symptom einer ethisch zweifelhaften Einschränkung der Aufarbeitungsbemühung im breiteren soziopolitischen Kontext gedacht werden muss. Ähnlich einer Studie über das Verhältnis von jüdischen und nicht-jüdischen Deutschen während der Zeit des Nationalsozialismus in der rheinischen Kleinstadt „Sonderburg“, so das von der Anthropologin Frances Henry gewählte Pseudonym,

15 Vgl. Ursula Büttner, Die deutsche Gesellschaft und die Judenverfolgung - ein Bericht über Forschungserträge und ungelöste Fragen, in: Ursula Büttner (Hrsg.), Die Deutsche Judenverfolgung im Dritten Reich, Frankfurt am Main 2003, S. 13-46. 
ist auch Unkel als Mikrokosmos zu begreifen, an dessen Beispiel sich grundsätzlichere soziopolitische und ethische Herausforderungen für eine aufrichtige Aufarbeitung aufzeigen lassen. ${ }^{16}$

\section{Aufarbeitung und das deutsche Unternehmertum}

In Unkel zeugt eine Gedenktafel an einem ehemaligen Wohnhaus einer vertriebenen und ermordeten jüdischen Familie von dem Bemühen seines heutigen Besitzerpaares um eine Aufarbeitung der NS-Vergangenheit. In unmittelbarer Nachbarschaft erzählt eine Bronzetafel vom Brand der Synagoge in der Reichspogromnacht 1939. Jedes Jahr kommen Dutzende von Einwohnerinnen und Einwohnern zusammen, um an das Leben und Sterben der jüdischen Bevölkerung der Stadt zu erinnern. Dabei kommt offen zur Sprache, dass es Unkelerinnen und Unkeler waren, die aktiv an diesen Verbrechen mitwirkten oder sie zumindest bereitwillig geschehen ließen. Bei den Gedenkveranstaltungen sind auch die Stadtspitze sowie Vertreterinnen und Vertreter namhafter Vereine und Institutionen anwesend und sprechen sich für Toleranz und ein Zusammenleben in Vielfalt aus.

Vorbildlich in Deutschland ist die weitgehende Akzeptanz der nationalen Schuld an der kaltblütigen Ermordung von sechs Millionen Menschen. Im Wissen um die Schuld der eigenen Nation zu leben und diese Schuld nicht als Last, sondern als Verantwortung zu akzeptieren, widerspricht einer Gesinnung des nationalen Extremismus, die gerade in jüngerer Zeit in vielen Ländern zu beobachten ist.

16 Vgl. Frances Henry, Victims and neighbors. Small town in Nazi Germany remembered, South Hadley, Mass. 1984. 
Die Aufarbeitung der NS-Vergangenheit wird abgebildet durch Kenntnis der geschichtlichen Zusammenhänge und des Anerkennens der eigenen Schuld. Sie findet ihren Ausdruck in der ernst gemeinten nationalen Entschuldigung und führt im günstigsten Fall ,wie von selbst“ zu einer Veränderung der Gesellschaft in allen Bereichen - vom Rechtssystem über die Medien bis hin zum Bildungsbereich. Eine echte nationale Entschuldigung geht mit einer Reihe umfassender Reformen einher, die so intensiv sind, dass sie als kulturelle Totalrevision bezeichnet werden können. Deutschland ist das einzige Land, das eine Entschuldigung dieser Größenordnung jemals in Angriff genommen hat.

Und doch ist es wichtig zu betonen, dass Aufarbeitung in Deutschland kein abgeschlossener Prozess ist. Die deutsche Gesellschaft hat gut daran getan, die Verbrechen der Shoah als Teil ihrer Geschichte anzuerkennen und die Verantwortlichen vor Gericht zu stellen. Auf Regierungsebene und auf der individuellen, persönlichen Ebene ist die deutsche Aufarbeitung ein Erfolg und ein Modell für viele andere Länder. Nichtdestotrotz ist die deutsche Aufarbeitung unvollständig und hat sich weitgehend blind gegenüber einer zentralen Säule des modernen deutschen Staates gezeigt: dem Unternehmens- und Finanzsektor.

Manche Unternehmen wurden wegen ihres Einsatzes von Zwangsarbeit und wegen des Profits, den sie aus dem Diebstahl jüdischen Eigentums schlugen, zur Rechenschaft gezogen. Viele von ihnen haben versucht, ihren Opfern Wiedergutmachungszahlungen zukommen zu lassen. Zugleich aber gibt es zahlreiche andere Unternehmen, die bis heute bemüht sind, diesen hässlichen Teil ihrer Geschichte zu verbergen.

Häufig konzentrierten sich Geschichtsbücher auf die Rolle vor allem hochrangiger Mitglieder von Regierung und Militär in der NS-Zeit. Zu oft ignorierten sie dabei die 
entscheidenden sozialen und wirtschaftlichen Ermöglicher und Profiteure. Doch müssten nicht auch ihre Namen genannt und - soweit nach dieser langen Zeit möglich - die Verantwortlichen zur Rechenschaft gezogen werden, damit die Aufarbeitung ihre volle Wirkung entfalten kann?

Aufarbeitung als wirkungsvoller Prozess begann im Rahmen der 1968er Bewegung, rund 20 Jahre nach den Nürnberger Prozessen. Einige der großen Unternehmer, die sich an den NS-Verbrechen beteiligt hatten, waren zwar in Nürnberg vor Gericht gestellt worden, aber die Vorstellung, dass die NS-Zeit mit den Kriegsverbrecherprozessen und der Entnazifizierung bereits geendet habe, wurde von den 68ern vehement bestritten. ${ }^{17}$ Allmählich manifestierte sich der von der Bewegung hervorgerufene Sinneswandel in der Öffnung von Archiven mit Dokumenten zur NS-Zeit und Wissenschaftlerinnen und Wissenschaftler begannen, Sachverhalte zu hinterfragen, die lange Zeit ignoriert worden waren.

1987 wurde das Chemie- und Pharmaunternehmen Interessensgemeinschaft Farbenindustrie AG (IG Farben) von dem Historiker Peter Hayes in die Pflicht genommen aufgrund seines Mitwirkens an NS-Verbrechen. Sie reichen von der Arisierung (der wirtschaftlichen Enteignung der jüdischen Bevölkerung Deutschlands zwischen 1933 und 1945) ${ }^{18}$ über die Verwendung von KZ-Häftlingen als Versuchskaninchen für Pharmaka bis hin zur Beteiligung an Herstellung und Vertrieb des Schädlingsbekämpfungsmittels Zyklon B, mit dem Jüdinnen und Juden und andere NS-Opfer in den

17 Vgl. Peter Hayes, Industry and ideology. IG Farben in the Nazi era., Cambridge 2000.

18 Vgl. z.B.: Christine Schoenmakers, The „legal“ theft of Jewish assets. The German Gold Discount Bank (Dego), in: Christoph Kreutzmüller/Jonathan R. Zatlin (Hrsg.), Dispossession. Plundering German Jewry. 1933-1953, Michigan 2017, S. 71-103, hier S. 93. 
Gaskammern ermordet wurden. ${ }^{19} 2001$ und 2004 veröffentlichte der Historiker Harold James seine Forschungsergebnisse über die Verbrechen der Deutschen Bank an den Jüdinnen und Juden: Sie umfassen die Ermöglichung und Durchführung von Arisierungen sowie die Kreditfinanzierung des Baus des KZ Auschwitz und einer benachbarten Gummifabrik (letztere wurde von IG Farben betrieben) sowie den aus der Sklavenarbeit von KZ-Häftlingen und der systematischen Ermordung der Jüdinnen und Juden gewonnenen Profit. ${ }^{20}$ Ebenfalls 2004 publizierte Hayes sein Werk über die Verbrechen des Chemiekonzerns Deutsche Gold- und SilberScheide-Anstalt (Degussa), die Arisierungen, Zwangsarbeit sowie die Produktion und den Vertrieb von besagtem Zyklon B miteinschließen. ${ }^{21}$ Seither haben andere Forscherinnen und Forscher wie der Historiker Joachim Scholtyseck beispielsweise die Firmengeschichten des Autoherstellers Bayerische Motorenwerke (BMW) (Arisierungen, Einsatz von Zwangsarbeiterinnen und Zwangsarbeitern), des Mischkonzerns Freudenberg, der sich als Zulieferer in der Auto- und Maschinenindustrie ebenso wie in der Lederverarbeitung einen Namen gemacht hat (Arisierungen, Verwendung von KZ-Häftlingen zur Produkttestung), und dem pharmazeutisch-chemischen Unternehmen Merck KGaA (Einsatz von Zwangsarbeiterinnen und Zwangsarbeitern) untersucht. ${ }^{22}$ Nichtsdestotrotz führte dies nur bei wenigen

19 Vgl. Hayes, IG Farben, S. 361-363, S. 370.

20 Vgl. James Harold, The Deutsche Bank and the Nazi economic war against the Jews, New York 2001; ders., The Nazi dictatorship and the Deutsche Bank, New York 2004, hier S. 161f, $214 f$.

21 Vgl. Peter Hayes, From cooperation to complicity. Degussa in the Third Reich, New York 2004.

22 Vgl. z.B. Joachim Scholtyseck, Der Aufstieg der Quandts. Eine deutsche Unternehmensdynastie, München 2011; vgl. ders., Freudenberg. Ein Familienunternehmen in Kaiserreich, Demokratie und Diktatur, München 2016; vgl. ders., Im Zeitalter der Weltkriege (1914-1948) [Unter Mitarbeit von Patrick Bormann], in: Casten Burhop/Michael Kißener/Hermann Schäfer/ 
Unternehmen zu einer aufrichtigen Auseinandersetzung mit ihrer NS-Geschichte, die eine umfassende Restrukturierung und das Bemühen um Wiedergutmachung beinhaltet hätte. Im Gegenteil befinden sich bis heute viele Unternehmen, die dem NS-Regime zuarbeiteten und von Kriegsverbrechen profitierten, in Familienhand, und 71 der 100 größten arbeitgebenden Unternehmen der NS-Zeit haben bis heute ihre Vergangenheit nicht wissenschaftlich aufgearbeitet, sodass in vielen Fällen das Ausmaß unklar ist, in dem Unternehmen und Familiendynastien von ihrer Rolle in der NS-Zeit profitierten. ${ }^{23}$

Ein wichtiges Werkzeug, das den wirtschaftlichen Profiteuren und Beteiligten an den NS-Verbrechen half, ihren guten Namen zu wahren und ihre Gewinne zu behalten, war der Nachweis der Entnazifizierung. Der Historiker Michael Wildt erläutert: „Mit sogenannten Persilscheinen stellten sich ehemalige Nationalsozialisten untereinander Entlastungszeugnisse aus. Was als politische Säuberung gedacht war, geriet ganz im Gegenteil zu einer Weißwäsche für ehemalige Mittäter und Mitläufer." ${ }^{24}$ Zwar hatten die alliierten Besatzungsmächte besagte Bescheinigungen ursprünglich als Nachweis der individuellen Unbetroffenheit ausstellen wollen, doch waren sie selbst schnell vom Ausmaß der dazu nötigen Untersuchungen überfordert, insbesondere als die Spaltung zwischen Westalliierten und Sowjetunion sich allmählich zuspitzte.

Joachim Scholtyseck (Hrsg.), Merck: von der Apotheke zum Weltkonzern, München 2018, S. 219-332.

23 Vgl. Harald Schumacher, Weiße Flecken im Wissen über die Unternehmen der NS-Zeit, in: WirtschaftsWoche (28.8.2016), abgerufen am 15.10.2020 von https://www.wiwo.de/unternehmen/industrie/historie-weisse-flecken-imwissen-ueber-die-unternehmen-der-ns-zeit/14457216.html.

24 Michael Wildt, Verdrängung und Erinnerung, in: Informationen zur politischen Bildung, 316/2012: Nationalsozialismus. Krieg und Holocaust (18.12.2012), S. 70, abgerufen am 25.10.2020 von https://www.bpb.de/ izpb/151963/verdraengung-und-erinnerung? $\mathrm{p}=$ all. 
Infolgedessen wurden Persilscheine vielen Industriellen und Geschäftsleuten rasch erteilt, nachdem Bekannte und zum Teil sogar überlebende ehemalige Opfer deren Unschuld bezeugt hatten. Angesichts der massenhaften Ausstellung dieser Dokumente könnte fast der Eindruck entstehen, dass es in den 1930er und 40er Jahren in Deutschland nur sehr wenige willige Nazis gegeben habe.

Auch die neu gegründete Bundesregierung unter Konrad Adenauer versäumte es, die Entnazifizierung des Landes voranzutreiben. Später, als sich Deutschland im Rahmen der 1968er - Bewegung um eine Aufklärung der NS-Verbrechen bemühte, erschwerten wiederum die in der unmittelbaren Nachkriegszeit ausgestellten Persilscheine die Aufdeckung von Mittäterschaften. So wurden viele, die aufgrund ihres Mitwirkens im NS-Regime vor Gericht hätten gestellt werden können, nie angeklagt. Das Ergebnis ist ernüchternd:

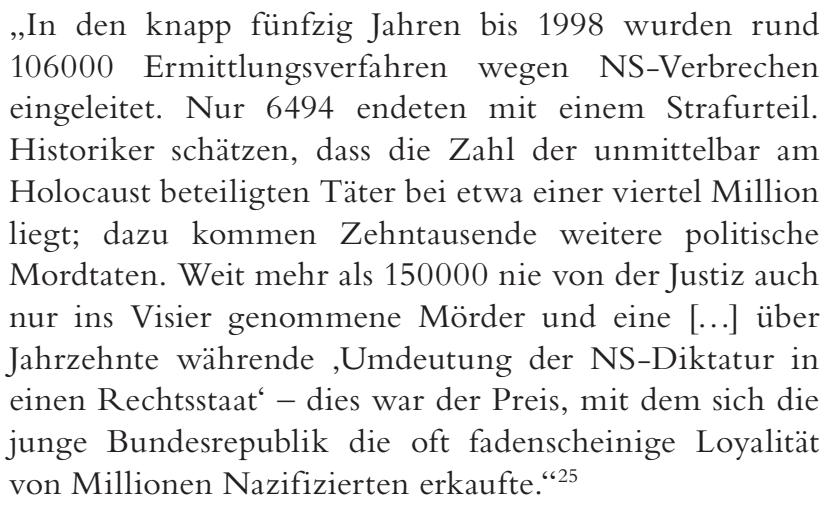

Zwar schlossen sich deutsche Unternehmen, die von diesen Verbrechen profitiert hatten, sowie Unternehmen, die erst nach den Jahren des NS-Regimes gegründet worden

25 Christian Staas, Was damals Recht war..., in: Zeit Geschichte, 1 (2009), abgerufen am 25.10.2020 von https://www.zeit.de/zeit-geschichte/2009/01/ Justiz/komplettansicht. 
waren, 1999 zusammen, um die Stiftung „Erinnerung, Verantwortung und Zukunft" (EVZ) mit 10,1 Milliarden DM zu finanzieren. Die Stiftung leistet Zahlungen an ehemalige NS-Zwangsarbeiterinnen und Zwangsarbeiter und fördert Projekte, die sich für NS-Opfer, für die Umsetzung der Menschenrechte und für eine Auseinandersetzung mit der Geschichte einsetzen. Doch ist die Unterstützung der Stiftung eben nicht an das Eingeständnis einer Schuld der einzahlenden Unternehmen oder einer sonstigen Verflechtung mit dem NS-Regime gebunden. Während 10,1 Milliarden DM zunächst nach einer beachtlichen Summe klingen, betrugen die individuellen Beiträge vieler NS-belasteter Firmen jeweils nur wenige Millionen - 5,1 Milliarden DM wurden gemeinsam von 6.500 deutschen Unternehmen eingezahlt, die fast äquivalente Restsumme wurde vom Bund beigesteu$\operatorname{ert}^{26}$ - und entsprechen in Anbetracht des dahinter verborgenen Leides und der Wertentwicklung des einst jüdischen Eigentums im Laufe der Jahrzehnte allenfalls dem sprichwörtlichen Tropfen auf dem heißen Stein. Doch auch wenn eine wirkliche Wiedergutmachung nicht möglich ist - schließlich lassen sich Menschenleben nicht einfach in Geld aufwiegen -, sind insbesondere die an den NS-Verbrechen beteiligten Unternehmen es ihren Opfern schuldig, dass zumindest die Wahrheit ans Licht kommt. Dies betrifft gerade jene Firmen und Profiteure, die durch ihre Taten in der NS-Zeit Schuld auf sich geladen haben und die bis heute über ihre Rolle in dieser Zeit schweigen.

Es gibt eine bestimmte Art von Unternehmen, die sich besonders scheut, die Aufarbeitung der eigenen Geschichte in Angriff zu nehmen. Der Wirtschaftshistoriker Johannes Bähr erläuterte 2016 im Interview:

26 Vgl. Stiftung EVZ, Zahlen und Fakten zur Fördertätigkeit (31.12.2019), abgerufen am 16.10.2020 von https://www.stiftung-evz.de/stiftung/zahlenund-fakten.html. 
„Familienunternehmen tun sich immer schwerer damit [d.h. mit der Aufarbeitung] auch als andere, weil es da nicht nur um die Vorgänger geht, sondern auch um die eigenen Väter und Großväter der heutigen Inhaber. Beispielsweise Henkel steht da auch noch aus oder Röchling." ${ }^{27}$

Auch der Historiker Paul Erker prangert in seiner jüngst erschienenen Studie über den Zuliefererkonzern für Kraft- und Luftfahrzeuge Continental mit dem vielsagenden Titel Zulieferer für Hitlers Krieg: Der Continental-Konzern in der NS-Zeit die mangelnde Aufarbeitung namhafter deutscher Unternehmen an:

„Es fehlt mithin noch immer unter anderem eine Studie zu Siemens in der NS-Zeit und auch dem Verhalten der Familie Siemens, wozu erstaunlicherweise - anders als in anderen Fällen wie etwa der Quandt-Geschichte auch bislang kein öffentlicher Druck besteht. Nach wie vor steht auch eine Untersuchung zum Henkel-Konzern in der NS-Zeit aus, auch eine Geschichte von Bayer als damaliger Teilbereich des IG Farben-Konzerns gibt es, anders als für Hoechst und BASF, bislang nicht." ${ }^{\text {28 }}$

Beide Historiker nennen eine Liste von Firmen, die ihre Geschichte bis heute, rund 75 Jahre nach dem Ende des NS-Regimes, nicht aufgearbeitet haben. Auch eine aktuelle geschichtswissenschaftliche Auseinandersetzung mit der Rolle von Handel und Konsum für das Funktionieren des NS-Regimes verweist auf eine willige Zusammenarbeit vieler Unternehmen, darunter auch Henkel, mit den Nazis. ${ }^{29}$

27 Johannes Bähr, Lufthansa.: „Adler und Kranich“. Wie deutsche Unternehmen mit ihrer NS-Geschichte umgehen (Interviewer: Nana Brink, 2016), abgerufen am 15.10.2020 von https://www.deutschlandfunkkultur.de/ lufthansa-adler-und-kranich-wie-deutsche-unternehmen-mit.1008. de.html?dram:article_id=351256.

28 Paul Erker, Zulieferer für Hitlers Krieg. Der Continental-Konzern in der NS-Zeit, Berlin/Boston 2020, hier S. 5, Fußnote 8.

29 Vgl. S. Jonathan Wiesen, Creating the Nazi marketplace. Commerce and consumption in the Third Reich, Cambridge 2010, hier S. 83f. 
Viele dieser Unternehmen wurden bereits 1950 in einem Werk des Kartellrechtsanwalts des US-Justizministeriums James Stewart Martin aufgelistet, das dieser basierend auf seiner Recherche über die Schlüsselbereiche der deutschen Industrie im Zweiten Weltkrieg verfasst hatte. ${ }^{30}$ Dies bedeutet wiederum, dass die Verbrechen jener Unternehmen eigentlich schon seit rund 70 Jahren öffentlich bekannt sein müssten.

\section{Henkel - ein Familienunternehmen in der NS-Zeit}

Ein Familienunternehmen, dessen mangelnde Aufarbeitung sowohl Bähr als auch Erker in den zitierten Passagen anprangern, ist der Wasch- und Reinigungsmittel-, Klebstoff- und Pflegeprodukthersteller Henkel, dessen vermutlich bekanntestes Produkt Persil ist. Dabei ist Henkel kein Einzelfall; im Gegenteil ist das Familienunternehmen als typisches Bild für den blinden Fleck zu begreifen, den das moderne Deutschland für viele Industrielle im Prozess der Aufarbeitung der NS-Zeit bis heute aufweist.

Das Henkel-Unternehmen war lange dafür bekannt, Forscherinnen und Forschern keinen Zugang $\mathrm{zu}$ seinen Archiven zu gewähren. ${ }^{31}$ Diese Abwehrhaltung gegenüber einer wissenschaftlichen Aufarbeitung der Unternehmensgeschichte scheint sich erstmals zu ändern: Im Oktober 2019 startete das Drittmittelprojekt „Die Geschichte des Unternehmens Henkel von 1876 bis heute“ unter der Leitung von Scholtyseck. Im Rahmen des vierjährigen Projekts erhält seine Forschungsgruppe uneingeschränkten

30 Vgl. James Stewart Martin, All honorable men. The story of the men on both sides of the Atlantic who successfully thwarted plans to dismantle the Nazi cartel system, Boston 1950.

31 Vgl. Hayes, Degussa, S. xviii. 
und exklusiven Zugang zu den Archiven des Unternehmens. Eine Veröffentlichung über die gewonnenen Einsichten ist vorgesehen. ${ }^{32}$ Lägen die Ergebnisse von Scholtyseck bereits vor, könnten vielleicht neue Fakten die im Folgenden berichteten Erkenntnisse infrage stellen; derzeit beruhen letztere auf den wenigen verfügbaren Daten, die eine Einschätzung der Rolle des Unternehmens in der NS-Zeit erlauben.

Das Unternehmen wurde 1876 gegründet von Friedrich „Fritz“ Henkel (1848-1930). Dieser starb - ebenso wie seine Söhne August (1874-1879) und Fritz (1875-1930) - vor der Machtergreifung der Nationalsozialisten. Sein Sohn Hugo (1881-1952) dagegen sowie Tochter Emmy Anna (1884-1941), verheiratet mit Ernst Hugo Lüps (1873-1933) und Mutter von Werner Lüps (1906-1942), erlebten die Zeit des NS-Regimes. Hugo Henkel, der von 1922 bis 1938 den Posten des ordentlichen Geschäftsführers der Henkel \& Cie GmbH innehatte und nach dem Tod des Unternehmensgründers und dessen Sohnes Fritz im Jahr 1930 die alleinige Firmenleitung übernommen hatte, trat noch 1933 in die NSDAP ein. 1938 veranlasste das NS-Regime Hugo Henkel, in den Beirat und Aufsichtsrat des Familienunternehmens zu wechseln und gleichzeitig seine Geschäftsführerposition freizugeben. Neue Geschäftsführer wurden sein Sohn Jost (1909-1961), sein Neffe Werner Lüps sowie Carl August Bagel (19021941), der Schwiegersohn von Fritz Henkel (Jr.). ${ }^{33}$ Jost war

32 Vgl. Universität Bonn (o. D.), Institut für Geschichtswissenschaft: Abteilung für Geschichte der Neuzeit. Lehrstuhl Prof. Dr. Scholtyseck: Forschungsprojekte, abgerufen am 1.11.2020 von https://www.igw.uni-bonn.de/de/abteilungsseiten/ abteilung-neuzeit/lehrstuhl-prof-dr-scholtyseck/forschungen.

33 Vgl. Wilfried Feldenkirchen/Susanne Hilger, Menschen und Marken. 125 Jahre Henkel: 1876-2001, Düsseldorf 2001, hier S. 68, abgerufen am 15.10.2020 von https:// www.henkel.de/resource/blob/264392/0c65103fb9ed05c33c6511fc1ade9f15/ data/menschen-und-marken-125-jahre-henkel.pdf; vgl. Henkel, 140 Jahre Chronik. 1876-2016, Düsseldorf 2016, abgerufen am 15.10.2020 von https:// www.henkel.de/resource/blob/264388/0fde75475ee97e29074487919b9d9360/ chronik-130-jahre-henkel-data.pdf. 
selbst NSDAP-Mitglied; Werner Lüps war bekannt als bedingungsloser NSDAP-Anhänger und galt zudem als von Hermann Göring hoch geschätzt. ${ }^{34}$ Carl August Bagels ideologische Ausrichtung ist nicht bekannt. Zusammen vertraten die drei jungen Geschäftsführer der Tradition folgend die drei Stämme der Familie Henkel, wobei die Nachkommen von Emmy Lüps nominell nur 20 Prozent des stimmberechtigten Unternehmenserbes auf sich vereinigen, während die Nachkommen der beiden Söhne Fritz Henkels (Jr.) für je 40 Prozent stehen.

Eine unternehmenseigene Publikation erzählt, das Verhältnis der Henkel-Familie zu den Nationalsozialisten sei nicht ungetrübt gewesen, was womöglich zur Abgabe der Geschäftsführung an die jüngere Generation geführt haben könnte. Doch erwähnt dieselbe Veröffentlichung auch eine Reihe von Auszeichnungen, die das Unternehmen seitens des NS-Regimes erhielt bis hin zu dessen Würdigung als NS-Musterbetrieb im Jahr 1940. ${ }^{35}$ Somit ist durchaus von einer Gleichschaltung des Unternehmens mit dem NS-Regime auszugehen, die sich nicht zuletzt in Berichten über Hitlers öffentliche Veranstaltungen und Reden äußerte und den Nationalsozialismus für eigene Zwecke der Öffentlichkeitsarbeit und des wirtschaftlichen Profits zu nutzen suchte. ${ }^{36}$ Zwar ist zu bedenken, dass dieses Vorgehen des Unternehmens auch Ausdruck eines wirtschaftlichen Pragmatismus gewesen sein kann und nicht zwangsläufig einer empfundenen ideologischen Nähe zum Nationalsozialismus entsprochen haben muss. Doch verweist Hayes explizit

34 Vgl. Ulrich Viehöver, Die EinflussReichen. Henkel, Otto und Co - Wer in Deutschland Geld und Macht hat, Frankfurt 2006, hier S. 208.

35 Vgl. Feldenkirchen/Hilger, 125 Jahre, S. 64, 68, 297.

36 Vgl. Elisabeth Schmitt, Musterbetrieb Deutscher Wirtschaft. Die Waschmittelund Seifen-Industrie: Henkel \& Cie., AG. Chemische Produkte, Düsseldorf/ Leipzig 1934 nach Angaben von Wiesen, Marketplace. 
darauf, dass sich die neue jugendliche Führungsriege des Henkel-Unternehmens eng mit dem NS-Regime identifiziert habe und ihm mit Enthusiasmus begegnet sei. ${ }^{37}$

Tatsache ist, dass Jost Henkel, Werner Lüps und Carl August Bagel als hochrangige Vertreter des HenkelUnternehmens aktiv an wegweisenden Entscheidungen beteiligt gewesen sein müssen. In ihre Zeit fiel auch der im Auftrag Adolf Hitlers umzusetzende Vierjahresplan, der laut der unternehmenseigenen Publikation „Menschen und Marken“ nicht nur Hersteller hochwertiger Konsumgüter, sondern auch Roh- und Grundstoffunternehmen betraf. ${ }^{38}$ Dies bedeutet letztlich, dass das Unternehmen von 1936 bis 1940 direkt und umfassend am Aufbau der nationalsozialistischen Kriegsmaschinerie mitwirkte, seine Produktionsbasis auszubauen und von den politischen Geschehnissen zu profitieren suchte ${ }^{39}$ und damit letztlich auch an der europaweiten Durchführung der sogenannten Endlösung beteiligt war.

So wird das Henkel-Unternehmen - ebenso wie weitere 40 der 100 größten Arbeitgeber der NS-Zeit - von dem Historiker Lutz Budraß als in besonderer Weise in die Verbrechen des NS-Regimes verstrickt eingeschätzt. Budraß beruft sich dabei auf drei Kriterien: die Beteiligung dieser Unternehmen an Arisierungen, die Beschäftigung von jüdischen Zwangsarbeiterinnen und Zwangsarbeitern und KZ-Häftlingen sowie die Übernahme von Betrieben in besetzten Gebieten. ${ }^{40}$ Hierzu passen würde die Übernahme von Anteilen der Böhme Fettchemie, einer ursprünglich jüdischen Firma, im Jahr 1935 durch das HenkelUnternehmen, wobei diese Übernahme nicht zuletzt durch einen „Kuhhandel“ mit Degussa zustande kam, bei dem die

37 Vgl. Hayes, Degussa, S. 57.

38 Vgl. Feldenkirchen/Hilger, 125 Jahre, S. 110.

39 Vgl. ebd., S. 89.

40 Vgl. Budraß, Lutz gemäß Schumacher, Weiße Flecken, in: WirtschaftsWoche. 
beiden arischen Chemie-Unternehmen jüdische Opfer der Arisierungen gemäß ihrer jeweiligen Interessenschwerpunkte unter sich aufzuteilen schienen. ${ }^{41}$ Ein weiteres Beispiel für den Profit des Unternehmens von Arisierungen ist der Fall der Firma Salamander, des vormals größten deutschen Schuhproduzenten, der Ende des 19. Jahrhunderts von Jakob Sigle und Max Levi gegründet worden war und bereits 1933 arisiert wurde. ${ }^{42}$ Als die jüdischen Besitzer der Firma keine andere Wahl hatten, als sich von ihrem Eigentum zu trennen, übernahm das Henkel-Unternehmen Aktien der profitablen Firma im Wert von 1.250.000 Reichsmark. Die Hälfte davon musste nach dem Krieg zurückgezahlt werden. Hierbei sei, so James, ein beträchtlicher Teil dieser Rückerstattungen von den Banken bezahlt worden, die in der NS-Zeit die Übernahme ausgehandelt hatten. Der Firmenanteil scheint dagegen kaum mehr als ein Almosen für das gewesen zu sein, was den ursprünglichen jüdischen Eigentümern gestohlen worden war. Weiter verweist James auf die Rolle, die die Deutsche Bank im Arisierungsprozess und bei der Enteignung der jüdischen Bevölkerung spielte. Aus Hugo Henkels Rolle als Mitglied des Aufsichtsrates der Deutschen Bank lässt sich dabei ableiten, dass die Familie Henkel und ihr Unternehmen mehr oder weniger direkt in eine beträchtliche Anzahl der von James aufgeführten Verbrechen verwickelt gewesen sein muss. ${ }^{43}$

41 Vgl. Hayes, Degussa, S. 80.

42 Vgl. Petra Bräutigam, Mittelständische Unternehmen im Nationalsozialismus. Wirtschaftliche Entwicklungen und soziale Verhaltensweisen in der Schuhund Lederindustrie Baden und Württembergs, München 1997.

43 Vgl. Harold, Deutsche Bank; vgl. United States Senate, Elimination of German resources of war. Hearings before a Subcommittee of the Committee on Military Affairs. Part 5. Testimony of Treasury Department, 1945, hier S. 775, abgerufen am 15.10.2020 von https://archive.org/details/ EliminationOfGermanResourcesForWar/Elimination\%20of\%20German\%20 Resources\%20for\%20War\%20Part\%205\%20-\%20Testimony\%20of\%20 Treasury\%20Department/page/n139/mode/2up. 
Das zweite von Budraß aufgeführte Kriterium, die Beschäftigung von jüdischen Zwangsarbeiterinnen und Zwangsarbeitern und KZ-Häftlingen, weist Henkels unternehmenseigener Blick auf seine Geschichte strikt von sich und räumt lediglich den Einsatz von Kriegsgefangenen und ausländischen Zivilarbeitern ein. ${ }^{44}$ Hayes stützt diese Aussage ansatzweise, indem er darauf verweist, dass KZ-Häftlinge insbesondere in kriegsrelevanten Unternehmen eingesetzt wurden, wozu Henkel selbst nicht gezählt habe. Gleichzeitig hebt Hayes jedoch die enge ideelle, personelle und wirtschaftliche Verflechtung des Henkel-Unternehmens mit dem eindeutig NS-belasteten Degussa-Konzern hervor. Unter anderem in dem Interesse, die Vormachtstellung der IG Farben auf dem Markt der deutschen Chemieindustrie zu brechen, veranlasste die Unternehmensführung von Jost Henkel, Werner Lüps und Carl August Bagel den umfangreichen Kauf von DegussaAktien. Die Verfügbarkeit dieser Aktien wiederum stand direkt in Verbindung mit der Enteignung deutscher Jüdinnen und Juden im Kontext der Reichspogromnacht 1938. Hayes beziffert den Anteil der im Henkel-Unternehmen befindlichen Degussa-Aktien mit mehr als 25 Prozent im Januar 1938, rund 40 Prozent im September 1939 und schließlich, vor dem Tod von Carl August Bagel im Jahr 1941, mit 48 Prozent. ${ }^{45}$ Degussa wiederum ließ rund 3.000 KZ-Häftlinge für sich arbeiten, von denen rund 40 Prozent jüdisch waren. ${ }^{46}$ Damit folgte Degussa dem Prinzip „Vernichtung durch Arbeit“, das, wie auf der Wannseekonferenz von 1942 deutlich formuliert, unmittelbar auf die Endlösung abzielte. ${ }^{47}$

44 Vgl. Feldenkirchen/Hilger, 125 Jahre, S. 93.

45 Vgl. Hayes, Degussa, S. 56f, 65.

46 Vgl. ebd., S. 18.

47 Vgl. Avraham Barkai, Die deutschen Unternehmer und die Judenpolitik im Dritten Reich, in: Ursula Büttner (Hrsg.), Die Deutsche Judenverfolgung im Dritten Reich, Frankfurt am Main 2003, S. 247-272, hier S. 259 f. 
Die Verbindung zu Degussa spielt auch eine Rolle für Henkels Bezug zum dritten von Budraß genannten Kriterium, der Übernahme von Betrieben in besetzten Gebieten. Während Henkels unternehmenseigene Publikation lediglich den Rückgriff auf Beuteware eingesteht, ${ }^{48}$ berichtet Hayes, dass Degussa im Rahmen der Arisierung in besetzten Gebieten Unternehmen in Böhmen und Mähren übernahm, ${ }^{49}$ sodass wiederum aufgrund der Nähe zu Degussa von einer Verstrickung des Henkel-Familienunternehmens in die Verbrechen des NS-Regimes auszugehen ist.

Erschreckenderweise geht die Verwicklung des HenkelUnternehmens in die Verbrechen der Endlösung noch viel weiter: Die Degussa-Tochterfirma Deutsche Gesellschaft für Schädlingsbekämpfung $\mathrm{GmbH}$ (Degesch) war der Patentinhaber von Zyklon B und saß an der Nahtstelle zwischen den Herstellerfirmen und denjenigen, die dieses Gift, mit dem etwa 1 Million Jüdinnen und Juden und andere NS-Opfer in den Gaskammern der Vernichtungslager vergast wurden, verkauften. ${ }^{50}$ Das Henkel-Unternehmen wiederum wurde von Hayes als Verbindung der Degussa zum NS-Regime bezeichnet. ${ }^{51}$ Vor allem aber war das Henkel-Unternehmen zum Zeitpunkt des tödlichen Einsatzes von Zyklon B in den Gaskammern ein bedeutsamer Miteigentümer von Degussa, der angesichts eines Aktienbesitzes von 48 Prozent sicherlich auch auf wegweisende Entscheidungen von Degussa - und damit indirekt auch auf Degesch - Einfluss nehmen konnte.

Angesichts der gegenwärtigen Quellenlage kann die groß angelegte Untersuchung von Hayes, ebenso wie dieses Buch,

\footnotetext{
48 Vgl. Feldenkirchen/Hilger, 125 Jahre, S. 78.

49 Vgl. Hayes, Degussa, S. 100.

50 Vgl. ebd., S. 2, S. 357-360.

51 Vgl. Peter Hayes, I.G. Farben revisited. Industry and ideology ten years later, in: John E. Lesch (Hrsg.), The German chemical industry in the twentieth century, Dordrecht 2000, S. 7-14, hier S. 13.
} 
die Verknüpfung des Henkel-Unternehmens mit Degussa nur grob umreißen. Nichtsdestotrotz scheint klar, dass die beiden Unternehmen eng miteinander verflochten und gemeinsam von zentraler Bedeutung für das NS-Regime waren. So kommt die Frankfurter Rundschau auf Grundlage von Hayes Degussa-Studie zu der erschütternden Erkenntnis: „man muss Persil und Zyklon B zusammen denken, wenn man die Geschichte der Degussa im ,Dritten Reich “ verstehen will.“ ${ }^{52}$

Nach dem Krieg wurden mehrere Mitglieder der Familie von der britischen Armee als Kriegsverbrecherin und Kriegsverbrecher inhaftiert: ${ }^{53}$ Hugo Henkel (NSDAPMitglied und Unternehmensleitung), Jost Henkel (NSDAP-Mitglied und Unternehmensleitung), Sigrid und Willy Manchot (Unternehmensleitung, eventuell NSDAP-Mitglieder), Reinhold Woeste (NSDAPMitglied und Unternehmensleitung) und Konrad Henkel (Herstellung der chemischen Waffe Soman gemeinsam mit Richard Kuhn, einem bekennenden Antisemiten und Nationalsozialisten, der mit dem Hauptverantwortlichen für das NS-Euthanasieprogramm zusammenarbeitete und verantwortlich war für den Einsatz finanzieller Ressourcen für tödliche Experimente mit KZ-Gefangenen). ${ }^{54}$ Doch trotz zahlreicher Hinweise auf eine Verwicklung des Henkel-

52 Malte Oberschelp, Persil und Zyklon B zusammendenken, in: Frankfurter Rundschau (4.2.2019), abgerufen am 16.10 .2020 von https://www.fr.de/politik/ persil-zyklon-zusammendenken-11726289.html.

53 Vgl. Feldenkirchen/Hilger, 125 Jahre, S. 110; vgl. Henkel, 140 Jahre.

$54 \mathrm{Ob}$ es sich bei den in den Klammern genannten Verbindungen zu den NS-Kriegsverbrechen um die offiziellen Haftgründe handelt, ist unbekannt. Im Falle von Sigrid Manchot waren keine Hinweise auf den Grund ihrer Inhaftierung zu finden. Die Angaben beruhen auf möglichen Anschuldigungen, die sich aus folgenden Quellen ableiten lassen: vgl. Feldenkirchen/Hilger, 125 Jahre; vgl. Henkel, 140 Jahre; vgl. Encyclopedia.com, Kuhn, Richard, o.D., abgerufen am 27.10.2020 von https://www.encyclopedia.com/people/science-andtechnology/chemistry-biographies/richard-kuhn auf der Grundlage von: Christian Selchow, Richard Kuhn (3.12.1900 Wien - 31.7.1967 Heidelberg), in: Archiv zur Geschichte der Naturwissenschaften 10 (1984), S. 473-497. 
Unternehmens in die Verbrechen des NS-Regimes kam das Unternehmen relativ unbeschadet davon und durfte nach weniger als eineinhalb Jahren mit einem Persilschein der Alliierten seine unternehmerischen Tätigkeiten wieder aufnehmen. Zwar beabsichtigte die britische Besatzung zunächst, die Henkel-Familie nicht wieder die Unternehmensführung übernehmen zu lassen, doch scheinen nicht zuletzt internationale Beziehungen des Unternehmens in die USA und auch nach England diesem Vorhaben Vorschub geleistet zu haben. ${ }^{55}$ Hinzu kam, angestoßen von der eingesetzten treuhänderischen Unternehmensführung, eine Mobilisierung der Henkel-Angestellten und der Presse, wie Wiesen ausführlich dargelegt hat. Diese traf den sprichwörtlichen Nerv der öffentlichen Wahrnehmung, die Henkel eng mit den deutschen Werten von Hygiene und Sauberkeit assoziiert sah: Die Kampagne behauptete mit dramatischen Bildern von toten Kindern, Friedhöfen und dem Sensenmann unter dem Titel „Tod durch Dreck“, dass die Zerstückelung des Henkel-Konzerns Deutschland zu Schmutz, Seuchen und Krankheiten verdammen würde und daher unbedingt abzuwehren sei. ${ }^{56}$ Auch beim Thema der Kompensationszahlungen für Zwangsarbeiterinnen und Zwangsarbeiter sowie für Enteignungen zeigte sich das Unternehmen uneinsichtig bezüglich der eigenen Vergehen und legte jegliche Zahlungen als Ausdruck des unternehmenseigenen guten Willens und seiner Großzügigkeit aus- nicht aber als Schuldeingeständnis. ${ }^{57}$

Der Bedeutungswandel des Wortes Persilschein (ursprünglich entsprach er im Soldatenjargon dem Gestellungsbefehl) in Richtung politisch-moralischen Reingewaschenseins

55 Vgl. Feldenkirchen/Hilger, 125 Jahre, S. 111f.

56 Vgl. S. Jonathan Wiesen, West German industry and the problems of the Nazi past. 1945-1955, Chapel Hill 2004, S. 61-65.

57 Vgl. Esther Leslie, Synthetic worlds. Nature, art and the chemical industry, London 2005. 
beziehungsweise Entnazifizierung wird hier um noch eine Dimension erweitert: Auch Henkel (dem Unternehmen wie der Familie) wurde eine weiße Weste attestiert - ein Persilschein ausgestellt.

\section{Henkel - eine Familie in Unkel und ihre Profite aus der NS-Zeit}

Die eingangs erwähnte Kleinstadt Unkel verehrt die Unternehmerfamilie Henkel als Inbegriff der Philanthropie und des sozialen Engagements: Fritz Henkel (Jr.), Sohn und Erbe des Firmengründers, wird geschätzt aufgrund seiner Industrieerfolge sowie seiner monetären Zuwendungen an diese kleine Stadt und ihre Bewohnerinnen und Bewohner. Und warum sollte Unkel ihn nicht wertschätzen und würdigen? Schließlich schenkte Fritz Henkel (Jr.), von der Lokalpresse auch als „Mr. Persil“"58 bezeichnet, der Stadt mehrere weitläufige Grundstücke als Parks und Erholungsräume. Diese gehören heute $\mathrm{zu}$ den wenigen zentral gelegenen Grünflächen der Kleinstadt.

Fritz Henkel (Jr.) starb 1930 im Alter von 55 Jahren, bevor das Unternehmen nazifiziert wurde und von der Enteignung der jüdischen Bevölkerung oder der Kriegsmaschinerie der Nationalsozialisten profitierte. Das Geschenk, das er Unkel zu Erholungszwecken gemacht hatte, war somit nicht befleckt. Niemand käme auf die Idee, die Ehrung seiner Person als Namenspatron von Verkehrsanlagen - Fritz-Henkel-Straße und Fritz-Henkel-Park - infrage zu stellen. Schließlich sind diese Landmarken bereits seit den 1920er Jahren mit seinem

58 Leo Klevenhaus, „Mr. Persil“ hat viel für Unkel getan, in: Kölnische Rundschau (12.03.2007), abgerufen am 15.10.2020 von https://www.rundschau-online. de/-mr--persil--hat-viel-fuer-unkel-getan-11577426. 
Namen verbunden, lange bevor überhaupt vorstellbar war, welcher Verbrechen Deutschland sich schuldig machen würde.

Wenn Unkel jedoch in jüngerer Zeit die HenkelFamilie ehrt, indem es zum Beispiel einem wichtigen Treffpunkt in den Außenanlagen eines der Altenheime der Stadt den Namen „Fritz-Platz“ verleiht, ${ }^{59}$ bleibt angesichts des Wissens um die kritischen Untersuchungen zur Geschichte des Henkel-Unternehmens ein unangenehmer Nachgeschmack. Die Gestaltung des Platzes war einer beträchtlichen Spende des im März 2021 verstorbenen Fritz Bagel zu verdanken, dem Urenkel des Unternehmensgründers, der, 1933 geboren, während der NS-Zeit noch ein Kind war. Im Jahr 2019 zum Ehrenbürger von Unkel ernannt, schenkte Fritz Bagel im Laufe seines Lebens der Stadt fast so viel wie seine Vorfahren und stiftete oftmals, wie im Falle des Fritz-Platzes, das notwendige Kapital, von dem das öffentliche Leben in Unkel profitiert. Fritz Bagel selbst war natürlich unschuldig an der dunklen Geschichte der Firma Henkel. Nichtsdestotrotz standen seine eigenen finanziellen Möglichkeiten mit großer Wahrscheinlichkeit in Verbindung mit jenem unsauberen Teil der Unternehmensgeschichte.

Die Generation vor den Nazis kann nicht für die Verbrechen ihrer Kinder verantwortlich gemacht werden, und Kinder von Nazis sind nicht für die Sünden ihrer Eltern verantwortlich - solange eine Aufarbeitung stattfindet und mögliche Sünden der Familienangehörigen kritisch hinterfragt werden. Die Geschichte geerbten Geldes muss aufgearbeitet werden, eine tief greifende Entnazifizierung von Personen und Gütern muss stattfinden, damit die Kinder von

59 Vgl. Horst-Dieter Küsters, Ein neuer Platz für Unkel. Neugestaltung des FritzPlatzes am Unkeler Christinenstift, in: General-Anzeiger (29.9.2016), abgerufen am 15.10.2020 von https:/ga.de/region/kreis-neuwied/neugestaltungdes-fritz-platzes-am-unkeler-christinenstift_aid-43042315. 
NS-Unterstützerinnen und -Unterstützern oder Profiteuren wirklich als unschuldig an deren Verbrechen angesehen werden können.

Ausgehend von den gegenwärtig verfügbaren Quellen muss deshalb die Frage gestellt werden, inwiefern es sich bei dem Familienvermögen bis heute um Profite handelt, die mit der NS-Zeit in Verbindung stehen. Dies ist besonders wichtig, da die Tochter von Fritz Bagel heute als die ,,neue PersilFrau“60 das gesamte Multi-Milliarden-Euro-Unternehmen Henkel leitet und als ,die wohl einflussreichste Frau im Dax ${ }^{\text {“61 }}$ gewürdigt wird.

Mit der eingangs angedeuteten Stadtratsentscheidung über die Umbenennung des bereits erwähnten Fritz-Henkel-Parks in Ilse-Bagel-Park wird die Unternehmensgeschichte von Henkel in Unkel wieder aktuell. In derselben Sitzung erhielt der Stadtrat auch eine Tischvorlage, um über die Annahme zweier Spenden von Fritz Bagel in Höhe von insgesamt $150.000 € \mathrm{zu}$ entscheiden. Dieses Geld wurde als zweckgebundene Spende für die Umgestaltung besagten Parks akzeptiert, was der Stadtbürgermeister im öffentlichen Teil der Sitzung mit den Worten kommentierte: „Einem geschenkten Gaul schaut man nicht ins Maul.“

Ilse Bagel (1908-1991) war die Tochter des in Unkel beliebten Fritz Henkel und die Mutter von Fritz Bagel. Aus ihren Lebensdaten erschließt sich unweigerlich, dass sie die NS-Zeit sowie die Ära der Entnazifizierung und der späteren

60 Martin Roos, Simone Bagel-Trah. Die neue Persil-Frau, in: Handelsblatt (15.4.2008), abgerufen am 15.10.2020 von https://www.handelsblatt. com/unternehmen/management/simone-bagel-trah-die-neue-persilfrau/2946750.html.

61 Christoph Kapalschinski, Porträtserie. Deutschlands wichtigste Managerinnen. Simone Bagel-Trah. Mächtige Kontrolleurin, in: Handelsblatt (22.6.2011), abgerufen am 15.10.2020 von https://www.handelsblatt.com/unternehmen/management/ portraetserie-simone-bagel-trah-maechtige-kontrolleurin/4303262-4. html?ticket=ST-712191-PWuwFHMhlWxxiQJ11fAb-ap5. 
Aufarbeitung als Erwachsene erlebte. Im Unterschied zum Unternehmensgründer Fritz Henkel (Sr.), seinem Sohn Fritz Henkel (Jr.) sowie dem bis zu seinem Tod im März 2021 in Unkel wirkenden Mäzen der Kleinstadt, Fritz Bagel, erfordert ihre Biografie daher besondere Aufmerksamkeit. ${ }^{62}$

1908 in Düsseldorf geboren als älteste Tochter von Fritz Henkel (Jr.), heiratete Ilse 1929 Carl August Bagel (19021941), der ab 1939 als Geschäftsführer der Henkel \& Cie GmbH sowie als Vorstandsmitglied der Henkel \& Cie AG in die Unternehmensannalen einging. Diese Ämter übte Carl August Bagel nur bis 1940 aus, als er aus gesundheitlichen Gründen diese Führungspositionen abgeben musste und auf seinen früheren Posten als Mitglied des Aufsichtsrates der Henkel \& Cie AG (1932-1938 und 1939-1941, davon stellvertretender Vorsitzender von 1934 bis 1938 und 1940 bis 1941) zurückkehrte sowie den Beirat der Henkel \& Cie GmbH (1939-1941, davon 1940 bis 1941 als stellvertretender Vorsitzender) unterstützte. 1941 verstarb Carl August Bagel.

Die Zeit des Bombenkriegs verbrachte Ilse Bagel mit ihren vier Kindern teils in Süddeutschland. Vor Kriegsende kehrte sie jedoch ins Rheinland zurück und erlebte am 8. März 1945 den Einmarsch der US-Soldaten in ihrer Villa in Unkel. Das Anwesen wurde von den US-Streitkräften beschlagnahmt und die Familie vertrieben. Am 31. März 1948 erhielt die Familie die Villa zurück; das Inventar war im Rahmen der Besetzung verschleppt und Teile des Gebäudes zerstört worden.

Was zunächst wie ein vandalistischer Umgang mit Kriegsbeute anmutet, mag tatsächlich in Verbindung

62 Die folgenden biografischen Angaben beziehen sich größtenteils auf den Bericht des Unkeler Stadtarchivars: vgl. Wilfried Meitzner, Ilse-Bagel-Park, in: Niederschrift über die 11. Sitzung des Stadtrates Unkel am 01.09.2020, Unkel 2020, S. 284-287, abgerufen am 15.10.2020 von https://unkel.morerubin1.de/meeting.php?id=ni_2020-SURAT-59. In geringerem Maße beruhen sie auch auf Aussagen des Unternehmens selbst: vgl. Henkel, 140 Jahre. 
gestanden haben mit der Bemühung der US-Besatzungsmacht um Aufklärung der Beteiligung der deutschen Industrie an den NS-Verbrechen. Aus den Ausführungen von James Stewart Martin, der in den 1940er Jahren die Geldspuren der deutschen Industrie verfolgte, bevor er nach dem Krieg als Leiter der Dekartellisierungsabteilung der US-geführten Militärregierung in Deutschland diente, geht hervor, dass jene 40 Industrielle, die wegen Kriegsverbrechen in Nürnberg angeklagt waren, nur die Spitze des Eisbergs darstellten und in vielen Fällen nicht einmal die schlimmsten Täterinnen und Täter oder Profiteure miteinschlossen. Mehr noch wird deutlich, dass die USA bereits früh um die zentrale Rolle von Henkel bei der Ermöglichung der NS-Wirtschaft gewusst haben müssen. ${ }^{63}$ Martin berichtet von vergleichbaren Villen, die bei Kriegsende von alliierten Streitkräften besetzt wurden und deren Inventar beschlagnahmt und an einen anderen Ort verschifft wurde. Oft handelte es sich bei diesem Inventar um gestohlene oder unrechtmäßig erworbene Güter. Weiter beschreibt Martin das Aufspüren und Wiederfinden von geplündertem Gold und anderen Gütern im Wert von rund einer halben Milliarde Dollar, ${ }^{64}$ die von den Nazis gestohlen und an scheinbar harmlosen Orten gelagert worden seien. Tatsächlich hätten die US-Soldaten nicht nur Wertgegenstände gefunden, sondern auch Mikrofilme mit belastendem Material über Unternehmensaktivitäten und NS-Verstrickungen. ${ }^{65} \mathrm{Ob}$ die mutwillige Verwüstung der Henkel-Villa in Unkel möglicherweise im Zusammenhang mit einem solchen Bemühen um Aufdeckung von Verbrechen

63 Vgl. Martin, Honorable Men, S. 111ff.

64 Berechnungen basierend auf dem Verbraucherpreisindex ergeben, dass die relative Kaufkraft einer halben Milliarde Dollar im Jahr 1945 der Kaufkraft von mehr als sieben Milliarden Dollar im Jahr 2021 entspricht. Vgl. Dollar Times, Inflation Calculator, abgerufen am 12.9.2021 von https://www. dollartimes.com/inflation/.

65 Vgl. Martin, Honorable Men, S. 59, S. $73 f$. 
stand, bleibt angesichts der derzeitigen Datenlage eine offene Frage.

Nach Freigabe der Villa war Ilse Bagel zunächst unschlüssig, ob sie die Villa und das mehr als fünf Hektar große Gelände weiter nutzen oder abgeben sollte. Versuche, das Anwesen oder Teile davon in die Verantwortung der Stadt oder der katholischen Kirche zu übergeben, schlugen fehl. Letztendlich schloss Ilse Bagel mit ihren Schwestern eine Vereinbarung über die Aufteilung des von ihrem Vater geerbten Landes. Ein zusätzlicher Pachtvertrag ermöglichte ihr, den Obst- und Gemüseanbau entlang der Fritz-HenkelStraße weiter zu betreiben. Dessen Hauptabnehmer war das Familienunternehmen selbst, bis dieses in den 1960er Jahren günstigere Lieferanten fand und Ilse Bagel den Anbau einstellte.

Im Laufe der Jahre machte sich Ilse Bagel wie schon ihr Vater durch Schenkungen einen Namen: 1959 spendete sie der evangelischen Kirche ein Grundstück unter der Bedingung, dass darauf eine Kirche errichtet werde. In den 1970er Jahren schenkte sie der Stadt Unkel ein Teilstück der Rheinpromenade und veranlasste ihre Schwestern dazu, auf einen Teil der Ufervorfläche ihrer Grundstücke zu verzichten, sodass ein befestigter Weg entlang des Rheins angelegt werden konnte. Ebenfalls in den 1970er Jahren erfolgte die Schenkung des bis vor Kurzem als Fritz-Henkel-Park bekannten Grundstücks. Stadtarchivar Meitzner resümierte in der Stadtratssitzung: „Ich denke, als Unkeler sollte man sich bewußt sein, welchen Schatz Ilse Bagel, die 1991 verstorben ist, uns [...] vermacht hat." ${ }^{\prime 66}$

Während der Bericht des Stadtarchivars die Geschichte der Familie während der NS-Zeit gänzlich außer Acht ließ und damit möglicherweise begünstigte, dass der Stadtrat einstimmig

66 Meitzner, Ilse-Bagel-Park, S. 287. 
für die Umbenennung des Parks zu ihren Ehren stimmte, ${ }^{67}$ verweist das Henkel-Unternehmen selbst auf eine aktive Rolle Ilse Bagels bei Unternehmensentscheidungen: Am 21. November 1947 nahm Ilse Bagel an einem festlichen Zusammenkommen der Familie nach deren Rehabilitierung teil. Darüber hinaus war sie von 1948 bis 1950 Mitglied des Aufsichtsrats der Henkel \& Cie AG, von 1967 bis 1974 Mitglied des Beirats derselben Firma sowie von 1967 bis 1968 Mitglied des Verwaltungsrats der Persil GmbH, von 1969 bis 1974 Mitglied des Verwaltungsrats der Henkel GmbH und schließlich von 1975 bis 1978 Mitglied des Gesellschafterausschusses der Henkel KGaA. ${ }^{68}$

Wie Ilse Bagels Rolle in diesen Räten genau ausgesehen hat, ist bisher weitgehend unbekannt. Aufschlussreich hinsichtlich der Einflussnahme der Frauen in der HenkelFamilie auf die Belange des Unternehmens sind jedoch die Ausführungen von Albrecht Woeste $(\star 1935$, Urenkel des Firmengründers, Stamm Lüps) und Christoph Henkel ( $\star 1958$, Urenkel des Firmengründers, Stamm Hugo Henkel) in der ZDF-Dokumentation Deutschlands größte Clans: Die PersilStory. Woeste erzählt, nach dem Tod von Jost Henkel 1961

67 Die Zweitautorin, die damals Stadtratsmitglied war, und viele ihrer Ratskolleginnen und -kollegen suchten, als sie die Unterlagen zur Umbenennung des Parks in der Woche vor der Sitzung erhielten, zunächst im Internet nach mehreren Variationen von „Ilse Bagel NS-Zeit“ und „Carl August Bagel Nazi-Zeit“ und sahen die ersten aufgeführten Trefferseiten nach Hinweisen auf ein Fehlverhalten durch. Dass bei dieser sehr oberflächlichen Suche keine belastenden Aussagen gefunden wurden sowie das eindringliche Lob, das Ilse Bagel durch den Stadtarchivar zuteilwurde, und der öffentliche Charakter der Sitzung begünstigten schließlich, dass sich der Stadtrat einstimmig für die Umbenennung aussprach. Niemand wollte möglicherweise anwesenden Angehörigen oder Freundinnen und Freunden der Bagel-Familie durch Fragen nach der NS-Zeit zu nahe treten, ohne gleichzeitig Beweise in der Hand zu halten - zumal sich der Stadtrat aufgrund der Tischvorlage bewusst war, dass eine Spende von $150.000 €$ im Raum stand. Im Nachhinein wünscht die Zweitautorin, dass sie bereits im Vorfeld der Sitzung mehr Zeit in die Recherche investiert hätte, um jene Informationen zu finden, die dem Stadtrat eine qualifizierte Entscheidungsgrundlage geboten hätten.

68 Vgl. Henkel, 140 Jahre. 
sei entschieden worden, dass die Unternehmensführung in der Familie verbleiben solle. Dieser Beschluss sei gefasst worden von den sechs Frauen, die die Unternehmerfamilie in der dritten Generation ausmachten, wobei ihre Wahl auf den einzigen verbliebenen männlichen Vertreter ihrer Generation, Konrad Henkel (1915-1999, den jüngeren Bruder von Jost), fiel. ${ }^{69}$ Dessen Sohn Christoph Henkel führt ergänzend über den Einfluss der Frauen auf die Unternehmensführung seines Vaters aus:

\begin{abstract}
„Vor nichts hatte mein Vater so sehr - ich will nicht sagen - Angst, aber Respekt und sorgenvollen Respekt und Stress wie seine zweiwöchentlichen oder monatlichen Geschwisterbesprechungen [d.h. Besprechungen mit den Frauen der dritten Generation]. Manchmal nahm er mich da mit. Und es war immer sehr freundlich. Am Anfang, da gab's ein Gläschen Sekt und so sonntagmittags und dann fingen die Damen an, Fragen zu stellen, und zwar sehr spezifische. “"70
\end{abstract}

Diese beiden Männer der vierten Generation (Albrecht Woeste und Christoph Henkel) berichten übereinstimmend, dass die sechs Frauen der dritten Generation - Ilse Bagel, Sigrid Manchot und Herta Pape (die drei Töchter von Fritz Henkel Jr.), Ruth Thorbecke und Lisa Maskell (Töchter von Hugo Henkel) sowie Ellen Woeste (Tochter von Emmy Lüps, geb. Henkel) - keine stillen Gesellschafterinnen waren. Im Gegenteil werden sie charakterisiert als zentrale Entscheidungsträgerinnen mit starkem Einfluss auf den Kurs des Unternehmens. Diese Rolle mag unterstützt worden

69 Vgl. Albrecht Woeste in ZDF, Deutschlands größte Clans. Die Persil-Story, 2017, hier 28:33-29:11 min, abgerufen am 26.10.2020 von https://www.zdf. de/dokumentation/zdfzeit/zdfzeit-deutschlands-grosse-clans-die-persilstory-100.html. Konrad Henkel gab erst 1990 seine Führungsfunktion ab an Alfred Woeste, der sie wiederum 2009 an Bagel-Trah weiterreichte: vgl. Henkel, 140 Jahre.

70 Christoph Henkel in ZDF, Persil-Story, 33:08-33:33min. 
sein durch zusätzliche Funktionen in den verschiedenen Gremien des Unternehmens. So saßen Ilse Bagel und Konrad Henkel zeitgleich im Verwaltungsrat der Henkel GmbH (1969-1974); im Beirat der Henkel \& Cie GmbH (1967-1974), im Verwaltungsrat der Persil GmbH (1967-1968) und im Gesellschafterausschuss der Henkel KGaA (1975-1978) überschnitten sich ihre Amtszeiten. Tatsächlich mag Ilse Bagels Rolle als informierte Entscheidungsträgerin im Vergleich zu den anderen Frauen zentral gewesen sein, insofern als die Unternehmenschronik nur sie eindeutig als Mitglied der verschiedenen Gremien identifiziert. ${ }^{71}$

Dabei beziehen sich Ilse Bagels offizielle Ämter auf die Nachkriegsära, sodass auf ihre Haltung zum NS-Regime nur indirekt Rückschlüsse gezogen werden können. Journalistische Ausführungen betonen das fast durchweg einheitliche, harmonische Bild, das die Unternehmensfamilie in der Öffentlichkeit abgibt: Bei Entscheidungen würden alle drei Stämme - die Nachkommen von Fritz Henkel (Jr.), von Hugo Henkel und von Emmy Lüps, geb. Henkel - gleichberechtigt ihre Meinung äußern, wobei sie in der Regel alle die gleiche Einstellung verträten. Mehr noch würden bedeutsame Entscheidungen zunächst stammintern abgesprochen, sodass auch Familienmitglieder fern der Führungsriege sich Gehör verschaffen könnten. Dabei stünden stets die Belange des Unternehmens über möglichen Befindlichkeiten der einzelnen Familienangehörigen. ${ }^{72}$ Aktuell weist das Henkel-Unternehmen darauf hin, dass es zu über 60 Prozent der Familie gehöre. ${ }^{73}$ Doch in der NS-Zeit hatte sich das

71 Ruth Thorbecke war von 1975 bis 1983 im Aufsichtsrat der Henkel KGaA, aber nur Ilse Bagel gehörte über einen längeren Zeitraum verschiedenen Gremien an: vgl. Henkel, 140 Jahre.

72 Vgl. Viehöver, EinflussReichen, S. 199ff; vgl. ZDF, Persil-Story, 33:08-33:33min.

73 Vgl. Henkel AG \& Co. KGaA, Aktien. Aktionärsstruktur, 2020, abgerufen am 15.10.2020 von https://www.henkel.de/investoren-und-analysten/aktien. 
Unternehmen noch vollständig im Familienbesitz befunden. ${ }^{74}$ Dies bedeutet, dass sich das Familienvermögen unweigerlich in Teilen auf die NS-Zeit zurückführen lässt. Eine firmeneigene Publikation verweist darauf, dass die britischen Besatzungsbehörden im Aufsichtsrat lediglich NSDAPMitglieder vorfanden und auch im Vorstand nur zwei Mitglieder gesessen hätten, die nicht dem Regime angehörten. Des Weiteren wird berichtet, dass nach der Einfrierung der Unternehmensvermögen gemäß Militär-Gesetz 52 vom 28. April 1945 „Henkel [später] das in den westlichen Besatzungszonen befindliche Vermögen, dem rund 74,4\% des Stammkapitals entsprach, zu einem überwiegenden Teil sukzessive zurückerhalten“"75 konnte.

Gesetzt den Fall, dass das harmonische Miteinander der Unternehmerfamilie auch für die NS-Zeit zutreffend gewesen wäre, hätte auch Ilse Bagel, prominent vertreten durch die Geschäftsführerrolle ihres Mannes Carl August, die Übernahme arisierter Betriebe und den Ankauf der DegussaAktien unterstützt. Dabei wäre festzuhalten, dass Zyklon B nur nach dem Tod Carl August Bagels für die Gaskammern verwendet wurde. Nichtsdestotrotz flossen die Gewinne aus den Degussa-Aktien des Henkel-Unternehmens - und somit auch die Gewinne aus dem Verkauf von Zyklon B an die SS - in das Vermögen des Familienunternehmens und damit letztlich in das Vermögen der Familienangehörigen selbst.

Die Verwicklungen der Familie und des Unternehmens Henkel in die NS-Verbrechen dürften Ilse Bagels Einkommen deutlich erhöht und die Grundlage für ihr Vermögen und ihre Investitionen in der Nachkriegszeit gelegt haben. Damit sind sie unweigerlich relevant für einen ehrlichen Umgang mit dem Vermächtnis von Ilse und ihrem Sohn Fritz Bagel.

74 Vgl. United States Senate, Elimination, S. 775.
75 Feldenkirchen/Hilger, 125 Jahre, S. 110. 
Was auch immer die Gründe für das Verhalten der einzelnen Familienmitglieder während der NS-Zeit gewesen sein mögen, verweisen die hier aufgeführten Daten auf eine Bereitschaft zur Zusammenarbeit, Beihilfe und Unterstützung des NS-Regimes und seiner schlimmsten Verbrechen durch das Henkel-Unternehmen. Dass bis heute nur wenige Fakten vorliegen, mindert diesen Eindruck nicht, sondern wirft eher die Frage auf, warum das Unternehmen so lange über sein Verhältnis zum NS-Regime und dessen Verbrechen weitgehend geschwiegen hat. Zwar gibt es unternehmenseigene Publikationen, die vereinzelt Licht ins Dunkel werfen, doch hielt das Unternehmen bis vor Kurzem seine Archive unter Verschluss und verweigerte sich damit einer wissenschaftlichen Untersuchung. ${ }^{76}$

Doch nicht nur das Verhalten des Henkel-Unternehmens wirft Fragen auf. Kritisch zu sehen ist auch die bereitwillige Rehabilitierung der NSDAP-nahen Henkel-Führungsriege der NS-Zeit, sowohl seinerzeit durch die Besatzungsmächte als auch später durch Deutschland selbst, die etwa die hochrangigen Auszeichnungen einiger der zunächst festgenommenen Familienmitglieder ermöglichte - Jost Henkel (1958 Großes Verdienstkreuz des Verdienstordens der BRD), Willy Manchot (1978 Bundesverdienstkreuz Erster Klasse) und Konrad Henkel (1980 Großes Verdienstkreuz des Verdienstordens der BRD, 1995 Großes Verdienstkreuz mit Stern des Verdienstordens der BRD). Bis heute zeigt sich, dass das Henkel-Unternehmen in der Tradition des einstigen Persilscheins wahrgenommen wird. Im Vordergrund steht nicht ein kritisches Hinterfragen der weißen Westen möglicher NS-Profiteure im Sinne des Aufarbeitungsmandats, sondern die Wertschätzung des Familienerbes, die sich

76 Vgl. Hayes, Degussa; vgl. Schumacher, Weiße Flecken, in: WirtschaftsWoche. 
oftmals in großzügigen Spenden und einem lokal hoch angesehenen Mäzenatentum niederschlägt.

Im Falle von Ilse Bagel bedeutet dies, dass ihre großzügigen Spenden von Kapital und Gütern an die Stadt Unkel sowie die evangelische Kirche hochgeschätzt und dankbar angenommen wurden. Doch muss auch betont werden, dass Ilse Bagel dieses Vermögen nicht durch eine NS-unbelastete Tätigkeit verdient hat. Vielmehr handelt es sich bei dem von ihr gespendeten Vermögen um Gewinne des HenkelUnternehmens, die wiederum in Verbindung stehen mit jenen NS-Verbrechen, die zur Ermordung von Millionen europäischer Jüdinnen und Juden sowie anderer NS-Opfer geführt haben.

Eine kritische Reflexion über das Unternehmensvermögen hätte mindestens zu weitreichenden ökonomischen Reparationen führen müssen. In der Nachkriegszeit hätte das Vermögen den Opfern der Shoah und ihren Hinterbliebenen ausgezahlt werden müssen, statt bei der Familie Henkel zu verbleiben. Zwar wird eine solche Wiedergutmachung angesichts der seit Ende des NS-Regimes vergangenen Jahrzehnte und des Versterbens von Opfern sowie Täterinnen und Tätern der ersten Generation immer weniger möglich. Nichtsdestotrotz besteht der moralische Wiedergutmachungsauftrag fort.

Dies ist der blinde Fleck der Aufarbeitung: In dem Glauben, sie habe stattgefunden, hinterfragen wir nicht länger. Wir missverstehen sie als abgeschlossenes Ereignis, nicht als Prozess, der Teil des Rückgrates unseres Gewissens und unserer Handlungen sein muss. ${ }^{77}$ Wenn namhafte deutsche

77 In der Arbeit des Erstautors für gemeinnützige Organisationen, die die Integration von Geflüchteten in Deutschland unterstützen, haben die entsprechenden Projekte seit 2015 nicht nur finanzielle Unterstützung von HenkelErbe Fritz Bagel und der milliardenschweren BMW-Erbin Susanne Klatten ( $\left.{ }^{\star} 1962\right)$ erhalten, sondern auch von der Hertie-Stiftung, der erst kürzlich vorgeworfen wurde, ihre NS-belastete Geschichte (Arisierungen) nicht ausreichend transparent aufarbeiten zu wollen. In Pressemitteilungen brachten 
Unternehmen dazu beigetragen haben, einige der schlimmsten Gräueltaten, die die Welt je gesehen hat, zu ermöglichen, dann bleibt die deutsche Wirtschaft NS-belastet, bis der volle Umfang der Beteiligung ans Licht gebracht wird und die betroffenen Unternehmen die Verantwortung für ihre dunkle Vergangenheit in vollem Ausmaß übernehmen. Im Falle des Henkel-Unternehmens steht dieser Schritt - ebenso wie bei mindestens 70 anderen namhaften Arbeitgebern der NS-Zeit - nach wie vor aus. ${ }^{78}$

Ohne die Mitwirkung eben dieser Unternehmen hätte Hitlers Judenhass wohl nicht eine so schreckliche Dimension der Shoah erreichen können. Die Philosophin Hannah Arendt kam aufgrund ihrer Analyse des Prozesses gegen den ehemaligen SS-Obersturmbannführer Adolf Eichmann zu der Erkenntnis, es sei oftmals ,,schiere Gedankenlosigkeit“79 gewesen, die die Durchführung der Shoah seitens „,erschreckend normal[er]"80 Bürgerinnen und Bürger ermöglicht habe. Wie viele andere auch, hatte sich Eichmann nur ,niemals vorgestellt, was er eigentlich anstellte" ${ }^{81}$ Auch oder gerade unter den veränderten Produktionsbedingungen, die sich aus dem NS-Regime und der Kriegswirtschaft ergaben, werden die Unternehmen um wirtschaftliche Rentabilität gekämpft bzw. Profitsteigerung angestrebt haben. Im Falle des Henkel-Unternehmens könnte dies die Übernahme ari-

die Organisationen, zum Teil unter Federführung des Erstautors, ihren Dank für die Spenden zum Ausdruck; die historischen Quellen der angenommenen Gelder wurden jedoch nicht hinterfragt. Vgl. z.B. Thorsten Schmitz, Geschichte der Hertie-Stiftung. Aufarbeiten ja, Transparenz nein, in: Süddeutsche 25.10.2020, abgerufen am 27.10.2020 von www.sueddeutsche.de/politik/ geschichte-der-hertie-stiftung-aufarbeiten-ja-transparenz-nein-1.5093262.

78 Vgl. Schumacher, Weiße Flecken, in: WirtschaftsWoche.

79 Hannah Arendt, Eichmann in Jerusalem. Ein Bericht von der Banalität des Bösen (Mit einem einleitenden Essay und einem Nachwort zur aktuellen Ausgabe von Hans Mommsen), München 2015, S. 57.

80 Arendt, Banalität, S. 400.

81 Arendt, Banalität, S. 56 [Hervorhebung im Original]. 
sierter Unternehmen sowie die Degussa-Aktienkäufe motiviert haben.

Ohne Zugang zur unternehmenseigenen Dokumentation der NS-Zeit müssen die vorhandenen Quellen somit unweigerlich zu der Annahme führen, dass die Geschäfte der Henkel-Großfamilie eng mit den verbrecherischen Taten des NS-Regimes verflochten waren. Möglicherweise sind das lange Schweigen über diese dunkle Vergangenheit und das Bemühen, belastende Dokumente bis vor Kurzem unter Verschluss zu halten, Ausdruck des Wunsches, die Unternehmerfamilie vor allem mit ihren wissenschaftlichen und wirtschaftlichen Höchstleistungen zu assoziieren. Eine ehrliche Aufarbeitung verlangt aber, hinter die Persilscheine $\mathrm{zu}$ schauen und jene Flecken auf den weißen Westen zu benennen, die sich auch mit einem potenten Waschmittel wie Persil nicht reinwaschen lassen.

\section{„Nie wieder" - ein lokales Paradoxon}

Warum ist es aber so wichtig, auf diese Verbrechen aufmerksam zu machen, rund 75 Jahre nach dem Ende des Zweiten Weltkriegs? Der augenfälligste, unmittelbarste Grund könnte sein, dass alles andere große Heuchelei wäre.

Unkel ist eine sehr stolze Stadt. Zu den Persönlichkeiten, auf die sie am meisten stolz ist, gehört der ehemalige Bundeskanzler Willy Brandt (1913-1992), der die letzten 13 Jahre seines Lebens in Unkel verbracht hat. Viel früher, noch als Bürgermeister von Berlin, dankte er dem ehemaligen NSDAP-Mitglied Jost Henkel mit einer Nachbildung der Berliner Freiheitsglocke dafür, dass seine Firma die Stadt Berlin unterstützt hatte. ${ }^{82}$

82 Vgl. Henkel, 140 Jahre, S. 46. 
Nichtsdestotrotz ist Brandt, bekannt als glühender Antifaschist, für eines der wichtigsten Symbole der historischen Aufarbeitung der Shoah verantwortlich: den Kniefall vor dem Denkmal für den Warschauer Ghettoaufstand in Polen, mit dem er 1970 eine unerwartete Schweigeminute für die Opfer des Nationalsozialismus initiierte. Ein Jahr später erhielt Brandt den Friedensnobelpreis.

Auf einer stadteigenen Webseite wird Brandt gewürdigt als „einer der bedeutendsten Nachkriegspolitiker Deutschlands und Europas“, und weiter heißt es: ,Zum Gedenken an den langjährigen Bürger benennt die Stadt im Jahr 1993 den unteren Markt Unkels in ,Willy-Brandt-Platz um. Im März 2011 eröffnet dort im Herzen der historischen Altstadt auch das Willy-BrandtForum, ein Museum zur Zeitgeschichte, das an Brandts Leben und Wirken erinnert und bundesweit Beachtung findet." ${ }^{\prime 3}$

An mehreren Stellen in der Stadt finden sich Plaketten, die auf Brandt hinweisen. Gedenktafeln und ein Brunnen mit Brandts Büste schmücken die Unkeler Innenstadt. Sein Bildnis ist auf einer Stele direkt vor dem Rathaus zu finden, und das Willy-Brandt-Forum ist eine zentrale Sehenswürdigkeit für Besucherinnen und Besucher der Kleinstadt, für die wiederum der Tourismus eine unverzichtbare Einnahmequelle ist.

Vom Willy-Brandt-Platz und dem besagten Museum aus sind es nur 300 Meter bis zu jenem Park, der kürzlich nach Ilse Bagel umbenannt wurde - eine Umbenennung, die wohlgemerkt verbunden war mit einer großzügigen Geldspende der Henkel-Familie. ${ }^{84}$ Ungeachtet der Unterschiede zwischen Willy Brandt und der Henkel-Familie werden beide in Unkel

83 Stadt Unkel, Berühmte Persönlichkeiten, o.D., abgerufen am 17.9.2020 von https://www.unkel-kulturstadt.de/unkel/Gesichter\%20\&\%20Geschichten/ Ber\%C3\%BChmte\%20Pers\%C3\%B6nlichkeiten/.

84 Tatsächlich würdigt unmittelbar vor dem Willy-Brandt-Forum eine kleine Tafel an einer Bank Fritz Bagels Ehefrau, die den Lindenbaum in der Mitte des Platzes sowie die Bänke als Sitzgelegenheiten gespendet hat. 
verehrt. Doch scheint die sich darin ausdrückende Haltung der Stadt gegenüber der NS-Vergangenheit paradox und reichlich unbekümmert.

Abschließend noch ein Wort zu Ilse Bagel: Wie zuvor berichtet, war sie von 1967 bis 1978 Mitglied in verschiedenen richtungsweisenden Gremien des Henkel-Unternehmens. Dies waren genau die Jahre, in denen der Aufarbeitung in Deutschland besondere Beachtung zuteilwurde, nicht zuletzt beflügelt durch die Bundeskanzlerschaft Willy Brandts. Die Entscheidung des Henkel-Unternehmens, über die eigene Geschichte während der NS-Zeit zu schweigen, muss auch mit den Entscheidungen dieser Unternehmensratsmitglieder zusammengehangen haben. Angesichts der gegenwärtigen Datenlage erscheint es daher schlechthin naiv, Ilse Bagel einen modernen Persilschein auszustellen - als ob sie von den Handlungen ihres Mannes Carl August an der Firmenspitze nicht profitiert und als ob sie während ihrer Zeit in den verschiedenen HenkelGremien nichts mit der Verweigerung einer Aufarbeitung zu tun gehabt hätte. Der einzig mögliche Weg, das Gegenteil zu beweisen, sind wissenschaftliche Untersuchungen der HenkelArchive. Deren lang erwartete und sich jetzt erstmals andeutende Öffnung ist ein notwendiger Schritt, um den Prozess der Aufarbeitung insgesamt voranzutreiben. Da die Rolle der Industrie in der NS-Zeit bisher nur unzulänglich untersucht und in der öffentlichen Diskussion angekommen ist, ist es unabdinglich, dass wir auch heute, mehr als 75 Jahre nach Kriegsende, der deutschen Geschichte immer wieder kritisch gegenübertreten, damit die Worte „Nie wieder“ nicht im Leeren verhallen. Eine wirkliche Aufarbeitung verlangt eine Analyse des gesamten Systems, das Unrecht und Völkermord ermöglichte. Dieser Prozess ist weder in Unkel noch im übrigen Deutschland ausreichend vorangetrieben worden, solange Unternehmen, die von der Shoah profitiert haben, nicht zur Verantwortung gezogen werden. 


\section{Ausblick zur Aufarbeitung im deutschen Unternehmertum}

Geschichtliche Aufarbeitung muss umfassend vollzogen werden; sie darf nicht einzelne Aspekte ausblenden.

Dass es den Nutznießerinnen und Nutznießern sowie den Unterstützerinnen und Unterstützern einiger der größten Verbrechen der Geschichte immer noch erlaubt ist, ihre Vergangenheit zu beschönigen, zeigt, dass die Aufarbeitung in Deutschland bisher nicht die notwendige Gründlichkeit erreicht hat - Aufarbeitung muss ein kontinuierlicher und systemischer Prozess sein. Aufarbeitung im Sinne einer wirklichen Bewältigung der Vergangenheit muss auch die Strukturen und Bedingtheiten unserer Gegenwart kritisch in den Blick nehmen. Nur dann kann ein „Nie wieder“ für die Zukunft gesichert werden.

Nichtsdestotrotz ist Deutschland zugute zu halten, dass es eines der wenigen Länder der Welt ist, in dem der Aufarbeitungsprozess so weit fortgeschritten ist, dass er in das nationale Selbstverständnis inkorporiert wurde. Während wir also auf den blinden Fleck der Aufarbeitung aufmerksam machen, müssen wir gleichzeitig jene lokale und nationale Kultur der Mahnmale und Gedenkveranstaltungen loben, die die Grundlage für eine ehrliche Bewertung der deutschen Geschichte bereitet. In dieser Hinsicht ist Deutschlands Aufarbeitungsprozess richtungsweisend, und es wäre wünschenswert, dass eines Tages auch Länder wie Polen, Kroatien, Rumänien, die Ukraine, Weißrussland, Russland und Frankreich ihr Mitwirken an der Ermordung der Jüdinnen und Juden ehrlich benennen. Ebenso ist es an der Zeit, dass andere Länder die jeweils dunklen Seiten ihrer Geschichte aufarbeiten und Verantwortung für ihren Beitrag zu Rassismus und Völkermord übernehmen.

Im deutschen Kontext ist es aufgrund juristischer Schlupflöcher unwahrscheinlich, dass Unternehmen wie 
Henkel jemals für ihren Einsatz von Zwangsarbeiterinnen und Zwangsarbeitern größere Zahlungen werden leisten müssen. ${ }^{85}$ Dies entbindet uns jedoch nicht von der moralischen Verpflichtung, gesellschaftlichen Druck auszuüben, wo (Familien-)Unternehmen sich sperren, die hässlichen Wurzeln ihres Reichtums anzusehen, öffentlich zu machen und die Verantwortung dafür zu übernehmen.

Wie kann eine solche Verantwortung aussehen? Vermögenswerte von Familien und Unternehmen, die mit den Verbrechen der Shoah und des Zweiten Weltkrieges in Verbindung gebracht werden können, wie es bei Henkel nachweislich der Fall ist, sollten für soziale und ökologische Projekte verwendet werden. Der Fokus sollte zum einen auf der Unterstützung der Schwächsten der Gesellschaft liegen (Geflüchtete, Migrantinnen und Migranten, Minderheiten), zum anderen auf Umweltinitiativen, die die Lebensgrundlage von Menschen verbessern und damit Konflikten vorbeugen beziehungsweise deren Folgen mildern helfen. Einen Park zu finanzieren, in dem alle Mitglieder der Gesellschaft willkommen sind, um dort ihre Freizeit zu verbringen, während andere öffentliche Räume privatisiert werden, ist ebenfalls eine durchaus sinnhafte Nutzung dieses Kapitals. Wichtig ist jedoch, auch bei der Namensgebung eines solchen Parks aufrichtig und transparent vorzugehen. Entsprechend müssen die Verwicklungen in NS-Verbrechen aufgedeckt und die damit verbundene Herkunft des Vermögens beim Namen

85 Eine detaillierte Aufstellung der Gründe, die von verstrichenen Fristen bis hin zur Verjährung etwaiger Ansprüche reichen, ist in folgendem Artikel zu finden: vgl. Ron Steinke/Nora Markard, Zwangsarbeit vor Gericht. Die deutsche Abwehr von Entschädigungsansprüchen ehemaliger NS-Zwangsarbeiter/ innen, 23.10.2007, abgerufen am 16.10.2020 von https://www.linksnet. de/artikel/20829; vgl. zum historischen Kontext auch Clemens Vollnhals, Zwischen Verdrängung und Aufklärung. Die Auseinandersetzung mit dem Holocaust in der frühen Bundesrepublik, in: Ursula Büttner (Hrsg.), Die Deutsche Judenverfolgung im Dritten Reich, Frankfurt am Main 2003, S. 381-380. 
genannt werden. Politikerinnen und Politiker, egal auf welcher Ebene, sowie andere Personen, die im Interesse der breiteren Öffentlichkeit stehen, sind dazu aufgerufen, äußerste Sorgfalt walten zu lassen. Nur so lässt sich verhindern, dass öffentliche Räume scheinbar blind nach Profiteuren der NS-Zeit benannt und Gelder ohne kritische Fragen nach ihrer Herkunft angenommen werden.

Angemessen wäre, im Ilse-Bagel-Park ein Denkmal für die während der NS-Zeit vom Henkel-Unternehmen eingesetzten Zwangsarbeiterinnen und Zwangsarbeiter zu errichten. Aufrichtig wäre die Anbringung einer Gedenktafel neben einer derjenigen, die die Zuwendungen der Bagels und Henkels an Unkel ehren, auf der die Verbindung des HenkelUnternehmens zu Zyklon B und damit zu den Gaskammern der Todeslager benannt wird. In dem Buch Unkel am Rhein: Chronik einer Stadt listet der ehemalige Stadtarchivar Rudolf Vollmer über 100 Unkelerinnen und Unkeler auf, die im Zweiten Weltkrieg ihr Leben verloren haben, sowie über zwanzig zivile Unkeler Opfer. ${ }^{86}$ Diesen mehr als 120 Unkelerinnen und Unkelern sind in der ganzen Stadt verschiedene Denkmäler gewidmet. Ehrlich wäre, neben einigen dieser Denkmäler auch eine Gedenktafel anzubringen, die auf die Beteiligung des Henkel-Unternehmens an den Vierjahresplänen der NS-Kriegsmaschinerie hinweist, welche die Voraussetzungen für unzählige grausame Todesfälle geschaffen hat.

Gewissenhaft wäre, wenn jene, die in der Vergangenheit NS-behaftete Spenden angenommen haben, Druck auf diejenigen ausüben, die nicht wollen, dass die Wahrheit ans Licht kommt. Als damaliger Leiter der Integrationswerkstatt, dem die Eheleute Fritz und Gisela (Ingo) Bagel im Rahmen des von der Hertie-Stiftung geförderten Deutschen Integrationspreises 2019 mehrere Tausend Euro ihres Reichtums spendeten, ist

86 Vgl. Rudolf Vollmer, Unkel am Rhein. Chronik einer Stadt, Unkel 1995. 
auch der Erstautor zur Ehrlichkeit verpflichtet: Dies bedeutet, den Bagels gegenüber auf der Notwendigkeit eines transparenten und verantwortungsvollen Umgangs mit den dunkleren Perioden der Unternehmensgeschichte zu bestehen - trotz der Anerkennung und Dankbarkeit für die empfangene Unterstützung für die Integration von Migrantinnen und Migranten und andere wohltätige Zwecke. Für eine Familie ist es schwer, Fragen dieser Tragweite über die eigenen Eltern zu stellen, und ein jeder, der bereit ist, dies zu tun, verdient Anerkennung. Das war das Besondere an den 68ern: Sie fragten, ,Was haben meine Eltern und Großeltern in den 1930er und 40er Jahren gemacht?", und sie scheuten nicht davor zurück, die Wahrheit über die Vergangenheit zu erfahren. Das ist die Grundlage der Aufarbeitung, und eine ähnliche Gesinnung und Stärke ist auch heute noch vonnöten. Nachbarinnen und Nachbarn sowie die Stadt selbst (beziehungsweise ihre offiziellen Repräsentantinnen und Repräsentanten) sind dazu aufgefordert, ein weiteres Mal ihre Stärke und ihren Mut zu zeigen und gemeinsam die Hinterbliebenen ihres größten Wohltäters und Mäzens zu bitten, über die gegenwärtige Forschung von Scholtyseck hinausgehend die Unternehmens-Archive für weitere Wissenschaftlerinnen und Wissenschaftler zu öffnen und Gewissheit über die Einstellung des Familienunternehmens zum NS-Regime, die im Kontext der NS-Zeit erworbenen Profite sowie über die Verstrickung des Unternehmens mit der Shoah zuzulassen. ${ }^{87}$

87 Das von Scholtyseck geleitete Projekt erforscht die gesamte Unternehmensgeschichte von ihrer Gründung im 19. Jahrhundert bis heute. Die in diesem Buch skizzierten Vermutungen zur Verstrickung des Unternehmens in die Verbrechen des NS-Regimes lassen jedoch eine gezielte wissenschaftliche Untersuchung der NS-Zeit und der Aufarbeitung wünschenswert erscheinen. 
Unkel muss sich verpflichten, „Nie wieder“ den Weg des geringsten Widerstands zu gehen: Die Stadt muss in Zukunft „geschenkten Gäulen ins Maul schauen“ und bei der Ehrung historischer Persönlichkeiten die erforderliche Sorgfalt walten lassen, insbesondere wenn dies bedeutet, unangenehme Fragen zu stellen. Die Stadtspitze unter der Führung des Bürgermeisters ist dazu aufgefordert, sich an jene moralische Richtschnur zu halten, die letzterer in seinen Ansprachen anlässlich des Gedenkens an die Reichspogromnacht selbst benennt, und diese auch bei Ehrungen der lokalen Mäzenenfamilie nicht aus den Augen zu verlieren. Der Pfarrer der lokalen evangelischen Kirche, der jedes Jahr ebenfalls an der ReichspogromnachtGedenkfeier teilnimmt, sollte ehrlich einräumen, auf welchem Grund seine Kirche gebaut wurde, und diejenigen, die sie seiner Gemeinde geschenkt haben, bitten, ausgehend von den zu erwartenden wissenschaftlichen Erkenntnissen zu NS-Verstrickungen des Unternehmens reinen Tisch zu machen und ihr Vermögen im Sinne möglicher Opfer des Unternehmens einzusetzen.

Doch ein solches Aufarbeitungsbemühen wird nur Wirkung zeigen, wenn auch über die Stadtgrenzen hinaus Menschen und Institutionen ihren Mut beweisen. Die Universität Düsseldorf, die beträchtliche Summen von der Henkel-Familie bezogen hat, und auch alle anderen beschenkten großen Institutionen müssten zu diesem Zweck einen ähnlichen Kurs einschlagen und „die wohl einflussreichste Frau im Dax " ${ }^{\prime 88}$ fragen, was die tatsächlichen Wurzeln ihrer Macht sind und wie sie verantwortungsvoll mit dem belastenden historischen Erbe umzugehen gedenke.

Es ist an der Zeit, der geschichtsbezogenen Gedankenlosigkeit nachdrücklich den Rücken zu kehren. $\mathrm{Zu}$

88 Kapalschinski, Managerinnen. 
oft ist diese Unbedarftheit historisch gewachsen; es wurde versäumt, die Missstände zeitnah nach dem Ende des NS-Regimes oder dem Beginn der Aufarbeitungsära zu beheben. Ein vorbildliches Bemühen, diesem Unrecht zu begegnen, zeigte sich in Freiburg, als kurz vor dem Jahrestag der Reichspogromnacht 2012 der Gemeinderat beschloss, alle ca. 1.300 Straßennamen der Stadt wissenschaftlich $\mathrm{zu}$ überprüfen und hinsichtlich ihrer historischen Belastung zu bewerten. Die beauftragte Kommission legte 2016 ihren ausführlichen Bericht mit einer transparenten Kategorisierung problematischer Straßennamen vor, erläuterte ihre Einordnung in verschiedene Belastungsgrade für betroffene Straßennamen und schloss mit einer Handlungsempfehlung, wie mit der gewonnenen Erkenntnis umzugehen sei. Dieser Abschlussbericht der Kommission ist wiederum über die Webseite der Stadt Freiburg einzusehen, sodass auch hier Transparenz gegenüber der Öffentlichkeit verwirklicht wird. ${ }^{89}$ Wenn Aufarbeitung richtig funktionieren soll, sollte jede Stadt eine ähnlich kritische Untersuchung in Angriff nehmen, nicht nur für bereits existierende Namen, sondern auch im Falle einer angestrebten Umbenennung.

Deutschland ist einen weiten Weg gegangen im Umgang mit den eigenen Verbrechen der NS-Zeit. Von unseren Mäzeninnen und Mäzenen müssen wir dasselbe erwarten wie von unseren Regierungen. Deutschland sollte beispielhaft vorangehen bei der nachhaltigen Benennung und Abtragung seiner Schuld. Diese Form der nationalen Entschuldigung dürfen wir nicht unerledigt lassen, sondern müssen uns aktiv für ein würdiges und integres Miteinander einsetzen, damit

89 Vgl. Kommission zur Überprüfung der Freiburger Straßennamen, Abschlussbericht, 2016, abgerufen am 1.11.2020 von https://www.freiburg. de/pb/site/Freiburg/get/params_E-1906631749/1028363/Strassennamen_ Abschlussbericht.pdf. 
sich die Geschichte nicht wiederholt. Dies, so schrieb Willy Brandt über das Miteinander von jüdischen und nicht-jüdischen Deutschen in Sonderburg, sei die zentrale Lehre, die wir angesichts der Schrecken der Shoah verinnerlichen müssen..$^{90}$

90 Willy Brandt, Foreword, in: Frances Henry (Hrsg.), Victims and neighbors. Small town in Nazi Germany remembered, South Hadley, Mass. 1984, S. vii-viii. 


\section{Gedenken als Freifahrtsschein: Unzulänglichkeiten der Aufarbeitung}

\section{Geschichte des lokalen Kontexts}

$D_{\text {Nationalsozialismus durch die deutsche Wirtschaft }}^{\text {ie mangelnde Aufarbeitung der Zeit des }}$ beschränkt sich nicht auf den Unternehmens- und Finanzsektor. Eng mit ihr verflochten ist das deutsche Selbstverständnis und die Verarbeitung des Nationalsozialismus durch die Erinnerungskultur in Wort (Rhetorik) und Tat (Manifestation). Erneut erlaubt ein Blick auf den Mikrokosmos „Unkel“, grundsätzliche Herausforderungen im Umgang mit der nationalsozialistischen Vergangenheit aufzuzeigen.

Wie der frühere Stadtarchivar Rudolf Vollmer berichtet, waren als ,jüdisch“ klassifizierte Personen in Unkel mindestens seit 1578 ansässig, wobei sie als sogenannte „Schutzjuden“ Geldzahlungen an den jeweiligen Landesherren leisten mussten, ohne dass sie dadurch jedoch ein dauerhaftes Bleiberecht erworben hätten. ${ }^{91}$ An anderer Stelle wird vermutet, dass bereits in der zweiten Hälfte des 13. Jahrhunderts Jüdinnen und Juden in Unkel

91 Vgl. Vollmer, Chronik, S. 165f. 
gelebt haben könnten. ${ }^{92}$ Menschen protestantischen Glaubens gelangten dagegen erst nach der preußischen Übernahme des Rheinlandes im Jahr 1815 nach Unkel. ${ }^{93}$ Noch 1885 machte die evangelische Bevölkerung auf dem Gebiet der heutigen Verbandsgemeinde Unkel lediglich 3,8 Prozent der gesamten Bevölkerung aus und war damit nur unwesentlich stärker vertreten als die jüdische Bevölkerung, zu der zu diesem Zeitpunkt 3,5 Prozent der in Unkel ansässigen Personen zählten. ${ }^{94}$

Vollmer zufolge erreichte die jüdische Bevölkerung von Unkel und den benachbarten Dörfern vermutlich um 1853 ihren zahlenmäßigen Höchststand von 100 Personen. ${ }^{95}$ Zwei Jahre nach der Machtergreifung Hitlers waren dagegen nur noch fünf Jüdinnen in Unkel gemeldet; weitere vier Jahre später lebten hier nur noch drei, die bis 1942 alle von Unkel wegzogen, wobei einige auswanderten, um dem NS-Terror zu entkommen. ${ }^{96}$

Eine Deportation unmittelbar von Unkel oder eine Ermordung der in der Kleinstadt ansässigen Jüdinnen und

92 Vgl. Alemannia Judaica, Unkel (Kreis Neuwied). Jüdische Geschichte/ Synagoge (Stand 30.6.2020), abgerufen am 20.7.2021 von https://www. alemannia-judaica.de/unkel_synagoge.htm.

93 Vgl. Wochenkurier Unkel, Restaurierte gusseiserne Grabkreuze wurden auf dem evangelischen Friedhof in Unkel wieder errichtet, in: Wochenkurier Unkel, 18 (2015), abgerufen am 20.7.2021 von https://www.muehlhoeferbestattungen.de/download-file?file_id $=351 \&$ file_code $=$ e35274667a.

94 Vgl. Königliches statistisches Bureau, Gemeindelexikon für das Königreich Preußen auf Grund der Materialien der Volkszählung vom 1. Dezember 1885 und anderer amtlicher Quellen. XII. Provinz Rheinland, Berlin 1888, hier S. $38 \mathrm{ff}$.

95 Im Jahr 1900 lebten nur noch 37 Jüdinnen und Juden in Unkel und den benachbarten Dörfern (s. Fußnote 103). Für den Zeitraum zwischen 1853 und der Jahrhundertwende sind keine weiteren Zahlen genannt. Vgl. Vollmer, Chronik, S. 176.

96 Vgl. Rudolf Vollmer, Die ehemalige jüdische Gemeinde der Bürgermeisterei Unkel, in: Heimatjahrbuch 1994 des Landkreises Neuwied, Neuwied 1994/95, S. 74-79; vgl. Alemannia Judaica. Unkel. - Die drei Kinder des Ehepaares Simon Levy und Sophie Landau emigrierten beispielsweise nach Buenos Aires (Heinz 1908 - 1969; Netty 1913 - 2013) und Haifa (Hannah 1910 - Emigration 1939, Todesjahr unbekannt). Vgl. Pablo Levy, UNKELPL, abgerufen am 20.7.2021 von https://unkelpl.wordpress.com/about/. 
Juden während der NS-Zeit ist nicht dokumentiert. Sophie Heilbronn (1866 in Unkel - 1942 in Theresienstadt), Anita Hirsch geb. Meyer (1897 in Unkel - 1944 in Auschwitz), Berta Paula Landau (1882 in Unkel - 1942 in Kulmhof/Chelmno), Frieda Levy (1877 in Unkel - 1942 in Kulmhof/Chelmno), Leopold Meyer (1888 in Unkel - 1942 in Auschwitz) und Henriette Wolff (1875 in Unkel - 1944 in Theresienstadt) verbrachten jedoch einen Teil ihres Lebens in Unkel, bevor sie in der Shoah ermordet wurden; ihre Namen werden heute in der Zentralen Datenbank der Namen der Holocaustopfer in der Gedenkstätte Yad Vashem ${ }^{97}$ und dem Gedenkbuch für die Opfer der Verfolgung der Juden unter der nationalsozialistischen Gewaltherrschaft in Deutschland 1933-1945 des Bundesarchivs ${ }^{98}$ geführt. ${ }^{99,100}$

97 Vgl. Yad Vashem, Zentrale Datenbank der Namen der Holocaustopfer, abgerufen am 21.7.2021 von https://yvng.yadvashem.org/?language=de.

98 Vgl. Das Bundesarchiv, Gedenkbuch. Opfer der Verfolgung der Juden unter der nationalsozialistischen Gewaltherrschaft in Deutschland 1933-1945, abgerufen am 21.7.2021 von https://www.bundesarchiv.de/gedenkbuch.

99 Die verschiedenen für dieses Buch konsultierten Quellen unterscheiden sich in der Schreibweise dieser Namen. So wird etwa Familie Meyer mitunter auch „Mayer" geschrieben oder Vornamen werden durch Spitz- und Rufnamen ergänzt oder ersetzt. Vgl. Bürgerforum Historische Altstadt Unkel, Neu gegründetes „Bürgerforum Historische Altstadt Unkel“ will Abriss eines historischen Fachwerkhauses verhindern, in: Wochen-Kurier Verbandsgemeinde Unkel, 17 (2021), abgerufen am 21.7.2021 von https:// ol.wittich.de/titel/427/ausgabe/17/2021/rubrik/alle/seite/0/sortiert/ inhaltsverzeichnis.

100 Vermutlich wurden deutlich mehr Jüdinnen und Juden, die einst in Unkel lebten, in der Shoah ermordet. Beispielsweise hatte das Unkeler Ehepaar Simon Hirsch Levy (Hermann) und Johanna Kahn fünf Kinder, darunter auch Frieda und Berta Paula (verheiratete Landau), die hier aufgeführt sind. Sohn Simon starb bereits 1924, doch über die Töchter Selma ( ${ }_{1874)}$ und Catchen ( $\star 1876)$ sind keine Details bekannt. Allerdings ist in der Datenbank der Gedenkstätte Yad Vashem „Selma Levi“ zu finden, deren Geburtsjahr mit dem der Unkelerin übereinstimmt. Weiteren Angaben zu ihrer Person ist zu entnehmen, dass sie sich während des Weltkrieges in Dortmund aufhielt bis zu ihrer Deportation nach Theresienstadt, wo sie 1942 ermordet wurde. Vgl. Levy, UNKELPL; vgl. Yad Vashem, Holocaustopfer. 
Rund 60 Jahre vor der Machtergreifung Hitlers, als Jüdinnen und Juden mehr als drei Prozent der Bewohnerinnen und Bewohner der Kleinstadt ausmachten, hatte sich die jüdische Gemeinde fest in Unkel etabliert und 1869 auch ein Grundstück für die Errichtung einer Synagoge erworben; die Einweihung des Gotteshauses erfolgte am 26. August 1874. Doch war Unkels jüdische Gemeinde eher klein, weshalb es, so wird berichtet, mitunter schwierig war, das Gebot des Minjan zu erfüllen, demzufolge mindestens zehn im religiösen Sinne erwachsene Männer ${ }^{101}$ anwesend sein müssen, um einen Gottesdienst zu feiern. ${ }^{102,103}$ Nachdem 1935 mit Jonas Levy das letzte männliche Mitglied der Unkeler jüdischen Gemeinde gestorben war, sollte die Synagoge verkauft werden. Zunächst fand sich jedoch kein Käufer. Erst zwei Monate nach dem Niederbrennen des Gotteshauses im Zuge der Novemberpogrome von 1938 erwarb ein Mitglied einer in Unkel ansässigen Familie das Grundstück und errichtete darauf ein Wohnhaus. Warum dieser Kaufvertrag erst im Januar 1939 zustande kam, während, so Vollmer, zuvor kein Interessent zu finden gewesen war, lässt sich auf Basis der heute verfügbaren Informationen nicht rekonstruieren. Auffallend ist jedoch der äußert geringe Kaufpreis von 1.100 Reichsmark. Ohne gesicherte Angaben zu den genauen Umständen des Verkaufs des Unkeler Synagogengeländes treffen zu können, verweist dieser Preis auf den generellen Kontext der Arisierung jüdischer Immobilien nach der

101 Die religiöse Mündigkeit wird erreicht durch den Übergangsritus der Bar Mizwa.

102 Vgl. Klaus Dieter Alicke, Lexikon der jüdischen Gemeinden im deutschen Raum. Online-Ausgabe, 2014, abgerufen am 21.7.2021 von https://www.jüdischegemeinden.de/index.php/gemeinden/u-z/1982-unkel-rheinland-pfalz.

103 Eine Auflistung der mündigen männlichen Mitglieder der jüdischen Gemeinde der Stadt Unkel des Jahres 1868 umfasst nur sieben Personen; gemeinsam mit der jüdischen Bevölkerung der benachbarten Dörfer (Scheuren, Erpel, Heister und Rheinbreitbach) wächst diese Liste an auf insgesamt 17 Personen. Vgl. Vollmer, Chronik, S. 170. 
Reichspogromnacht. Die Historikerin Irmtrud Wojak und ihr Kollege Peter Hayes haben diesen mit Bezug auf einen Beitrag ihres Kollegen Wolf Gruner wie folgt charakterisiert:

„,seit 1938 [versuchten] eifrige Beamte und Angestellte unter Berufung auf gemeinnützige Zwecke [...], sich den ,verfallenen' Besitz jüdischer Organisationen und Privatpersonen $\mathrm{zu}$ sichern. Zwangsüberschreibungen $\mathrm{zu}$ verordneten Preisen, Zwangsveräußerungen von verbrannten Synagogen gegen Übernahme der Abrißkosten von den Gemeinden, Umwidmungen jüdischer Wohlfahrtseinrichtungen, Zwangsversteigerungen der Liegenschaften jüdischer Eigentümer zur Begleichung der verhängten Raubsteuern bzw. Bezahlung der Deportationskosten sowie die kostenlose Übereignung des Eigentums der als Reichsfeinde oder Ausgebürgerte deklarierten Juden gehörten zu den seitens der Kommunen angewandten Mitteln, um dieses Ziel im großen Umfang zu erreichen." ${ }^{\text {"104 }}$

Orchestriert wurde die Arisierung spätestens ab dem 10. Dezember 1938 durch den Staat selbst, der auf Geheiß von Hermann Göring, Oberbefehlshaber der Luftwaffe und enger Vertrauter Hitlers, auf jegliches jüdisches Eigentum, auch auf Grundstücke und Häuser, zugriff. ${ }^{105}$ Dabei wurde der Kaufpreis überprüft und genehmigt, wenn dieser weniger als der Verkehrswert betrug und somit die jüdischen Verkaufenden benachteiligte; war der Kaufpreis dagegen höher als der Verkehrswert, verleibte sich der Staat die Differenz von Kaufpreis und Verkehrswert als sogenannte

104 Irmtrud Wojak/Peter Hayes, Einleitung, in: dies. (Hrsg.), „Arisierung“ im Nationalsozialismus. Volksgemeinschaft, Raub und Gedächtnis, Frankfurt am Main 2000, S. 7-14, hier S. 11.

105 Vgl. Elfi Pracht-Jörns, Jüdisches Leben im NS-Staat. Einführung, in: dies. (Hrsg.), Jüdische Lebenswelten im Rheinland. Kommentierte Quellen von der Frühen Neuzeit bis zur Gegenwart (Mit einem Vorwort von Monika Grübel und Georg Mölich), Köln/Weimar/Wien 2011, S. 232-239, hier S. 239. 
Arisierungsabgabe ein. ${ }^{106}$ Die Grundlage hierfür hatte der Staat gelegt, als er ,Jüdischen Gemeinden Ende März [1938] ihren Status als Körperschaften öffentlichen Rechts entzogen und sie zu Vereinen bürgerlichen Rechts degradiert hatte“107. Infolge der Reichspogromnacht wurde mancherorts sogar argumentiert, die angesichts der brandgeschädigten Synagogen anfallenden Abrissarbeiten begründeten den niederwertigen Kaufpreis; im März 1939 fügte das Reichskirchenministerium hinzu, der Abriss und das Entfernen der Trümmer oblägen gar den jüdischen Gemeinden selbst. ${ }^{108}$ In dieser absurden Argumentation zeigt sich auf bestürzende Weise, wie „Gesetze und Verordnungen den Entwicklungen meist hinterherliefen, die durch übereifrige Kräfte oder durch Sachzwänge hier und dort schon längst zu Tatsachen und üblicher Praxis geworden waren"109. Menschenverachtendes Unrecht wurde nicht nur gebilligt, sondern durch den Staat legalisiert und letztlich wurden seine Fortführung und Weiterentwicklung gefördert.

\section{Gedenkveranstaltung - zur Rhetorik der Aufarbeitung}

Wie vermag Deutschland heute dem Unrecht und Leid begegnen, das es einst seiner jüdischen Bevölkerung zugefügt hat?

106 Vgl. Roland R. Vogel, Zur Einschätzung von Verkaufspreisen von Grundbesitz in der Nazizeit vor dem Krieg (1935 bis 1938), in: ZOV Zeitschrift für offene Vermögensfragen 9 (1999), S. 92-101.

107 Wolf Gruner, Die Grundstücke der „Reichsfeinde“. Zur „Arisierung“ von Immobilien durch Städte und Gemeinden 1938-1945, in: Irmtrud Wojak/ Peter Hayes, „Arisierung“ im Nationalsozialismus. Volksgemeinschaft, Raub und Gedächtnis, Frankfurt am Main 2000, S. 125-156, hier S. 127.

108 Vgl. Gruner, Grundstücke.

109 Dirk Van Laak, Die Mitwirkenden bei der „Arisierung“. Dargestellt am Beispiel der rheinisch-westfälischen Industrieregion 1933-1940, in: Ursula Büttner (Hrsg.), Die Deutsche Judenverfolgung im Dritten Reich, Frankfurt am Main 2003, S. 273-304, hier S. 274. 
Eine adäquate Antwort auf diese Frage zu finden ist nicht nur Aufgabe des deutschen Staates als Gesamtheit, sondern jeden Individuums für sich. Auch im Mikrokosmos der Kleinstadt müssen sich die Bewohnerinnen und Bewohner zur Shoah positionieren und ihre eigene Rolle beim Gedenken an die Opfer finden.

Ein Ansatz, Erinnerungskultur im sozialen Gedächtnis $\mathrm{zu}$ verankern, sind Gedenkveranstaltungen, die anlässlich bestimmter Jahrestage begangen werden. Prominentes Beispiel hierfür sind die Veranstaltungen zum Jahrestag der Reichspogromnacht von 1938. Ausgehend von den Bemühungen eines kleinen Kreises von Anwohnerinnen und Anwohnern, dem Initiativkreis Wider das Vergessen, wird in Unkel der jüdischen Opfer der Reichspogromnacht jedes Jahr gedacht im Rahmen einer Veranstaltung am Standort der ehemaligen Synagoge, von dem die Anwesenden dann zum ehemaligen jüdischen Friedhof ziehen, um dort die Namen der früheren jüdischen Bevölkerung Unkels zu verlesen.

Die Stadtspitze, vertreten durch Stadt- und Verbandsgemeindebürgermeister sowie durch Repräsentantinnen und Repräsentanten der evangelischen und katholischen Kirchen und namhafter lokaler Vereine, ist bei diesen Gedenkfeiern meist zugegen. ${ }^{110}$ Der Stadtbürgermeister ist nicht nur als Zuschauer anwesend, sondern hat auch Anteil an der Gestaltung der Gedenkfeier, indem seine Ansprache die Beiträge des Initiativkreises ergänzt. Im Jahr 2018 verwiesen bereits die einleitenden Worte des Stadtbürgermeisters auf die zeitüberdauernde Aktualität und gesellschaftliche Relevanz des Gedenktages:

110 Die Mäzen-Familie Henkel nahm, soweit der Autorin und dem Autor bewusst, in den vergangenen Jahren nicht an den Gedenkveranstaltungen zur Reichspogromnacht teil. Ob sie in früheren Jahren durch ihre Anwesenheit ein Zeichen zu setzen suchte, ist der Autorin und dem Autor nicht bekannt. 
„Es liegt in unserer historischen Verantwortung, den Pogrom und alle weiteren Gräueltaten des nationalsozialistischen Verbrecherregimes nicht und niemals in Vergessenheit geraten zu lassen. Darum, verehrte Gäste, ist es wichtig, in Stunden wie dieser immer und immer wieder an die schrecklichen Ereignisse dieser furchtbaren Nacht heute vor 80 Jahren, die der Auftakt zur Umsetzung der systematischen, furchtbarsten Vernichtungsmaschinerie der deutschen Geschichte war, zu erinnern:

Gegen das Vergessen, gegen das Verdrängen und vor allem gegen das Leugnen unserer historischen Schuld und Verantwortung. [...]

,Wer sich nicht an die Vergangenheit erinnern kann, ist dazu verdammt, sie zu wiederholen.

Dieses Zitat des Philosophen George Santayana steht über Block 4 des Vernichtungslagers Ausschwitz." "111

Im weiteren Verlauf der Ansprache betonte der Bürgermeister, das Gedenken dürfe nicht zum inhaltslosen Ritual erstarren, sondern müsse als solide und zugleich lebendige mentale und emotionale Orientierungsmarke dienen. Der Gedenktag sei ein ,stetiger Auftrag an uns, die Erinnerung wach zu halten“; ${ }^{112}$ das Erinnern sei zu kombinieren mit ,aktiv-positivem Handeln",113 das sich im Bewusstsein der eigenen Verantwortung für das Wohlergehen der eigenen Person und das Wohlergehen anderer ausdrücke, das sich der Maxime der Nächstenliebe verschrieben habe und jedem Individuum abverlange, sich für die Umsetzung dieser Werte anzustrengen. Nur durch ein solches Handeln lasse sich einer Wiederholung historischer Gräueltaten ein Stück weit vorbeugen. ${ }^{114}$

111 Stadtbürgermeister, Unveröffentlichte Ansprache anlässlich der Gedenkveranstaltung vom 10. November 2018, die der Autorin und dem Autor in gedruckter Form vorlag.

112 Ebd.

113 Ebd.

114 Vgl. ebd. 
Anlässlich des Gedenktages 2019 knüpfte der Stadtbürgermeister sinngemäß an seine Ansprache von 2018 an und mahnte, insbesondere angesichts des Erstarkens antisemitischer Gesinnungen und dem gleichzeitigen Wegsterben jener, die aufgrund ihrer eigenen Erfahrungen die Schrecken der Geschichte bezeugen können, die Bedeutung des Erinnerns und Gedenkens hochzuhalten. Die im Namen Deutschlands begangene Shoah bedinge ,eine Scham, die kein Ende finden [dürfe]“.115 Mutig forderte der Stadtbürgermeister die Bundespolitik in Gestalt des Antisemitismus-Beauftragten der Bundesregierung heraus, indem er dessen an die jüdische Bevölkerung gerichtete Warnung kritisierte, das Tragen einer Kippa sei nicht überall in Deutschland sicher:

\begin{abstract}
„Der Umstand, dass ein Beauftragter der Bundesregierung der [sic] jüdischen [sic] Gemeinschaft offiziell wissen lässt, dass Mitmenschen jüdischen Glaubens nicht überall in Deutschland vor Judenhass und Gewalt sicher sein können, ist ein Armutszeugnis für den Rechtsstaat und die politische Wirklichkeit in Deutschland." ${ }^{116}$
\end{abstract}

Als Ursache für diese Haltung des AntisemitismusBeauftragten benannte Unkels Stadtbürgermeister die „Ignoranz von Politik, Gesellschaft und Medien[,] das Prinzip der Lehre aus dem Holocaust, dass nie wieder Juden Opfer von Gewalt jedweder Art werden dürfen, zu verteidigen und zu leben“.117 In diesem Sinne prangerte der Stadtbürgermeister die Unzulänglichkeit der gelebten Erinnerungskultur an, ermahnte die Gesellschaft und verurteilte die Einstellung der Bundesregierung als Ausdruck tatenloser Resignation. Seinen Worten ist von einer humanistischen Perspektive absolut

115 Stadtbürgermeister, Unveröffentlichte Ansprache, 10. November 2019.

116 Ebd.

117 Ebd. 
zuzustimmen und ist auch aus der jüdischen Perspektive des Erstautors zu begrüßen.

Doch ist Diskurs nicht allein Rhetorik, sondern er steht, etwa im Foucault'schen Verständnis, in unmittelbarer Wechselwirkung mit dem pragmatisch-strategischen Kontext. Mehr noch enthalten Diskurse oftmals Widersprüchlichkeiten, deren Aufdecken unbedingt erforderlich ist, um den Charakter des Diskurses zu analysieren. ${ }^{118}$ Im Umgang mit der Vergangenheit geht es eben nicht nur um Geschichte als Faktensammlung, sondern auch um Erinnerung als identitätsprägende, da gelebte Geschichte, als kollektives Gedächtnis der Gesellschaft. ${ }^{119}$ Wie der Ägyptologe und Kulturwissenschaftler Jan Assmann erläutert: „,Das Gedächtnis rekonstruiert nicht nur die Vergangenheit, es organisiert auch die Erfahrung der Gegenwart und Zukunft." ${ }^{120}$ Bezogen auf den Umgang mit der NS-Vergangenheit ist mit den Worten des ehemaligen KZ-Häftlings, politischen Aktivisten und Diplomaten Stéphane Hessel warnend hinzuzufügen: „Der Nazismus ist besiegt worden dank dem Opfer unserer Brüder und Schwestern in der Résistance und der im Kampf gegen die faschistische Barbarei verbündeten Nationen. Doch die Bedrohung ist nicht vollständig gebannt.“121

\section{Stadtbild - die Architektur des Gedenkens}

Die Vergangenheit wird nicht nur auf der rhetorischen Ebene (re-)konstruiert und festgeschrieben, sondern auch in vielerlei

118 Vgl. Michel Foucault, Archäologie des Wissens (Ulrich Köppen, Übers.), Sinzheim 1981.

119 Vgl. Jan Assmann, Das kulturelle Gedächtnis. Schrift, Erinnerung und politische Identität in frühen Hochkulturen, München 1999.

120 Ebd., S. 42.

121 Stéphane Hessel, Empört Euch! (Michael Kogon, Übers.), Berlin 2011, hier S. 21. 
anderen Lebensbereichen. Ein Zeugnis der Vergangenheit ist das Stadtbild: Es erlaubt das Herstellen eines Bezugs zu den historischen Wurzeln und verortet so die kulturelle Identität einer Stadt im Hier und Jetzt; zugleich ist das im äußeren Erscheinungsbild ausgedrückte Selbstverständnis einer Stadt richtungsweisend für deren Zukunft.

In Unkel ist es nicht nur der unreflektierte Umgang mit dem Mäzenatentum und den der Stadt und der Kirche geschenkten Anwesen, die auf die Notwendigkeit einer erneuten und tiefgreifenderen Aufarbeitung hinweisen. Es gibt weitere Grundstücke und Immobilien, die Gefahr laufen, zum Opfer von profitorientiertem Denken und zweifelhaften architektonischen Entscheidungen zu werden, obwohl deren geschichtliche Verankerung zukunftsweisend für ein ernst gemeintes „Nie wieder“ sein sollte: Ein ehemaliges Hotel etwa wurde 2019 abgerissen und, während die Baulücke im historischen Stadtkern auf eine Einigung von Stadtspitze und Investor wartete, der der Innenstadt abgewandte Teil des Geländes von jeglichem Pflanzenbewuchs befreit, um (übergangsweise) in einen geschotterten Parkplatz verwandelt zu werden. Immerhin hatte es die Stadt in ihrer ursprünglichen Ausschreibung für die Bebauung des Areals interessierten Investoren freigestellt, das zum Stadtkern hin benachbarte „Roos-Haus“, in dem im ausgehenden 19. Jahrhundert der jüdische Mitbürger Bernhard Mayer gelebt hatte, in ihre Planung einzugliedern. ${ }^{122}$ Dank dieses Vorgehens könnte das alte Fachwerkhaus tatsächlich vor dem Abriss gerettet werden, sofern sein maroder Zustand eine Instandsetzung und spätere Nutzung nach wie vor ermöglicht.

Schräg gegenüber von dem früheren Hotelgelände gibt es einen weiteren, deutlich kleineren Parkplatz mit Garagen,

122 Vgl. Bürgerforum Historische Altstadt Unkel, Abriss eines historischen Fachwerkhauses. 
der privat von Anwohnerinnen und Anwohnern genutzt wird. Der asphaltierte Hof hinter dem Gittertor markiert den Standort der früheren Synagoge von Unkel. Lediglich eine unscheinbare Gedenktafel an einer Außenmauer des Parkplatzes weist seit 1985 auf die Bedeutung des Ortes hin, indem sie ihn charakterisiert als ,zerstört in der Zeit der Verfolgung unserer jüdischen Mitbürger am 10. November 1938“. Damals hatten sich zwei Unkeler die Schlüssel zur Synagoge von der Witwe des letzten männlichen jüdischen Gemeindemitglieds aushändigen lassen, um das Gotteshaus in Brand zu stecken, während besagte Witwe von ihrem Wohnhaus aus die Tat hilflos mitansehen musste. Als die mutmaßlichen Täter sich 1949 vor Gericht verantworten sollten, wurden sie freigesprochen. ${ }^{123}$

Unkeler Anwohnerinnen und Anwohner, die die Brandstifter 1938 beobachtet hatten, wussten jedoch um deren Vergehen: Mitunter wurde dieses Wissen zum persönlichen Vorteil genutzt, etwa als Druckmittel zur Durchsetzung eigener Grundstücksinteressen gegenüber einem der Schuldigen. Zugleich schien das Wissen um die Identität der Brandstifter in Unkel entweder wenig verbreitet zu sein, oder aber deren aktive Teilhabe an der Reichspogromnacht galt als nicht besonders ehrenrührig, insofern als diese Beihilfe zur Shoah im Falle eines der Täter seiner späteren Karriere als Bürgermeister nicht im Wege stand. ${ }^{124}$

Der zweite Ort, an dem anlässlich des Jahrestages der Reichspogromnacht der verfolgten und ermordeten Jüdinnen und Juden gedacht wird, ist der ehemalige jüdische Friedhof

123 Vgl. Vollmer, Chronik, S. 172.

124 Diese Informationen beruhen auf informellen Gesprächen, die die Autorin und der Autor mit Personen führten, deren Familien seit mehreren Generationen in Unkel ansässig sind, sowie mit Personen, die in der Vergangenheit selbst versucht hatten, durch Interviews oder Einsichtnahme ins Stadtarchiv Aufschlüsse bezüglich der Identität der Täter zu erhalten. 
in Unkel. Dieser Friedhof war erst 1877 neben dem evangelischen/städtischen Friedhof der Kleinstadt eingerichtet worden. Zwischen 1879 und 1940 wurden dort „42 jüdische Mitbürger sowie 5 Kinder [...] begraben“. ${ }^{125} 1941$ wurde die Schließung des jüdischen Friedhofs angeordnet aufgrund, so die offizielle Begründung, seines verwahrlosten Zustandes. Schließlich hatte das Berliner Reichskirchenministerium bereits im August 1938 verfügt, dass ein jüdischer Friedhof, wenn er nicht (mehr) genutzt werde, keinen historischen, wissenschaftlichen oder künstlerischen Mehrwert biete und daher nicht erhalten werden müsse. ${ }^{126}$ Wie Vollmer berichtet, wurden die Grabsteine in die benachbarte ehemalige Kiesgrube geworfen und der Ort als öffentliche Bleiche genutzt $^{127}$ - ein Ausdruck gängiger kommunaler Praxis, wie Gruners Ausführungen zur Arisierung von Synagogen und jüdischen Friedhöfen klar erkennen lassen. ${ }^{28}$

Nach dem Ende der NS-Zeit wurden nur acht Grabsteine wiedergefunden und aufVeranlassung der US-Besatzungsbehörden auf dem entweihten Gelände des Friedhofs wieder aufgestellt, wobei die heutige Positionierung der Steine nicht den ursprünglichen Stellen der Gräber entspricht. ${ }^{129}$ Diese Information ist auch auf einer Informationstafel am Eingang des Friedhofs zu lesen, die der Initiativkreis Wider das Vergessen dort im Jahr 2015, nach Rücksprache mit der Jüdischen Kultusgemeinde Koblenz sowie nach Zustimmung des Stadtrats, anbringen ließ. Somit sind die Grabsteine heute zwar Relikte einer in der Vergangenheit gelebten jüdischen (Begräbnis-)Kultur; aufgrund der Entweihung des Friedhofs in der NS-Zeit ist dieser jedoch nicht länger ein sinnbildliches Haus des Friedens oder

\footnotetext{
125 Vollmer, Chronik, S. 173.

126 Vgl. Gruner, Grundstücke.

127 Vollmer, Chronik.

128 Vgl. Gruner, Grundstücke, S. 127.

129 Vgl. Alicke, Lexikon der jüdischen Gemeinden.
} 
Haus der Ewigkeit, wie er es gemäß der gelebten jüdischen Tradition sein sollte.

Abgesehen von dem Standort der ehemaligen Synagoge und dem jüdischen Friedhof, auf die sich die Unkeler Gedenkkultur explizit bezieht, hat die jüdische Bevölkerung das Stadtbild auch an anderen Stellen geprägt, derer seltener gedacht wird: Bis vor wenigen Jahren gab es in der Innenstadt ein Fachwerkhaus, dessen Fundamente bis ins 16. Jahrhundert zurückreichten und in dem ab Mitte des 19. Jahrhunderts die jüdische Familie Meyer lebte, so auch die Töchter Caroline Meyer und Anne/Anita Hirsch, geb. Meyer, die beide in der Shoah ermordet wurden. Dieses Zeugnis jüdischen Lebens in Unkel wurde abgerissen, als das benachbarte Hotel auf dem Grundstück des alten Fachwerkhauses einen Erweiterungsbau plante und - entgegen seinen ursprünglichen Absichtsbekundungen - den Zustand des historisch wertvollen Gebäudes schließlich doch als zu marode einschätzte, um eine aufwändige Sanierung in Angriff $\mathrm{zu}$ nehmen. ${ }^{130}$ Die Argumentation lautete damals, das wirtschaftliche Überleben des Hotels hinge ab von dem Errichten eines Wellnessbereiches und bedinge daher den Abriss des Gebäudes. Anstelle dieses ansehnlichen Wellnessbereichs wich das sogenannte Bachem-Haus letztlich jedoch einem wenig frequentierten hoteleigenen Parkplatz.

Gegenwärtig droht ein weiteres Haus mit jüdischer Geschichte Opfer von Profitdenken zu werden. In dem Fachwerkhaus wohnte im 19. Jahrhundert eine jüdische Familie, die das Erdgeschoss als Kolonialwarenladen und Drogerie nutzte. Tochter Julie führte das Geschäft fort bis

130 Vgl. Sabine Nitsch, Rheinhotel schafft Parkraum. Baulücke in Unkel wird erst einmal zementiert, in: Rhein-Zeitung, 7. November 2017, abgerufen am 21.7.2021 von https://www.rhein-zeitung.de/region/aus-den-lokalredaktionen/ kreis-neuwied_artikel,-rheinhotel-schafft-parkraum-bauluecke-in-unkel-wirderst-einmal-zementiert-_arid,1727418.html. 
zu dessen Verkauf im Jahre 1907. ${ }^{131}$ Auch im Falle dieses Hauses wird argumentiert, das Gebäude sei einsturzgefährdet und müsse daher abgerissen werden. Auf dem Grundstück des geschichtsträchtigen Fachwerkhauses und seines von der Innenstadt abgewandten Gartens sollen, so die Planung des Investors, drei neue Häuser errichtet werden.

Besagte Kolonialwarenhändlerin Julie war verheiratet mit Jonas Levy (1858-1935), der 25 Jahre lang das Unkeler Bürgermeisteramtsbüro leitete und somit tragender Bestandteil der lokalen Politik war. Als Wohnhaus nutzte das Ehepaar Levy mit seinen Kindern ein weiteres Haus in der Nähe des Stadtkerns, dessen Fassade nach wie vor das Stadtbild ziert. Die heutigen, nicht-jüdischen Besitzer brachten vor wenigen Jahren eine kleine Plakette in ihrem Garten an, die auf die historische Bedeutung des im Volksmund auch ,Judenvilla“ genannten Hauses hinweist. Unmittelbar gegenüber diesem Haus hatte einst Julies Bruder Robert den Bau besagter Unkeler Synagoge initiiert. ${ }^{132}$ Somit zeugt das Stadtbild an dieser Straßenecke sowohl von einer gewissen Ehrerbietung, die der jüdischen Geschichte Unkels entgegengebracht wird, als auch von der „Entjudung“ Unkels im Rahmen der Shoah.

Als der Initiativkreis Wider das Vergessen im Jahr 2015 beantragte, den einstigen Synagogenplatz sowie auch den Jüdischen Friedhof stärker als Stätte des kollektiven Gedenkens zu würdigen und durch offizielle Hinweisschilder auf diese Orte zu verweisen, wurde diese Anregung vom Stadtrat angenommen und die Beschilderung entsprechend verbessert. ${ }^{133}$ Anders verhielt es sich im Falle der einzigen

131 Vgl. Bürgerforum Historische Altstadt Unkel, Abriss eines historischen Fachwerkhauses.

132 Vgl. Bürgerforum Historische Altstadt Unkel, Abriss eines historischen Fachwerkhauses.

133 Vgl. Stadtrat Unkel, Niederschrift über die 11. Sitzung des Stadtrates der Stadt Unkel für die Wahlperiode 2014-2019 am Mittwoch, 11. November 
nach einem jüdischen Mitbürger - Simon Levy - benannten Straße. Hier hatte der Initiativkreis beantragt, Beruf und Funktion (Metzger und Gemeinderatsmitglied) des posthum Geehrten zu ergänzen und dadurch den Informationswert der Straßenbeschilderung zu erhöhen. Der Stadtrat lehnte die Ergänzung jedoch ab, wobei er zur Begründung lediglich anführte, die Beschriftung des Schildes mit dem Namen und den Lebensdaten des Geehrten sei seinerzeit mit dem damaligen Stadtarchivar und den Nachkommen Simon Levys abgestimmt worden. ${ }^{134}$ Auf dieser Grundlage wurde dem jüdischen Bürger die beantragte Gleichbehandlung mit anderen Persönlichkeiten, denen Straßen gewidmet wurden - etwa dem evangelischen Pfarrer Alfred Bierwirth, in dessen Amtszeit der Bau der evangelischen Kirche auf dem von Ilse Bagel geschenkten Grundstück fiel-, verwehrt.

Tatsächlich verweist der hier skizzierte Umgang Unkels mit den architektonischen Zeugnissen jüdischen Lebens auf ein systemimmanentes Problem: Sofern Aufarbeitung ihren Ausdruck beispielsweise in Gedenkfeiern findet, bezieht sie sich auf das verstorbene, erloschene, ermordete jüdische Leben. Es wird erinnert und beteuert, die Shoah dürfe sich nicht wiederholen. Doch wird dabei das Judentum oftmals auf den Genozid reduziert. Jüdisches Leben - damals wie heute - kommt dagegen kaum zur Sprache. Zeugnisse jüdischen Lebens und eines Miteinander in Vielfalt schwinden zusehends. Investitionen werden dort getätigt, wo monetäre Gewinne locken, während (historisch) wertvolle Kulturdenkmäler abgerissen werden.

2015. Beschluss 122/14-19, abgerufen am 13.6.2021 von https://unkel. more-rubin1.de/meeting.php?sid=ni_2015-SURAT-13.

134 Vgl. Stadtrat Unkel, Niederschrift über die 10. Sitzung des Stadtrates der Stadt Unkel für die Wahlperiode 2014-2019 am Dienstag, 29. September 2015. Beschluss 101/14-19, abgerufen am 13.6.2021 von https://www. unkel-kulturstadt.de/unkel/Stadt\%20\&\%20Mensch/Stadt\%20Unkel/ Protokolle/2015/Stadtrat_Niederschrift_150929-10.pdf. 
Während Unkels unmittelbare Nachbargemeinde sich inzwischen aufgeschlossen gegenüber der Installation von Stolpersteinen zeigt, ${ }^{135}$ hat selbst dieses Symbol des Gedenkens und Innehaltens in Unkel noch keine Unterstützung gefunden. Als Begründung wird mitunter hervorgebracht, dass es keine direkten Deportationen von Unkel in die Konzentrationslager gegeben habe, weshalb keine „Notwendigkeit“ für Stolpersteine bestehe. ${ }^{136}$

Zweifellos ist die Eignung von Stolpersteinen als individualisiertes bauliches Denkmal des Innehaltens umstritten als nachvollziehbaren Kritikpunkt äußert etwa Charlotte Knobloch, Präsidentin der Israelitischen Kultusgemeinde München und Oberbayern und Commissioner for Holocaust Memory in World Jewish Congress, dass niemand auch nur sinnbildlich auf die Ermordeten treten solle. ${ }^{137}$ Doch zeugen die kurzen Schriftzüge auf den Steinen immerhin von einer grundsätzlichen Anerkennung der Tatsache, dass es

135 Vgl. Ortsgemeinderat Rheinbreitbach, Niederschrift über die 10. Sitzung des Ortsgemeinderates Rheinbreitbach für die Wahlperiode 2019-2024 am 09.09.2020, abgerufen am 13.6.2021 von https://unkel.more-rubin1.de/ meeting.php?sid=ni_2020-OGRH-45. S. 196.

136 Auch in besagter Nachbargemeinde gab es vermutlich keine direkten Deportationen. Nichtsdestotrotz wurden dort im Juni 2021 die ersten Stolpersteine verlegt, um an drei Jüdinnen zu erinnern, die in der Shoah ermordet wurden. Dabei ist die Haltung Unkels zur Verlegung von Stolpersteinen umso eklatanter angesichts der Diskrepanz zwischen jenen Ressourcen, die für das Gedenken der in der Shoah ermordeten Jüdinnen und Juden aufgewandt werden, und jenen, die mit der Erinnerung an Personen verknüpft sind, die im NS-Regime mitwirkten oder aber von seinen Gräueltaten profitierten. So erfuhr der Erstautor in einem Interview mit dem Diakon der lokalen katholischen Kirche von einer umfangreichen Beerdigungsprozession für einen jungen Wehrmachtssoldaten, die von einem höherrangigen NS-Funktionär geleitet wurde. Der mit Fackeln beleuchtete Trauerzug habe durch die Stadt geführt, der Grabstein sei mit Runen verziert worden und die Stadt selbst trage bis heute die Kosten für die Grabpflege.

137 Vgl. z.B. Charlotte Knobloch, Stadtratshearing am 5. Dezember 2014 - zum Thema „Stolpersteine“, abgerufen am 22.7.2021 von https://www.ikg-m. de/wp-content/uploads/2014/12/2014-12-05-Dr-Knobloch_StatementStolpersteine.pdf. 
vor der Shoah jüdisches Leben auf dem Gebiet des heutigen Deutschland gegeben hatte, sowie von dem deutschen Eingeständnis, schuldig geworden zu sein durch den Genozid, der aus jedem noch so kleinen Dorf Menschen aufgrund ihrer vermeintlichen Andersartigkeit in den Tod trieb. Der Zentralrat der Juden in Deutschland bezieht unter der Leitung seines Präsidenten Josef Schuster Stellung zum Konzept der Stolpersteine:

„Durch die Stolpersteine kommen die Menschen im Alltag mit dem Thema für sie überraschend und unvorhergesehen in Berührung. Stolpersteine verdeutlichen, dass jene Menschen, die grausam ermordet wurden, mitten unter uns gelebt haben und dass ihre Entrechtung und Verfolgung vor aller Augen passiert ist. Durch das Lesen der Inschriften der Messingsteine verbeugen wir uns wortwörtlich vor den Menschen, die dem Nationalsozialismus zum Opfer fielen.“"138

Auf diese Weise können Stolpersteine zumindest als mahnende Gedenkanregung fungieren, wenn auch diese Art des Erinnerns an die Opfer der Shoah nicht genügen kann.

Als im Mai 2021 im Gedenken an den im Vormonat verstorbenen Fritz Bagel eine Spendenannahme von 58.000 Euro vom Stadtrat beschlossen werden sollte, erinnerten sich einige Ratsmitglieder ihres unguten Gefühls bei der Umbenennung des Fritz-Henkel-Parks und der damit verbundenen Spendenannahme und fragten nach den Quellen dieses in Aussicht gestellten Kapitals. Der Stadtbürgermeister lehnte es zwar, wie er sagte, ,,aus Pietätsgründen“ ab, diese Information öffentlich $\mathrm{zu}$ machen, aber er verschob die Abstimmung um einen Monat und gewährte den Ratsmitgliedern in

138 Zentralrat der Juden in Deutschland, Häufig gestellte Fragen (FAQ) an den Zentralrat der Juden. Fragen zum Zentralrat der Juden in Deutschland, abgerufen am 22.7.2021 von https://www.zentralratderjuden.de/service/faq/. 
der Zwischenzeit die Möglichkeit, bei Interesse die Liste der Spenderinnen und Spender einzusehen. Zugleich bat er darum, die Namen der Spendenden vertraulich zu behandeln.

Dieses Vorgehen zeugt von Kompromissbereitschaft und einem gewissen Fingerspitzengefühl für die Situation. Gleichzeitig aber weicht es ab von der gängigen Praxis, im öffentlichen Teil der Sitzung über Spendenannahme unter namentlicher Nennung der Finanzquelle zu entscheiden. Warum sollte bei Spenden, die von der hinterbliebenen Familie zum Gedenken an den verstorbenen Mäzen erbeten wurden, anders vorgegangen werden als bei Zuwendungen, die von weniger namhaften Spendenden stammen? Die rechtliche Grundlage ist in beiden Fällen gleich. Das Bewusstsein, auf die Großzügigkeit des anderen angewiesen zu sein, verbunden mit einer Dankbarkeit, die sich aus vergangenen Zuwendungen speist und womöglich mit einem Gefühl der Verpflichtung zu einem besonderen Entgegenkommen einhergeht, ist auf der zwischenmensch lichen Ebene nachvollziehbar. Systemisch jedoch verweist eine solche Sonderbehandlung auf einen Missstand.

Im Kommunalbrevier ist zwar zur Gemeindefinanzierung zu lesen: „Spenden und ähnliche Zuwendungen Dritter an die Gemeinde sind ein gängiges Finanzierungsmittel. Die Gemeinden sind auf solche Leistungen ihrer Bürgerinnen und Bürger angewiesen." ${ }^{139}$ Zugleich wird wenige Seiten später auf die zentrale Bedeutung des Transparenzgebots verwiesen, wenn auch ohne nähere Angaben zu dessen Umsetzung. Damit wird die finanzielle Angewiesenheit von Kommunen auf Spenden nicht nur hingenommen, sondern offen als Teil der politischen Struktur ausgewiesen. Angesichts der Tatsache, dass Großspenden wohl nur von finanzstarken Bürgerinnen

139 Kommunale Spitzenverbände Rheinland-Pfalz. Gemeinde- und Städtebund Landkreistag Städtetag, Kommunalbrevier Rheinland-Pfalz, Bodenheim 2019, S. 871. 
und Bürgern zu erwarten sind, wird das Mäzenatentum regelrecht institutionalisiert und die politische Unabhängigkeit der Kommunen aufs Spiel gesetzt. Im Kontext der Aufarbeitung der NS-Zeit bedeutet dieser systemimmanente Missstand, dass Reichtum, der sich aus Gewinnen im Zusammenhang mit dem NS-Regime speist, auf der Ebene von Kommunen weiterhin handlungsweisend sein kann. In einem solchen Setting genügt es nicht, die Namen der Gönnerinnen und Gönner publik zu machen: Im Falle des verstorbenen Mäzens Fritz Bagel gingen aus der Spenderliste keine direkten Interessenkonflikte oder hochgradig zweifelhafte Quellen der eingegangenen Gelder hervor. Wohl aber waren manch Angehörige darauf zu sehen, die auch in den vorstehenden Ausführungen zu „Henkels Persilschein“ Erwähnung gefunden haben, wodurch eine Assoziation der Geldquellen mit der NS-Zeit naheliegt. Wie Avraham Barkai festgehalten hat: „Mehr als irgendeine andere Gesellschaftsschicht profitierten die Unternehmer vom Wirtschaftsaufschwung und der Aufrüstung, und danach - im Kriege - von den Früchten der Ausplünderung der Juden und der eroberten Gebiete.“140 Auch wenn nicht alle Unternehmerinnen und Unternehmer unmittelbar die Gräueltaten des NS-Regimes mitgestalteten, sei ihnen doch die Rolle stiller Teilhabender zugekommen, die von dem politischen Unrechtssystem profitierten, ${ }^{141}$ es mitunter aber auch, wie der Historiker Ian Kershaw feststellt, durch aktive Komplizenschaft unterstützten. ${ }^{142}$

Die Arisierungen, von denen viele Unternehmen profitierten, lassen sich nicht einfach rückgängig machen; vielmehr

140 Barkai, Unternehmer und Judenpolitik, in: Büttner (Hrsg.), Judenverfolgung, S. 248.

141 Vgl. ebd.

142 Vgl. Ian Kershaw, The persecution of the Jews and German popular opinion in the Third Reich, in: Leo Baeck Institute Year Book 26 (1981), S. 261-289, hier S. 289. https://doi.org/10.1093/leobaeck/26.1.261. 
sind noch heute die Auswirkungen als „eine der grössten Besitzumschichtungen der Neuzeit" ${ }^{\text {"143 }}$ im Mikrokosmos der Kommunen zu entdecken. Aufgrund dessen besteht eine ,personale Täter-Opfer-Beziehung“"144 fort, die heute, fast 80 Jahre nach Ende der NS-Zeit, ihren Ausdruck findet in der monetären und ideellen Schuld der Erbinnen und Erben der einstigen Täterinnen und Täter gegenüber der enteigneten jüdischen Bevölkerung sowie in gesellschaftlichen Machtstrukturen, die nach wie vor vom Einfluss der NS-Zeit zeugen. NS-belastetes Vermögen verblieb oftmals in den Händen der Profiteure, anstatt zurückzufließen an die jüdischen Eigentümerinnen und Eigentümer bzw. ihre überlebenden Nachkommen oder stellvertretende jüdische Institutionen, sodass auch das heutige wirtschaftliche und gesellschaftliche Gefüge noch durchdrungen ist von jener NS-Belastung.

Gestützt wird dieses System indirekt durch die Unbedarftheit größerer Bevölkerungsteile: Das Grauen der Erinnerung an das von dem NS-Regime verursachte Leiden lässt das deutsche Gedenken an seine jüdischen Opfer oft eher hilflos als durchdacht und mitfühlend wirken. Außerhalb offizieller Gedenkveranstaltungen gerät die aus der NS-Vergangenheit gewachsene Verantwortung zu schnell in Vergessenheit. ${ }^{145}$

143 Van Laak, Die Mitwirkenden bei der „Arisierung“, in: Büttner (Hrsg.), Judenverfolgung, S. 273.

144 Vgl. Goschler, Auseinandersetzung um die Rückerstattung, in: Büttner (Hrsg.), Judenverfolgung, S. 362.

145 Beispielsweise wurde seitens der Stadtspitze ein Filmdreh stolz als Einnahmequelle für die Kommune präsentiert, ohne jedoch zu berücksichtigen, dass anlässlich der Dreharbeiten wenige Tage nach dem Jahrestag der Reichspogromnacht Schauspieler in original NS-Uniformen auf dem Weg zum Drehort in einem historischen Lokal den früheren Standort der Synagoge passierten. Darauf angesprochen, dass in diesem Fall mehr Pietät angebracht gewesen wäre, sagte der für die Koordination mit dem Filmteam verantwortliche Erste Beigeordnete zwar sichtlich betroffen zu, bei weiteren Drehtagen anders zu verfahren. Dass bei wirtschaftlichen Planungen und Entscheidungen auf kommunaler Ebene nicht einmal bei klarem historischen 
Wenn es aber darum geht, eine Kultur des „Nie wieder“ zu garantieren, ist die Voraussetzung dafür, wie Adorno sagte, „ohne Angst, bei irgendwelchen Mächten anzustoßen, offen mit diesem Allerwichtigsten sich [zu beschäftigen] [...], also über das gesellschaftliche Kräftespiel [zu] belehren, das hinter der Oberfläche der politischen Formen seinen Ort hat". ${ }^{146}$

\section{Judenfreie Aufarbeitung?}

Wie kann angesichts der hier aufgezeigten Herausforderungen Aufarbeitung gelingen? Natürlich geht es darum, an das unglaubliche Leiden der Shoah zu erinnern. Doch sollte es kein Selbstzweck sein, immer wieder aufs Neue Bilder des Schreckens zu zeigen und mahnend den Zeigefinger zu heben. In einer Zeit, in der die Täterinnen und Täter ebenso wie die überlebenden Opfer der Shoah versterben, vermögen nur noch wenige Menschen, authentisch zu berichten als Zeuginnen und Zeugen einer Zeit, deren Vermächtnis auch heute noch das deutsche Selbstverständnis und Miteinander prägen sollte. Mit dem Sterben der Zeitzeuginnen und Zeitzeugen rückt auch das Begreifen des Geschehenen und das Nachempfinden des Grauens und der Schmerzen zunehmend in weite Ferne, selbst wenn, wie der Historiker

Bezug zur NS-Zeit eine Überprüfung der ethischen Konsequenzen a priori vorgenommen wird, verweist jedoch erneut auf die Unbedarftheit vieler Deutscher im Umgang mit dem leid- und schuldvollen historischen Erbe. Diese ist nicht auf private Begegnungen beschränkt, sondern äußerst sich auch auf (lokal-)politischer Ebene. Vgl. Haupt-, Wirtschaftsförderungs-, Planungs- und Bauausschuss des Stadtrates Unkel, Niederschrift über die 10. Sitzung des Haupt-, Wirtschaftsförderungs-, Planungs- und Bauausschusses des Stadtrates Unkel der Wahlperiode 2019-2024 am 24.11.2020, S. 152-170, hier S. 164, abgerufen am 3.7.2021 von https://unkel. more-rubin1.de/meeting.php?sid=ni_2020-SUHAWPLB-10.

146 Adorno, Erziehung nach Auschwitz, in: Adorno (Kadelbach, Hrsg.), Erziehung zur Mündigkeit. 
Clemens Vollnhals festhält, gleichzeitig mit dem Verblassen der Erinnerung ,mit zunehmender zeitlicher Distanz die Auseinandersetzung mit dem Nationalsozialismus an emotionaler Schärfe gewonnen“"147 hat. Doch sowohl das lückenhafte Erinnern als auch die kritische Auseinandersetzung verweisen oft auf ein grundsätzliches Problem in der Begegnung mit der Shoah. Bereits vor 18 Jahren prangerte Büttner an, ,,[e]s fehl[e] [...] das Bindeglied, um die Geschichte der nichtjüdischen und der jüdischen Deutschen als eine Geschichte zu erfassen“. 148

Unerlässlich wäre, um die Verknüpfung der Schicksale zu begreifen und den nachfolgenden Generationen zu ermöglichen, die eigene Verantwortung angesichts der Geschichte $\mathrm{zu}$ verstehen, die jüdische Identität nicht länger auf die Opferrolle zu beschränken. Bisher ist der Völkermord an der jüdischen Bevölkerung jedoch alldominierend, wenn die jüdische Identität in Deutschland thematisiert wird, wie unter anderem Michel Friedman, Vorsitzender des Zentralrates der Juden in Deutschland, in einem Interview kritisch anmerkt. ${ }^{149}$ Provokativ stellt der Politikwissenschaftler und Publizist Max Czollek die rhetorische Frage in den Raum: „Was bedeutet Jüdischkeit jenseits der Themen Shoah, Antisemitismus und Israel, die von außen an einen herangetragen werden?“"150

147 Vollnhals, Zwischen Verdrängung und Aufklärung, in: Büttner (Hrsg.), Judenverfolgung, S. 381.

148 Büttner, Gesellschaft und Judenverfolgung, in: dies. (Hrsg.), Judenverfolgung, S. 18 [Hervorhebung im Original].

149 Vgl. Michel Friedman, Michel Friedman und Max Czollek über jüdisches Leben in Deutschland: „Das ist Gedächtnistheater!“ (Interview: Mareike Fallet, Claudia Keller), in: Chrismon Januar 2021, abgerufen am 29.6.2021 von https://chrismon.evangelisch.de/artikel/2020/51011/ michel-friedman-und-max-czollek-ueber-juedisches-leben-in-deutschland.

150 Max Czollek, Michel Friedman und Max Czollek über jüdisches Leben in Deutschland: „Das ist Gedächtnistheater!“ (Interview: Mareike Fallet, Claudia Keller), in: Chrismon Januar 2021, abgerufen am 29.6.2021 von https:// chrismon.evangelisch.de/artikel/2020/51011/michel-friedman-und-maxczollek-ueber-juedisches-leben-in-deutschland. 
Wird die jüdische Identität auf diese Trias reduziert, droht das Judentum im Diskurs nicht-jüdischer Deutscher als musealisiertes Shoah-Gedenken zu erstarren, sodass Jüdinnen und Juden sowie jüdisches Leben auch rund 80 Jahre nach der Shoah nicht wieder in Deutschland präsent oder gar willkommen sind. Darüber hinaus legt ein Diskurs, der die Jüdinnen und Juden als Zielscheibe antisemitischer Ideologien und Übergriffe charakterisiert, die Fortsetzung der Opferrolle nahe. Schließlich wird durch die Assoziation mit Israel das Miteinander jüdischer und nicht-jüdischer Menschen in Deutschland auf problematische Weise politisiert: Erstens wird suggeriert, Israel sei das wahre Zuhause der in Deutschland lebenden Jüdinnen und Juden. Damit wird ihre Teilhabe am modernen Deutschland auf die Rolle und die Interessen von Gästen reduziert, denen zwar freundlich begegnet werden sollte, die letztlich aber einem anderen geografischen und kulturellen Raum angehören und aufgrund dessen auch nur ein eingeschränktes Mitspracherecht besitzen können. Zweitens suggeriert diese Verknüpfung im Kontext der Aufarbeitung, dass alle Reparationen, die Israel nach der Shoah gezahlt wurden, tatsächlich Wiedergutmachungszahlungen an den politischen Repräsentanten der gesamten jüdischen Schicksalsgemeinschaft zur Tilgung der deutschen Schuld an Jüdinnen und Juden gewesen wären - dabei gilt zwar Israel weltweit als Zuhause der meisten Jüdinnen und Juden, doch beheimatet es aktuellen Zahlen zufolge nur knapp 47 Prozent aller jüdischen Menschen. ${ }^{151}$ Drittens verlagert die Assoziation mit Israel das Verhältnis von jüdischen und nicht-jüdischen Menschen in Deutschland auf die Frage der politischen Positionierung zum Israel-Palästina-Konflikt; entweder wird Israel blind verteidigt, um jeglicher deutscher

151 Vgl. Sergio DellaPergola, World Jewish Population, 2019, in: Arnold Dashefsky/Ira M. Sheskin (Hrsg.), The American Jewish Year Book, 2019, Bd. 119, Dordrecht 2020. 
Kritik an der jüdischen Schicksalsgemeinschaft vorzubeugen, oder aber es wird versucht, die deutsche Schuld zu relativieren durch den Hinweis auf das israelische Vorgehen gegen Palästinenserinnen und Palästinenser. In beiden Fällen wird Israel/Palästina zum Stellvertreterschauplatz, dank dessen nicht-jüdische Deutsche eine aufrichtige Auseinandersetzung mit der eigenen Geschichte inklusive einer kritischen Reflexion der Aufarbeitung der NS-Zeit umgehen.

Die Reduzierung der Rolle der jüdischen Bevölkerung auf die Trias Shoah, Antisemitismus und Israel ist zudem absurd, insofern als Jüdinnen und Juden oftmals ein Mitspracherecht bei eben diesen Themen verwehrt bleibt. So initiieren zwar nicht-jüdische Privatpersonen, Initiativkreise und Vereine Gedenkveranstaltungen für die Opfer der Shoah; jedoch geschieht dies nur selten gemeinsam mit Jüdinnen und Juden. ${ }^{152}$ In der Absicht, die deutsche Sichtweise auf dieses Phänomen zu verstehen, sprach der Erstautor dieses Buches mit nicht-jüdischen Deutschen, die sich aktiv für eine Erinnerungskultur einsetzen und die die zentrale Bedeutung des Gedenkens und Mahnens gerade in Zeiten eines wachsenden Antisemitismus klar benennen. Ihre Haltung zeugte von einer grundsätzlichen Unsicherheit, ob Jüdinnen und Juden überhaupt eine aktive Rolle in der deutschen Aufarbeitung einnehmen könnten oder gar sollten. Diese Unsicherheit verweist erneut auf das eklatante Missverständnis der Bedeutung der jüdischen Bevölkerung für die deutsche Identität: Die Rolle der Jüdinnen und Juden wird auf die der Opfer in einer zeitlich begrenzten Vergangenheit, der NS-Zeit, beschränkt. Dass Jüdinnen und Juden einst Mitbürger der deutschen Gesellschaft waren, mag im Rahmen von Gedenkveranstaltungen beschworen

152 Die Gründe dafür sind sicherlich mannigfaltig, sodass eine umfassende Darstellung den Rahmen dieses Buches sprengen würde. 
werden; dieser Umstand geht jedoch nicht notwendigerweise einher mit der Erkenntnis, dass jüdische Menschen nach wie vor Anteil an der deutschen Identität - sowie Interesse an einer ehrlichen Aufarbeitung der deutschen NS-Belastung haben.

Ähnlich kritisiert die Vorsitzende der Amadeu Antonio Stiftung ${ }^{153}$ Anetta Kahane unter Berufung auf den Sozialwissenschaftler Samuel Salzborn (2020), ${ }^{154}$ dass in Deutschland lange eine „Erinnerungsabwehrgemeinschaft“ eine ehrliche Shoah-Forschung verhindert habe, indem Jüdinnen und Juden von der (wissenschaftlichen) Aufarbeitung ausgeschlossen wurden, welche wiederum von nicht-jüdischen Deutschen ohnehin nur zögernd in Angriff genommen worden sei. ${ }^{155}$ „Dass Juden jedoch lange Zeit und bis heute in der Holocaust- und Antisemitismusforschung kaum vorkommen, ihnen im Gegenteil sogar bedeutet wird, dass sie in dem Bereich nichts zu suchen hätten, ist eine Anmaßung", ${ }^{156}$ schreibt Kahane empört - bezeichnenderweise in einer Publikation, die sich der Feier jüdischen Lebens im Gebiet des heutigen Deutschlands seit 1.700 Jahren widmet. Während das Festjahr 2021 begangen werden soll mit dem erklärten Ziel, ,jüdisches Leben sichtbar und erlebbar zu machen und dem erstarkenden Antisemitismus

153 Ziel der gemeinnützigen Stiftung ist die Stärkung der Zivilgesellschaft gegen Rassismus, Rechtsextremismus und Antisemitismus.

154 Vgl. Samuel Salzborn, Antisemitismus als negative Leitidee der Moderne, Frankfurt am Main 2020.

155 Vgl. Anetta Kahane, Jüdische Existenz in Deutschland - Eine jüdische Perspektive auf das bundesweite Feierjahr „1.700 Jahre jüdisches Leben in Deutschland“, in: Institut für Demokratie und Zivilgesellschaft (Hrsg.), Wissen schafft Demokratie. Schwerpunkt Antisemitismus, Bd. 8, Jena 2020, S. 116-125. https://doi.org/10.19222/202101/10.

156 Kahane, Jüdische Existenz, in: Institut für Demokratie und Zivilgesellschaft (Hrsg.), Antisemitismus, S. 122. 
etwas entgegenzusetzen“157, verkennt jedoch der Kurztitel der Aktion „\#2021JLID - Jüdisches Leben in Deutschland“ erneut den miteinander verflochtenen Charakter jüdischen und nicht-jüdischen Lebens in der Region. Schließlich blickt das jüdische Leben in diesem Teil Europas auf eine längere Geschichte zurück als der deutsche Staat selbst, wobei angesichts der historischen Eckdaten der im heutigen Deutschland siedelnden Völker die Selbstidentifikation als jüdisch ansatzweise mit der Autoidentifikation als fränkisch, alamannisch oder thüringisch im Übergang von Spätantike zu Frühmittelalter vergleichbar sein könnte.

Unabdingbar für eine ehrliche Aufarbeitung wäre folglich ein konstruktives Miteinander von Menschen verschiedener Hintergründe sowohl in der Shoah- und Antisemitismusforschung als auch bei der Gestaltung von Gedenktagen oder Bildungsprojekten: Eine authentische Aufarbeitung muss gemeinsam von jüdischen und nicht-jüdischen Menschen durchgeführt werden - wohlgemerkt als Dialog in Andersartigkeit. „Gemeinsam“ bedeutet hier nicht ,auf dieselbe Weise“, sondern in Kontakt miteinander. Vom Leid der Jüdinnen und Juden zu berichten kann nur ein Teil der Aufarbeitung sein. Er muss ergänzt werden um die kritische Frage, wie Auschwitz möglich werden konnte, wie Millionen nicht-jüdische Deutsche den Völkermord an ihren Nachbarinnen und Nachbarn zulassen, ihn mitansehen und zu seiner Durchführung beitragen konnten. Die Verantwortung der Täterinnen und Täter, so Friedman, habe nicht erst in den Gaskammern begonnen. ${ }^{158}$ Angesichts der sichtbar gewordenen Unzulänglichkeiten der Aufarbeitung ist hinzuzufügen: Die Verantwortung endete nicht mit

157 321-2021: 1700 Jahre jüdisches Leben in Deutschland e.V., Festjahr 2021. Jüdisches Leben in Deutschland, abgerufen am 22.7.2021 von https:// 2021jlid.de/.

158 Vgl. Friedman, Jüdisches Leben in Deutschland, in: Chrismon Januar 2021. 
Auschwitz, sondern sie währt bis heute fort als Appell an die nachfolgenden Generationen, immer wieder aufs Neue jene unangenehmen Fragen zu stellen, die unerlässlich sind, um nicht nur die Shoah in ihrem historischen Kontext abzubilden, sondern auch die Auswirkungen des Völkermordes bis heute zu verstehen. Hierzu gehört ebenfalls, alte Persilscheine als Zeugnisse der Unschuld zu überprüfen und im Zweifel die strukturellen Unzulänglichkeiten der Aufarbeitung in Wirtschaft und Politik anzuprangern. Zwar

\begin{abstract}
„ist [es] fraglich, ob man selbst nach weiteren, noch ausstehenden Einzelforschungen den genauen Anteil der von der nationalsozialistischen Judenpolitik direkt oder indirekt profitierenden deutschen Unternehmer und den genauen Umfang ihrer Gewinne je wird errechnen können. Trotzdem kann kaum bezweifelt werden, dass die Mehrzahl derjenigen unter ihnen, die durch ihre wirtschaftliche Stellung in der Lage waren, sich an den ,Arisierungen' vor dem Krieg und an dem systematischen Judenmord während des Krieges zu bereichern, dies ohne allzu viele Skrupel getan hat - seien es mittelständische Besitzer oder die Direktoren grosser [sic] Gesellschaften. Dabei haben sie nicht nur die sich bietenden Gelegenheiten wahrgenommen, sondern oft auch mit Erfolg eigene Initiativen ergriffen und den direkten Zugang zu den Machtträgern dazu benutzt, für sie vorteilhafte Bedingungen zu schaffen." ${ }^{159}$
\end{abstract}

Dass diese Profiteure des Nationalsozialismus bis heute Einfluss nehmen auf (Lokal-)Politik und gesellschaftliches Miteinander, hat das Beispiel der Mäzenenfamilie HenkelBagel klar gezeigt. Deutlicher noch wird die NS-geschichtlich bedingte Einflussnahme am Beispiel der BMW-Erbin Susanne Klatten, die nicht nur als drittreichste Deutsche gekürt wurde, sondern auch beschrieben wird als ,zu den

159 Barkai, Unternehmer und Judenpolitik, in: Büttner (Hrsg.), Judenpolitik, S. $263 f$. 
größten Parteispendern der CDU und FDP“160 gehörig, während ihr jüngerer Bruder Stefan Quandt als fünfreichster Deutscher dem Aufsichtsrat der Frankfurter Allgemeinen Zeitung angehört. ${ }^{161}$

Auch über die Verknüpfungen von Profiten aus Arisierungen mit kommunaler wie nationaler Politik sowie der möglichen Beeinflussung einer der größten überregionalen Tageszeitungen hinaus gibt es zahlreiche Beispiele für die fortwährende „Veruntreuung“ arisierten Reichtums. Geradezu absurd ist die monetäre Unterstützung eines neuen Nationalismus durch deutsche Unternehmen mit NS-Belastung: Henkel rühmt sich damit, von 2015 bis 2018 „Offizieller Partner des Deutschen Fußball-Bundes“ sowie „Offizieller Premium Partner der Frauen-Nationalmannschaft" gewesen zu sein, und ist seit 2018/2019 stolzer Hauptsponsor des Fußballvereins Fortuna Düsseldorf. ${ }^{162}$ Ähnlich sind heute die Commerzbank (Arisierungen) ${ }^{163}$ und die Volkswagen

160 Christopher Stolz, Das sind die fünf reichsten Deutschen. Von Susanne Klatten bis Klaus-Michael Kühne, in: Der Tagesspiegel, 10.6.2021, abgerufen am 29.6.2021 von https://www.tagesspiegel.de/wirtschaft/von-susanneklatten-bis-klaus-michael-kuehne-das-sind-die-fuenf-reichsten-menschendeutschlands/27273338.html?utm_source=pocket-newtab-global-de-DE.

161 Vgl. ebd.

162 Vgl. Henkel AG \& Co. KGaA, Sponsoring, abgerufen am 3.7.2021 von https://www.henkel.de/unternehmen/sponsoring.

163 Der Historiker Bernhard Lorentz charakterisiert die Commerzbank bei der Durchführung der Arisierungen als aktiven Partizipanten, der durch seine Netzwerkarbeit die radikale Entwicklung der jüdischen Enteignungen - und damit letztlich die Durchführung der Shoah, wenn auch nicht notwendigerweise ausgehend von einer antisemitischen Ideologie - entscheidend unterstützte. Vgl. Bernhard Lorentz, Die Commerzbank und die „Arisierung“ im Altreich. Ein Vergleich der Netzwerkstrukturen und Handlungsspielräume von Großbanken in der NS-Zeit, in: Vierteljahreshefte für Zeitgeschichte, 50 (2002), S. 237-269. - Der Historiker Christoph Kreutzmüller dagegen sieht die ideologische Verortung der Bank deutlich kritischer: Sie habe keine Skrupel gezeigt, die NS-Rassenpolitik auszunutzen, und ihr Umgang mit den jüdischen Opfern der Arisierungen sei selbst von Antisemitismus geprägt gewesen. Vgl. Christoph Kreutzmüller, Händler und Handlungsgehilfen. Der Finanzplatz Amsterdam und die deutschen Großbanken, Stuttgart 2005; 
AG (Arisierungen, Beschäftigung von Zwangsarbeiterinnen und Zwangsarbeitern sowie KZ-Häftlingen) ${ }^{164}$ Partner des Deutschen Fußball-Bundes. ${ }^{165}$ Dabei ist die Verknüpfung von Sport und Nationalstolz für Deutschland beginnend mit dem Sieg der (west)deutschen Fußballnationalmannschaft im Jahr 1954 - dies bedeutet, kurz nach dem Verlieren des Zweiten Weltkriegs und der moralischen Niederlage, durch die Shoah schuldig geworden zu sein - klar belegt. ${ }^{166}$ Ebenfalls Partner des Deutschen Fußball-Bundes ist das Familienunternehmen adidas, ${ }^{167}$ dessen Umgang mit seiner NS-Geschichte starke Parallelen zum Verhalten von Henkel aufweist: Adolf und Rudolf Dassler gründeten Anfang der 1920er Jahre die Schuhfabrik „Gebrüder Dassler“, die in den folgenden Jahren, mit Ausnahme des Jahres der Machtergreifung Hitlers, einen raschen Umsatz- und Gewinnzuwachs verzeichnen konnte. Dieser blieb auch in den ersten Kriegsjahren weitgehend stabil und sank erst ab 1943 deutlich ab, wobei 1944 und 1945 der Umsatz durch die Produktion von Rüstungsgütern den auf die Schuhproduktion zurückzuführenden Umsatz

vgl. auch Ludolf Herbs/Thomas Weihe (Hrsg.), Die Commerzbank und die Juden 1933-1945, München 2004.

164 Über die Rolle von Volkswagen in der NS-Wirtschaft gibt es zumindest wissenschaftliche Untersuchungen. Vgl. Schumacher, Weiße Flecken, in: WirtschaftsWoche; vgl. Hans Mommsen/Manfred Grieger, Das Volkswagenwerk und seine Arbeiter im Dritten Reich, Düsseldorf 1996; vgl. Klaus Jörg Siegfried, Rüstungsproduktion und Zwangsarbeit im Volkswagenwerk 1939-1945. Eine Dokumentation (Wolfsburger Beiträge zur Stadtgeschichte und Stadtentwicklung), Frankfurt am Main 1999.

165 Vgl. DFB, Der DFB. Verbandsstruktur. Partner des DFB, abgerufen am 3.7.2021 von https://www.dfb.de/verbandsstruktur/partner-des-dfb/.

166 Vgl. z.B. Franz J. Brüggemeier, Zurück auf dem Platz. Deutschland und die Fußball-Weltmeisterschaft 1954, München 2004; vgl. Henk Erik Meier/ Michael Mutz, Sport-related national pride in East and West Germany, 19922008. Persistent differences or trends towards convergence?, in: SAGE Open, 6 (2016), S. 1-10. https://doi.org/10.1177/2158244016665893.

167 Vgl. DFB, Verbandsstruktur. 
deutlich überstieg. ${ }^{168}$ Die adi $\&$ käthe dassler memorial foundation stellt die Sportbegeisterung des Firmengründers Adolf Dassler in den Vordergrund und leitet daraus nicht zuletzt dessen NS-Unbescholtenheit ab, etwa weil der Sprinter Jesse Owens 1936 bei den Olympischen Spielen in Berlin Schuhe der Dassler-Brüder getragen haben soll. Indem er den Afroamerikaner mit seinen Schuhen ausstattete, habe sich Adolf Dassler von dem NS-Regime politisch distanziert; die NSDAP-Mitgliedschaft der Brüder sei allein Ausdruck der wirtschaftlichen Notwendigkeit gewesen, sich weitgehend systemkonform zu verhalten. Da Adolf Dassler nie politisch aktiv gewesen sei und er während der NS-Zeit einen jüdischen Freund geschützt habe, sei auch im Entnazifizierungsverfahren nach dem Krieg seine Kategorisierung von „,belastet“ herabgestuft worden auf die eines bloßen „Mitläufers“, sodass er ab 1947 schließlich auch die Firma wieder als Inhaber führen konnte. ${ }^{169}$

Die einzige Arbeit zur Geschichte von adidas während der NS-Zeit, die wissenschaftliche Ansprüche erhebt, weist die Firma dagegen eher als Familienunternehmen mit NS-Belastung aus: Die Historikerin Anne Sudrow merkt zunächst an, die Quellenlage zur Unternehmensgeschichte sei lückenhaft und halte nicht immer einer wissenschaftlichen Überprüfung stand. Gesichert sei jedoch, dass Adolf Dassler $^{170}$ nicht nur Hitlerjugendfunktionär gewesen sei,

168 Vgl. Anne Sudrow, Das Unternehmen „Sportschuhfabrik Gebrüder Dassler" von der Gründung bis zum Ende von Nationalsozialismus und Entnazifizierung (1919-1948), in: Christian Kleinschmidt/Rainer Karlsch/ Jörg Lesczenski/Anne Sudrow (Hrsg.), Unternehmen Sport. Die Geschichte von Adidas, München 2018, S. 19-75.

169 Vgl. adi \& käthe dassler memorial foundation, Leben und Werk. Chronik und Biografie von Adi \& Käthe Dassler, abgerufen am 3.7.2021 von https:// www.adidassler.org/de/leben-und-werk/chronik.

170 Dieser kurze Abriss über die Beziehung von adidas zur NS-Zeit stellt Adolf Dassler in den Vordergrund, insofern als sich die Brüder - nicht zuletzt ausgelöst durch gegenseitige Beschuldigungen im Rahmen ihrer 
sondern auch bei privaten öffentlichkeitswirksamen Feiern die entsprechende Uniform getragen habe. Adolf Dassler habe seine NSDAP-Mitgliedschaft zwar nicht explizit als Bekenntnis zur NS-Ideologie ausgelegt, doch könnten seine entsprechenden Äußerungen auch Ausdruck einer gängigen Verteidigungsstrategie in Entnazifizierungsverfahren gewesen sein. Wirtschaftliche Vorteile im Sinne von Großaufträgen habe die Parteimitgliedschaft nicht eingebracht; möglicherweise habe das Familienunternehmen aber ihretwegen von einer vergleichsweise hohen Lederzuteilung für die Schuhproduktion profitiert. Die Ausstattung von Owen und anderen Olympiasiegern durch die Dassler-Brüder sei wiederum ein ökonomisch motivierter Schachzug gewesen, dem offenbar keine größeren ideologischen Schwierigkeiten im Wege gestanden hätten. Dass Owen tatsächlich bei seinen olympischen Siegen Dassler-Schuhe getragen habe, werde dagegen von keinem offiziellen Dokument gestützt. Es sei nicht davon auszugehen, dass sich Adolf Dassler durch eine Ausstattung ausländischer Sportler in Gefahr gebracht hätte, insofern als er im Rahmen des Entnazifizierungsverfahren keinerlei Aussagen in dieser Richtung zu seiner Entlastung hervorgebracht hätte. Die Quellenlage verweise zudem darauf, dass es unter hohen Sportfunktionären Fürsprecher gegeben habe, die 1943 gegen die Stilllegung der Sportschuhproduktion zugunsten der Rüstungsproduktion aufbegehrt hätten. Auch sei nicht auszuschließen, dass die Firma Gebrüder Dassler in Verbindung gestanden habe mit der berüchtigten „Schuhprüfstrecke“ des

Entnazifizierungsverfahren - zerstritten, sodass die Firma adidas ohne Beteiligung von Adolfs Bruder Rudolf gegründet wurde. Rudolf Dassler wiederum gründete die Firma Puma, deren Sportausrüstungssortiment bis heute oft in Konkurrenz zu den Sportartikeln von adidas steht. Sudrow berichtet auch im Falle Rudolfs von naheliegenden Verbindungen zur Gestapo und SS, weshalb in seinem Fall von einer ähnlich gearteten NS-Belastung ausgegangen werden kann. Vgl. Sudrow, „Sportschuhfabrik Gebrüder Dassler“, in: Kleinschmidt/Karlsch/Lesczenski/Sudrow (Hrsg.), Unternehmen Sport. 
KZ Sachsenhausen, bei der viele KZ-Häftlinge im Rahmen der Produkttestung qualvoll $\mathrm{zu}$ Tode kamen. Eine solche Verbindung sei naheliegend, insofern als Adolf Dassler mit Werkstoffen gearbeitet habe, die auf dieser Strecke getestet wurden, und er ab 1943 wiederholt mit der Firma Freudenberg ${ }^{171}$ korrespondiert habe, wobei es nicht zuletzt um das Thema der Produkttestung gegangen sei. ${ }^{172}$

Von einen unmittelbaren Rückgriff aufKZ-Häftlinge für die Schuhproduktion oder - testung berichtet Sudrow nicht, wohl aber von der Beschäftigung von mindestens neun ausländischen Zivilarbeiterinnen, Zivilarbeitern und Kriegsgefangenen, die als Zwangsarbeiterinnen und Zwangsarbeiter zunächst in der Schuh- und später in der Rüstungsproduktion tätig waren. ${ }^{173}$ Nachdem Adolf Dassler in seinem Entnazifizierungsverfahren durch den halbjüdischen Bürgermeister des Nachbarortes entlastet wurde, indem dieser angab, von Dassler vor der Deportation ins KZ gewarnt und dadurch gerettet worden zu sein, wurde Adolf Dassler lediglich zu einer Geldstrafe und einer kurzwährenden Sperre seiner Inhaberschaft verurteilt. ${ }^{174}$ Ohne Zugriff auf Daten zu haben, die Dasslers Entlastung im Entnazifizierungsverfahren stützen oder aber ihr widersprechen würden, sei angemerkt, dass das Verfahren angesichts etwa der Verbindungen zur Firma Freudenberg an jene Weißwascherei durch Persilscheine erinnert, die Wildt angeprangert hat. ${ }^{175}$ Wenn folglich mit der Commerzbank, der Volkswagen AG und adidas - sowie vormals auch Henkel - namhafte wirt-

171 Diese „Teststrecke“ wurde auch von dem zu einem früheren Zeitpunkt erwähnten Lederverarbeitungskonzern Freudenberg genutzt. Vgl. Scholtyseck, Freudenberg.

172 Vgl. Sudrow, „Sportschuhfabrik Gebrüder Dassler“, in: Kleinschmidt/ Karlsch/Lesczenski/Sudrow (Hrsg.), Unternehmen Sport.

173 Vgl. ebd., S. 62.

174 Vgl. ebd., S. 72.

175 Vgl. Wildt, Verdrängung und Erinnerung, in: Informationen zur politischen Bildung, S. 70. 
schaftliche Akteure den Deutschen Fußball-Bund unterstützen und dadurch indirekt einen neuen deutschen Nationalstolz unterstützen, der nicht zuletzt als „Aufbegehren gegen die Holocaustidentität" ${ }^{176}$ verstanden werden kann, ist dies keine „saubere“ philanthropische Maßnahme. Vielmehr handelt es sich dabei erneut um ein Sichtbarwerden der mangelhaften Aufarbeitung seitens deutscher Institutionen mit NS-Belastung.

Die bis heute fortbestehenden systemischen Ungerechtigkeiten verweisen darauf, dass ein Eingestehen der Schuld an der Shoah zu keiner Absolution führen kann. Wie Czollek festhält: „Die jüdische Seite weiß, dass nie wieder alles gut wird. Diejenigen, die versöhnen können, sind tot. [...] Das vergessen wir [i.e. die Jüdinnen und Juden] nicht. “177 In einem Essay führt er weiter aus:

„Da wäre [...] die Tatsache, dass Enteignung, Verfolgung, Vernichtung und Verwertung von jüdischem Eigentum und jüdischen Körpern auch in der Gegenwart weiterhin wirksam sind. Und zwar auf jüdischer Seite, weil die toten Verwandten nicht zurückkommen - und aufseiten der Täter^innen und ihrer Nachkommen, weil aus der Nazi-Zeit herrührende materielle Vorteile für Firmen, Familien und Individuen bis heute Vorteile bedeuten." ${ }^{\text {"178 }}$

Werden das Ausmaß der Schuld einerseits und des Leidens andererseits verkannt und Jüdinnen und Juden zum homogenisierenden Sammelbegriff für die Opfer der Shoah stilisiert, sind auch die mit viel gutem Willen veranstalteten Gedenkveranstaltungen kaum mehr als Ausdrücke von

176 Dagmar Schediwy, Ganz entspannt in Schwarz-Rot-Gold? Der neue deutsche Fußballpatriotismus aus sozialpsychologischer Perspektive, Münster 2012, hier S. 311.

177 Czollek, (2021a), Jüdisches Leben in Deutschland, in: Chrismon Januar 2021.

178 Max Czollek, Versöhnungstheater. Anmerkungen zur deutschen Erinnerungskultur, 2021, abgerufen am 26.7.2021 von https:// www.bpb.de/geschichte/zeitgeschichte/juedischesleben/332617/ versoehnungstheater-anmerkungen-zur-deutschen-erinnerungskultur. 
„Gedächtnistheater“, wie Czollek unter Berufung auf den Soziologen Michal Bodemann erklärt. ${ }^{179}$ Salzborn (2020b) zufolge könnte dieses ,Theater“" womöglich gar darauf abzielen, nicht-jüdischen Deutschen eine „kollektive Unschuld“ am Völkermord der Shoah zu testieren; ${ }^{180}$ vor allem, meint Czollek, diene diese Art des Erinnerns aber dem sprichwörtlichen Reinwaschen der individuellen und familiären Weste ${ }^{181}$ bis hin zu einer vollständigen Verdrehung der historischen Fakten. ${ }^{182}$ Wie auf einer Theaterbühne inszeniere Deutschland seine Erinnerung an die Shoah letztlich mit dem Ziel, sich angesichts dieser Aufarbeitung beruhigt dafür loben zu können, dass der Nationalsozialismus überwunden sei. ${ }^{183}$ Unter dem Deckmantel einer neuen moralischen Reinheit aber droht die Gefahr eines neuen wachsenden Antisemitismus und deutschen Nationalismus. ${ }^{184}$ Czollek erläutert anschaulich:

„Die Dethematisierung persönlicher oder familiärer Verstrickung kommt dem neuen Nationalismus entgegen, weil sie die Abwehr von Erinnerung erleichtert: Wir lassen uns nicht weiter ein schlechtes Gewissen einreden! Und dann malst du dir die [deutsche] Fahne auf die Wange und schaltest bei der nächsten Nazi-Doku kopfschüttelnd weiter, weil immer gehts um den Holocaust, und was hat das schon mit dir zu tun?" 185

Aufarbeitung als öffentlich inszeniertes Ritual bewirke nicht länger kollektive Betroffenheit, sondern normalisiere das Grauen und lasse die biografischen Bezüge der Einzelnen zum

179 Vgl. Max Czollek, Desintegriert Euch, München 2018.

180 Vgl. Samuel Salzborn (2020b), Kollektive Unschuld: Die Abwehr der Shoah im deutschen Erinnern, Berlin 2020.

181 Vgl. Max Czollek, Gegenwartsbewältigung, München 2020.

182 Vgl. Friedman, Jüdisches Leben in Deutschland, in: Chrismon Januar 2021.

183 Vgl. Y. Michal Bodemann, „Gedächtnistheater“. Die jüdische Gemeinschaft und ihre deutsche Erfindung (Mit einem Beitrag von Joel Geis), Berlin 1996.

184 Vgl. Czollek, Jüdisches Leben in Deutschland, in: Chrismon Januar 2021.

185 Czollek, Gegenwartsbewältigung, S. 29. 
NS-Regime vergessen, kritisiert Czollek. ${ }^{186}$ Dies bedeutet auch, dass eine Übersetzung der historisch bedingten Verantwortung hinsichtlich ihrer Relevanz für das heutige Miteinander von Menschen verschiedener Hintergründe versäumt wird.

Wirklich verantwortungsvoll wäre dagegen, die Shoah nicht allein als Verbrechen an Jüdinnen und Juden zu begreifen, sondern sich aufgrund der kollektiven Schuld und Scham entschieden gegen jegliche Manifestation von Rassismus im Besonderen und Diskriminierung im Allgemeinen zu wenden. Die Verantwortung müsse in dem Versprechen münden, die Würde des Menschen jederzeit zu verteidigen, fasst Friedman zusammen. ${ }^{187}$

Als 2015 Hunderttausende Menschen vor dem Bürgerkrieg in Syrien flohen und in Europa ein neues Zuhause suchten, wirkte Deutschland einen Augenblick lang, als habe es diese ethische Grundhaltung verinnerlicht. Es schien, als habe die Willkommenskultur 70 Jahre nach Ende des Zweiten Weltkrieges endgültig die Nazis besiegt. Aus heutiger Sicht muss diese euphorisch-hoffnungsvolle Einschätzung relativiert werden. Ebenso wie nach der gelungenen Ersthilfe für Geflüchtete im Integrationsprozess systemische Hürden sichtbar werden, die das Miteinander der Kulturen erschweren, können bei Gedenkveranstaltungen manche Redner durchaus die richtigen Worte finden. Im Hintergrund spielt jedoch das Gedächtnistheater auf einer Bühne aus Lügen und Halbwahrheiten, so lange Profiteure der NS-Wirtschaft auch in der heutigen Gesellschaftsstruktur noch Hauptrollen besetzen. Die junge Generation als mögliches Publikum ist längst ermüdet angesichts dieses Theaters. Die Betroffenheitsrhetorik und die Bilder des Leides lähmen das Interesse an einer Auseinandersetzung mit der

186 Vgl. Czollek, Gegenwartsbewältigung.

187 Vgl. Friedman, Jüdisches Leben in Deutschland, in: Chrismon Januar 2021. 
NS-Vergangenheit, anstatt zu mobilisieren. Kritische Fragen werden nicht gestellt; das auf der Grundlage der NS-Zeit etablierte System bleibt unangetastet.

Notwendig wäre ein Aufschrei der Empörung angesichts der fortwährenden Ungerechtigkeiten. Wie Hessel vor mehr als 10 Jahren als Appell an die junge Generation formulierte:

\begin{abstract}
„Mischt euch ein, empört euch! Die Verantwortlichen in Politik und Wirtschaft, die Intellektuellen, die ganze Gesellschaft dürfen sich nicht kleinmachen und kleinkriegen lassen $[\ldots]$.

Ich wünsche allen, jedem Einzelnen von euch einen Grund zur Empörung. Das ist kostbar. Wenn man sich über etwas empört, wie mich der Naziwahn empört hat, wird man aktiv, stark und engagiert. Man verbindet sich mit dem Strom der Geschichte, und der große Strom der Geschichte nimmt seinen Lauf dank dem Engagement der Vielen - zu mehr Gerechtigkeit und Freiheit" ${ }^{188}$
\end{abstract}

Wissenschaftliches Erkenntnisinteresse und betroffenes Gedenken sind nur zwei Aspekte der Aufarbeitung. Dringend notwendig wäre, diese beiden um Empörung zu ergänzen. Das Leiden der jüdischen Bevölkerung evoziert Betroffenheit, doch die bis heute fehlende Gerechtigkeit sollte außerdem Entrüstung hervorrufen und zu Protesten führen. Empörung sollte nicht Anhängerinnen und Anhängern von Nationalismus und Rassismus vorbehalten bleiben, ist sie doch eine angemessene Reaktion auf die Schrecken der Shoah sowie auf die Tatsache, dass viele Profiteure des NS-Unrechtsregimes auch heute noch Privilegien genießen, die auf die NS-Wirtschaft und den Völkermord zurückzuführen sind.

Die kalte, emotionslose Herangehensweise an die akademische Analyse der NS-Vergangenheit und ihrer Auswirkungen bis in die heutige Zeit ist vielleicht eines der

188 Hessel, Empört Euch!, S. 10. 
größten Hindernisse für Jüdinnen und Juden, sich als vollwertiger Teil der heutigen deutschen Gesellschaft zu fühlen. Weder die akademische Aufarbeitung noch die Betroffenheit können Jüdinnen und Juden im heutigen Deutschland das Gefühl geben, dass, falls sich die Geschichte zu wiederholen drohte, nicht-jüdische Deutsche empört protestieren und ihre Nachbarinnen und Nachbarn - unabhängig von deren Kultur, Religion oder Abstammung - schützen würden. Erfolgreiche Aufarbeitung darf nicht allein die Vergangenheit im Blick haben, sondern muss im Jetzt als entschiedenes „Nie wieder“ in den deutschen Werten, im Bewusstsein und im Handeln der Menschen verankert sein und dadurch in Gegenwart und Zukunft vulnerable Bevölkerungsgruppen - jüdische wie nicht-jüdische - schützen.

Eine solche Bereitschaft zur Empörung tatsächlich in der heutigen deutschen Gesellschaft zu etablieren ist eine Herausforderung, setzt sie doch einen bewussten, kritisch-reflektierenden Umgang mit der nationalen Geschichte und der gesellschaftlichen Gegenwart, vor allem aber auch mit der eigenen Rolle innerhalb der Ungerechtigkeiten des heutigen Systems voraus. Schließlich ist davon auszugehen, dass sich in fast jeder Familiengeschichte Personen finden lassen, die aktiv das NS-Regime unterstützten, dem Völkermord tatenlos zusahen oder aber auf die ein oder andere Weise von der Shoah profitierten - sei es im großen Rahmen seitens des deutschen Unternehmertums oder aber im kleinen, privaten Rahmen durch den Kauf eines Möbelstücks weit unter seinem rechtmäßigen, angemessenen Preis. ${ }^{189}$ Anzunehmen, dass nur ein kleiner Kreis von Personen die Shoah ermöglicht und durchgeführt habe, sei, so der Historiker und

189 Vgl. Günther Jikeli, A model for coming to terms with the past? Holocaust remembrance and antisemitism in Germany since 1945, in: Israel Journal of Foreign Affairs, 14 (2021), S. 427-446. https://doi.org/10.1080/23739770.20 20.1859247. 
Antisemitismusforscher Günther Jikeli, nicht mehr als eine bequeme Lüge, Ausdruck des Wunsches, sich einer ehrlichen Auseinandersetzung mit der Shoah und ihren Auswirkungen und sich damit folglich der kollektiven Schuld und Verantwortung zu entziehen. ${ }^{190}$ Unschuldsbeteuerungen sind hier ebenso fehl am Platz wie Gedankenlosigkeit. Versöhnung im Sinne von Vergebung wird durch symbolische Akte des Gedächtnistheaters nicht zu erreichen sein, wie Czollek nicht müde wird hervorzuheben. ${ }^{191}$

Erforderlich ist von deutscher Seite eine „Aufarbeitung der Aufarbeitungskultur" hin zu einer tiefgreifenden und ehrlichen Entnazifizierung NS-belasteter systemischer Strukturen. Essentiell ist dabei, jüdisches Leben in all seinen Facetten als Teil von Deutschland zu begreifen und das soziale Miteinander neu zu denken.

\section{Ausblick zur internationalen Bedeutung der deutschen Aufarbeitung}

Dass die deutsche Aufarbeitung der NS-Geschichte unmittelbar relevant ist für das Verhältnis von Jüdinnen und Juden (unabhängig von ihrer nationalen Identifikation) und nicht-jüdischen Deutschen ist selbstverständlich. Doch auch im internationalen Kontext wird der deutsche Umgang mit der NS-Belastung als bedeutsam und mitunter sogar als richtungsweisend empfunden. Angesichts der deutschen Aufarbeitung empfiehlt etwa die jüdisch-amerikanische Moralphilosophin Susan Neiman den USA, sich an Deutschland ein Beispiel zu nehmen und sich ihrer Vergangenheit der Sklaverei

190 Vgl. ebd.

191 Vgl. Czollek, Versöhnungstheater. 
zu stellen. ${ }^{192}$ Der Historiker, Politikwissenschaftler und Philosoph Ton Nijhuis sieht in der deutschen Einstellung zur eigenen Geschichte eine „Inspirationsquelle für andere europäische Mitgliedsstaaten“, ${ }^{193}$ er fragt sich, ob Deutschland auch für Korea und Südostasien diese Funktion haben könnte, und nennt Deutschland unter Berufung auf den ungarischen Schriftsteller Péter Esterházy „Weltmeister der Vergangenheitsbewältigung“. ${ }^{194}$ Journalistische Quellen wiederum berichten, dass sich auch andere Länder im Zusammenhang mit der Aufarbeitung (Kambodscha Verbrechen der Roten Khmer; Ruanda - Völkermord an den Tutsis) an Deutschland gewandt und vor allem auch deutsche Juristinnen und Juristen im Rahmen von UN-Sondertribunalen gern zurate gezogen wurden aufgrund ihrer nationalen Aufarbeitungserfahrung. ${ }^{195}$

Gleichzeitig verweisen vorstehende Ausführungen ebenso wie andere akademische Beiträge darauf, dass die deutsche Aufarbeitung unvollständig ist und mitunter eher halbherzig praktiziert wird. Jikeli kommt gar zu dem vernichtenden Urteil, Deutschland sollte keinesfalls eine Vorbildfunktion aufgrund seines Umgangs mit der eigenen Vergangenheit einnehmen. Er begründet, über einen zu langen Zeitraum hinweg seien historische Aspekte verdrängt oder Fakten verdreht worden. Dies habe erneut antisemitisches Gedankengut gefördert, das sich etwa in der Ansicht widerspiegele, Jüdinnen

192 Vgl. Susan Neiman, Learning from the Germans. Race and the memory of evil, New York 2019.

193 Ton Nijhuis, Export hit "Vergangenheitsbewältigung". Germany and European integration as a model for Korea and East Asia?, in: Asian Journal of German and European Studies, 1(2016). https://doi.org/10.1186/ s40856-016-0003-0.

194 Vgl. ebd.

195 Vgl. Cornelius Wüllenkemper, Exportschlager Aufarbeitung. Deutsche Berater helfen bei Bewältigung von Diktaturen, in: Deutschlandfunk, 16.5.2013, abgerufen am 5.7.2021 von https://www.deutschlandfunk.de/ exportschlager-aufarbeitung.724.de.html?dram:article_id=246856. 
und Juden würden zu viel über die Shoah sprechen. Der Wunsch vieler Deutschen, die NS-Vergangenheit hinter sich lassen zu können, sei zwar nachvollziehbar, doch verhindere diese Grundeinstellung eine ehrliche Auseinandersetzung mit dem NS-Erbe vor allem im privaten Umfeld. ${ }^{196}$

Dass Historiker wie Scholtyseck sich in bisher wissenschaftlich nicht ausgewertete Archive als Schlüssel zur NS-Vergangenheit begeben, ist wichtig. Doch kann dies nur ein erster Schritt sein, dem notwendigerweise ein zweiter folgen muss. Die gewonnenen Informationen beziehungsweise die wissenschaftlich aufgearbeiteten historischen Fakten müssen gesellschaftliche Bedeutung erlangen, sie müssen Empörung auslösen und dadurch Reformen anstoßen.

Das ritualisierte Gedenken und die wissenschaftliche Analyse um diese Handlungsebene - und infolgedessen eine strukturelle Veränderung der Gesellschaft hinsichtlich der Stellung NS-belasteter Institutionen - zu erweitern ist nicht nur im deutschen Kontext essenziell für eine authentische Aufarbeitung. Darüber hinaus gewinnt sie an internationaler Bedeutung, wenn Deutschland von anderen Gesellschaften, die Verbrechen gegen die Menschlichkeit verübt haben, beispielsweise in Ruanda, oder von Reformbewegungen in den USA als Modell für einen ehrlichen Umgang mit der Vergangenheit gesehen wird.

Doch inwieweit muss sich die Gesellschaft als Ganzes der Verbrechen bewusst sein, auf denen ihre zentralen Institutionen (Unternehmen, Geldinstitute, Transportwesen, Freizeitgestaltung) aufgebaut sind und aus denen sie weiterhin Gewinne beziehen? Die Entnazifizierung als „misslungene gesellschaftliche Säuberung “197 im Anschluss an den Zweiten

196 Vgl. Jikeli, Coming to terms with the past, in: Israel Journal of Foreign Affairs, S. 15.

197 Kerstin von Lingen, Erfahrung und Erinnerung. Gründungsmythos und Selbstverständnis von Gesellschaften in Europa nach 1945, in: Archiv für 
Weltkrieg brauchte die 1968er Generation, um überhaupt das Gespräch wieder auf die Frage der individuellen Schuld zu lenken. Diese Protestbewegung gilt weithin als erfolgreich. ${ }^{198}$ Das nationale Narrativ der erfolgten Aufarbeitung oder gar Vergangenheitsbewältigung ${ }^{199}$ wird geglaubt, und dieser Glaube beeinflusst den Umgang mit anderen, verwandten Themen: Wenn angenommen wird, die Aufarbeitung sei erfolgreich und bis auf den Imperativ des chronisch rezidivierenden Gedenkens bestimmter Jahrestage abgeschlossen, erscheint der deutsche Weg als probater Umgang, um schuld- und schambehaftete Ereignisse der Vergangenheit (beispielsweise die Kolonialgeschichte) vor einem neuen Bedeutungshorizont $\mathrm{zu}$ betrachten und schließlich aus der Aufarbeitung geläutert und vielleicht sogar versöhnt hervorzugehen.

Doch angesichts der aufgezeigten Unzulänglichkeiten der deutschen Aufarbeitung müssen wir kritisch hinterfragen, ob diese Aufarbeitung tatsächlich eine Erfolgsgeschichte ist, oder ob es sich in Wirklichkeit um einen Scheinerfolg handelt, der erlaubt, die Abgründe der Verbrechen und derer, die davon profitiert haben, nicht weiter zu beleuchten. Ist der deutsche Umgang mit der NS-Vergangenheit ein Modell zur Aufarbeitung der Geschichte und zur wirklichen Reformierung der Gegenwart oder ist er ein Modell, das erlaubt, die Geschichte so aussehen zu lassen, als sei sie

Sozialgeschichte, 48 (2009), S. 149-184, hier S. 178.

198 Der Erstautor vorliegenden Buches schrieb in seiner Rolle als Journalist zu Beginn der \#BlackLivesMatter-Bewegung einen Artikel mit dem Titel „The Art of the National Apology“ (Die Kunst der nationalen Entschuldigung), basierend auf dem Glauben, Deutschland habe sich um eine gründliche Aufdeckung der NS-Verbrechen bemüht und habe spätestens unter dem Druck der 1968er tiefgreifende gesellschaftliche Veränderungen angestoßen, sodass es heute tatsächlich eine Vorbildrolle einnehmen könne.

199 Dieser Terminus suggeriert das Bezwingen der NS-Zeit, als hätte das heutige Deutschland gegen jene moralisch verwerfliche NS-Elite der Vergangenheit gekämpft und sei siegreich aus der Auseinandersetzung hervorgegangen. 
aufgearbeitet, während die Dinge ihren gewohnten Gang gehen und Produktivität oder Profitmöglichkeiten unangetastet bleiben? Henkel und Unkel sind keine Einzelfälle, sondern Teil eines deutschlandweiten Phänomens einer vorgetäuschten oder vermeintlichen Vergangenheitsbewältigung.

Bei aller Desillusionierung angesichts des mangelhaften Status quo der deutschen Aufarbeitung gibt sie im internationalen Vergleich doch auch Anlass für Hoffnung: Im Unterschied zu anderen Ländern, deren Geschichte durch Verbrechen gegen die Menschlichkeit belastet ist, zeigt sich Deutschland immerhin fortwährend bemüht. Zwar wird die deutsche Aufarbeitung zu Recht als Gedächtnistheater kritisiert, doch ist anderswo nicht einmal eine solch halbherzige Herangehensweise an die historische Schuld zu finden. Trauriges Beispiel dafür ist in vielen Ländern der Umgang mit der indigenen Bevölkerung als bis heute marginalisiertes Opfer von

„Verbrechen gegen die Menschlichkeit: Mord, Ausrottung, Versklavung, Deportation oder andere unmenschliche Handlungen, begangen an einer Zivilbevölkerung, oder Verfolgung aus politischen, rassischen oder religiösen Gründen“. 200

Allerdings ist auch hervorzuheben, dass Deutschland die Aufarbeitungskultur wohl kaum aus freien Stücken in Angriff nahm. Vielmehr bedurfte es der geschwächten Position des Verlierers: Der Nationalsozialismus als Staatsideologie und

200 Völkerrechtskommission, Im Statut des Nürnberger Gerichtshofs und im Urteil des Gerichtshofs anerkannte Grundsätze des Völkerrechts (Auswärtiges Amt, Übers.), abgerufen am 18.8.2021 von https://www.un.org/depts/ german/internatrecht/nuernberg1946-aa-grunds.pdf; vgl. englischsprachiges Original: United Nations (IMT), Charter of the International Military Tribunal, 1945, abgerufen am 6.7.2021 von https://www.legal-tools.org/ doc $/ 64 f f d d /$. 
Projektionsfläche des „kollektive[n] Narzißmus“, 201 den Adorno den Deutschen dieser Zeit bescheinigt hat, war mit dem Tod Hitlers und dem Verlieren des Krieges zusammengebrochen und brandmarkte nun Deutschland national und international als moralisch verwerfliche Täternation. Die Verliererrolle bedeutete, dass Deutschland aufgrund seines niedrigen Platzes in der internationalen Staatenhierarchie nicht anders konnte, als sich mit seiner NS-Vergangenheit auseinanderzusetzen, seine Schuld zu bekennen und infolgedessen wenigstens eine Erinnerungspolitik zu etablieren. Nur indem Deutschland als Reaktion auf den vor allem von den USA ausgeübten Druck ${ }^{202}$ Bereitschaft zeigte, sich den moralischen Maximen der internationalen Gemeinschaft wieder unterzuordnen, vermochte es, sich als Teil dieser weitgehend $\mathrm{zu}$ rehabilitieren. ${ }^{203,204}$ Österreich, Italien, Japan und Frankreich seien von den USA nach Kriegsende nicht in gleicher Weise dazu angehalten worden, sich ihrer faschistischen Vergangenheit und ihrer Sympathie für den

201 Adorno, Was bedeutet, in: Adorno (Kadelbach, Hrsg.), Erziehung zur Mündigkeit.

202 Vgl. Richard Ned Lebow, Future conditional. The U.S. and its past, in: Kerstin von Lingen (Hrsg.), Kriegserfahrung und nationale Identität in Europa nach 1945. Erinnerung, Säuberungsprozesse und nationales Gedenken (Band 49 Krieg in der Geschichte, hrsg. Stig Förster/Bernhard R. Kroener/Bernd Wegner). Paderborn/München/Wien/Zürich 2009, S. 74-91, hier S. 87.

$203 \mathrm{Zu}$ den verschiedenen Bedürfnissen von Opfer- und Tätergruppen vgl. Nurit Shnabel/Arie Nadler, A Needs-Based Model of Reconciliation. Satisfying the differential emotional needs of victim and perpetrator as a key to promoting reconciliation, in: Journal of Personality and Social Psychology, 94 (2008), S. 116-132.

204 Dabei sollte der wiedererlangte politische und ökonomische Machtstatus Deutschlands nicht darüber hinwegtäuschen, dass die Bewertung der deutschen Entschuldigung und Wiedergutmachungsbemühungen seitens der Opfer der Shoah bzw. deren Erbberechtigten und stellvertretenden Organisationen bis heute ein kritisches Kriterium für die Ausdehnung des deutschen Handlungsspielraumes und seiner internationalen Positionierung bleibt. 
Nationalsozialismus $\mathrm{zu}$ stellen, unter anderem um einem reaktionären Linksruck in diesen Ländern vorzubeugen, erläutert der Politologe Richard Ned Lebow. Entsprechend sei in diesen Ländern Aufarbeitung nicht Teil des nationalen Narratives; stattdessen werde jeglicher Widerstand gegenüber den deutschen Nationalsozialisten als ruhmreicher Teil der eigenen Geschichte in den Vordergrund gestellt. Osteuropäische Staaten wiederum seien nach Ende des Kalten Krieges von den USA unter den Präsidenten George Bush Sr. und Bill Clinton sowie seitens der EU dazu aufgefordert worden, die den deutschen Nationalsozialisten im eigenen Land zuteil gewordene Unterstützung kritisch zu reflektieren, sofern sie in Zukunft westlichen Bündnissen angehören wollten. Dieser externe Druck, führt Lebow weiter aus, habe jedoch nur in jenen Fällen die intendierte Wirkung entfalten können, in denen er intern auf ein Mindestmaß an Akzeptanz der eigenen Mitschuld gestoßen sei. ${ }^{205}$

Angesichts dieser politologisch und historisch verorteten Perspektive auf die Voraussetzungen der Aufarbeitungsbereitschaft verwundert es kaum, dass Länder ohne äußeren Druck (aufgrund ihres vergleichsweise hohen Status im internationalen Gefüge) oder inneren Zwang (in Form sozialer Bewegungen mit großer politischer Tragweite) sich selten ihrem Anteil an Verbrechen gegen die Menschlichkeit gestellt haben. So ringt beispielsweise die \#BlackLivesMatterBewegung in den USA um Aufarbeitung der an der afroamerikanischen Bevölkerung verübten Verbrechen und, damit verbunden, um umfassende Reformen mit dem Ziel einer gleichberechtigten gesellschaftlichen Stellung; Bolivien als lateinamerikanisches Land mit einem hohen Anteil indigener Bevölkerung unterzeichnete die Indigenous and

205 Vgl. Lebow, Future conditional, in: Von Lingen (Hrsg.), Kriegserfahrung und nationale Identität, S. 87f. 
Tribal Peoples Convention ( $N^{\circ}$ 169) der International Labour Organisation (ILO) erst als Reaktion auf einen international beachteten Protestmarsch zahlenmäßig kleiner und verstreut lebender Ethnien und erkannte damit erstmals die kulturelle Diversität seiner Bevölkerung an; ${ }^{206}$ Australien und Kanada äußerten erst 2008 eine Entschuldigung für die an der indigenen Bevölkerung verübten Gräueltaten - nicht zuletzt als Reaktion auf den internationalen politischen Kontext, inklusive der Völkermorde in Ruanda und Jugoslawien. ${ }^{207}$ Die erst jüngst in Kanada entdeckten Gräber indigener Kinder in der Nähe von Zwangsinternaten schaffen zusätzliche Fakten, die Gegenstand einer ehrlichen Aufarbeitung sein müssen. Nach wissenschaftlicher Faktensammlung und Analyse jener historischen Verbrechen muss dann eine nationale Erinnerungspolitik und -kultur einsetzen, in deren Folge tief greifende Reformen zur marginalisierten Stellung der indigenen Bevölkerung stehen müssen.

Wie also ist der deutsche Beitrag zur Aufarbeitung im internationalen Kontext zu bewerten? Kann oder sollte tatsächlich von einer Vorbildrolle ausgegangen werden? Der Blick auf den Stand der Aufarbeitung in Deutschland ist sicherlich ernüchternd: Eine tief in der Gesellschaft verwurzelte und umfassende Erinnerungskultur scheint in

206 Vgl. Indigenous and Tribal Peoples Convention, C 169, 27.6.1989, abgerufen am 16.12.2012 von http://www.ilo.org/dyn/normlex/ en/f?p=1000:12100:0::NO::P12100_INSTRUMENT_ID:312314; vgl. Katharina F. Gallant, Evo Morales und Barack Obama zwischen Kulturdialog und Kulturkonflikt. Brücken der Interkulturalität in Abya Yala und America (Berliner Beiträge zur Ethnologie, Bd. 34), Berlin 2014.

207 Vgl. z.B. den Vortrag von Kerstin von Lingen im Rahmen der Kölner Vorträge im Wintersemester 2020/21, welcher - ironischerweise - über das Wissenschaftsportal L.I.S.A. der Gerda Henkel Stiftung abgerufen werden kann: vgl. Kerstin von Lingen, Dekolonialisierung der Gesellschaft durch Entschuldigungspolitik gegenüber first nations? Vom Umgang mit den "Stolen Generations“ in Australien und den „Residential Schools“ in Kanada, 24.11.2020, abgerufen am 7.7.2021 von https://lisa.gerda-henkel-stiftung. de/koelnervortraege_kerstinvonlingen. 
Deutschland nicht vorzuherrschen; vielmehr sind „die Mechanismen der Steuerung des nationalen Gedenkens“208 als Erinnerungspolitik sichtbar. Als solche ist das Gedenken in der Gesellschaft nicht eine von innen heraus empfundene Notwendigkeit, sondern eher ein von außen übergestülpter Verhaltenskodex, der Deutschland (gerade auch auf dem internationalen Parkett) Haltung bewahren lässt, der mitunter von der Bevölkerung aber als einengend empfunden wird, da er den freien Ausdruck unterbindet. Offizielle Gedenkveranstaltungen sowie die Thematisierung der Shoah im Bildungsbereich oder auch durch die (staatlichen) Medien geben vor, wie kollektive Erinnerung und Verantwortung aussehen sollen. Auf (lokal-) politischer Ebene und im Privaten zeigt sich jedoch weiterhin, was Adorno schon 1959 anprangerte: „Verdrängung des Gewußten oder halb Gewußten“" und „Mangel an Affekt gegenüber dem Ernstesten“. 209 Weitgehend unerreicht durch das Gedenken der Gräueltaten und des Leides bleibt auch die emotionale Ebene, die nach Hessel unbedingt miteinbezogen werden muss, um einen neuen Umgang mit der belastenden Vergangenheit zu ermöglichen: ${ }^{210}$ Anstatt angesichts des Grauens zu resignieren, gilt es, „dem Entsetzen [standzuhalten] durch die Kraft, selbst das Unbegreifliche noch zu begreifen", ${ }^{211}$ und durch eine gesellschaftliche Veränderung einen aktiven Umgang mit der kollektiven Schuld zu ermöglichen. Nur so kann

208 Kerstin von Lingen, Kriegserfahrung und die Formierung nationaler Identität in Europa nach 1945. Eine kurze Einführung, in: dies. (Hrsg.), Kriegserfahrung und nationale Identität in Europa nach 1945: Erinnerung, Säuberungsprozesse und nationales Gedenken (Band 49 Krieg in der Geschichte, hrsg. Stig Förster/Bernhard R. Kroener/Bernd Wegner). Paderborn/München/Wien/Zürich 2009, S. 11-26, hier S. 12.

209 Adorno, Was bedeutet, in: Adorno (Kadelbach, Hrsg.), Erziehung zur Mündigkeit.

210 Vgl. Hessel, Empört Euch!

211 Adorno, Was bedeutet, in: Adorno (Kadelbach, Hrsg.), Erziehung zur Mündigkeit. 
Brauner Boden

die Aufarbeitung der NS-Zeit gelingen, dem von Adorno kritisierten „Zerrbild, dem leeren und kalten Vergessen“212 der Rücken gekehrt und die „objektiven gesellschaftlichen Voraussetzungen“"213 verändert werden, die jenen Strukturen und Institutionen mit NS-Belastung bis heute Bestand geben. 


\section{Abschließende Betrachtungen zur NS-Durchdrungenheit}

$\mathrm{W}$

ir sitzen gemütlich im Esszimmer an dem hübschen antiken Tisch, der seit den späten 1930er Jahren im Besitz unserer Familie ist. Auf ihm stehen ein paar Tassen mit dampfendem Kaffee, den wir heute Morgen noch schnell bei EDEKA gekauft und jetzt mit einem Filter von Melitta aufgebrüht haben. Neben den Kaffeetassen stehen zum Naschen zwei Schälchen mit Keksen: für die Erwachsenen Butterblätter, die mit der schönen Eichenlaubform, und für die Kinder LEIPNIZ-Kekse, beide von Bahlsen. Außerdem liegt auf dem Tisch Das große Dr. Oetker Backbuch. Es ist ein wenig in die Jahre gekommen, wurde es doch schon 1983 herausgegeben, doch gelegentlich blättern wir noch gerne darin, wenn wir auf der Suche nach süßen kulinarischen Inspirationen sind - die wir mit unserem Thermomix von Vorwerk heute natürlich viel leichter zubereiten können oder uns an den duftenden Gugelhupf erinnern, den Oma immer in unserer Kindheit gebacken hat. Beim Gedanken an die kürzlich verstorbene Großmutter rollt uns eine Träne über die Wange, die wir schnell mit einem Tempo-Taschentuch wegwischen... 
Dies ist weder eine Szenenbeschreibung aus einer Vorabendserie, noch geht es hier um Schleichwerbung. Ganz im Gegenteil: Die in diesem Absatz willkürlich zusammengestellte Gruppe von beliebten Unternehmen profitierte wie Henkel, BMW und die anderen im Vorherigen aufgeführten Familienunternehmen von der NS-Zeit, wenn auch auf unterschiedliche Weise. Der genossenschaftlich organisierte EDEKA-Verbund blickt zurück auf eine freiwillige Gleichschaltung des Unternehmensverbundes, zunächst unter der Leitung des bereits 1933 in die NSDAP eingetretenen Generaldirektors Fritz Borrmann. Zwei Jahre später wurde dieser abgelöst von Paul König, der bis 1966 Hauptbetriebsführer von EDEKA blieb. Wie die verbandseigene Publikation zur Geschichte der EDEKA Zentralorganisation berichtet, verbreitete Paul König aktiv fake news, indem er jegliche „Greueltaten“ oder entsprechende Absichten des NS-Regimes gegenüber Jüdinnen und Juden in einem Brief an ausländische Einzelhandelsorganisationen leugnete, kurz bevor am 1. April 1933 die Entrechtung der jüdischen Bevölkerung mit dem Boykott jüdischer Geschäfte begann. Im Rahmen der Arisierungen übernahm EDEKA drei jüdische Weinkellereien, wobei mindestens zwei der jüdischen Enteigneten die Shoah nicht überlebten. Besagter Publikation des Verbandes ist zu entnehmen, dass EDEKA in der Nachkriegszeit die jüdischen Geschädigten bzw. ihre Erbberechtigten möglichst kostengünstig ,abspeisen“ wollte und Schadensersatzzahlungen verweigerte. Dabei hatte der Verband nicht nur direkt von den Arisierungen profitiert, sondern auch den Anschluss Österreichs und des Sudetenlandes genutzt, um seinen Umsatz zu steigern. Nach dem Ende des NS-Regimes begründeten die EDEKA-Führungskräfte ihre NSDAP-Eintritte mit wirtschaftlichen Interessen, und Paul König, der 1933/34 Mitglied der SA sowie ab 
1937 NSDAP-Mitglied gewesen war, konnte nach der Entnazifizierung als „Unbelasteter“ seine Leitungsfunktion wieder einnehmen. ${ }^{214}$

Allerdings gibt es Grund, an der Angemessenheit dieser Einstufung zu zweifeln. Der Journalist und Autor Lorenz S. Beckardt berichtet in seinem familienbiografischen Werk Der Jude mit dem Hakenkreuz, sein Großvater sei Mitglied der EDEKA-Genossenschaft gewesen, habe aufgrund seiner jüdischen Herkunft aber sein Geschäft aufgeben müssen und sei später wegen „Rassenschande“ denunziert und ins KZ Buchenwald gebracht worden. Aus diesem wurde er 1940 entlassen, woraufhin er nach England emigrierte. Nach Ende des NS-Regimes kehrte er jedoch nach Deutschland zurück und trat auch wieder der EDEKA bei, ,obwohl die Genossenschaft 1933 keinen Finger gerührt hatte, um ihm beizustehen“. ${ }^{215}$ Weiter erzählt Beckardt: „Er [sein Großvater] wusste, dass die selbständigen Kaufleute zum harten Kern der NSDAP-Wähler gehört hatten. [...] Er teilte der Edeka mit, dass er anlässlich seiner 25-jährigen Mitgliedschaft die übliche Ehrung erwarte. “216 Daraufhin wurde ihm jedoch zynisch vorgehalten, er habe 16 Jahre dieser Dienstzeit versäumt, ,und Direktor Paul König weigerte sich, die Jubiläumsurkunde zu unterzeichnen“. ${ }^{217}$

Noch unverfrorener als bei EDEKA zeigt sich der Judenhass in der Geschichte des Familienunternehmens Melitta. Wie der Sozialwissenschaftler Werner Dirks und der zu regionaler Zeitgeschichte publizierende Kristan Kossack herausstellen, leitete Horst Bentz von 1929 bis 1980 das Unternehmen,

214 Vgl. Holger Martens/Christine Lindner/Kai Rump, Dokumentation der Geschichte der EDEKA Zentralorganisation unter besonderer Berücksichtigung der EDEKABANK AG. 1907 bis 2012, Hamburg 2020.

215 Lorenz S. Beckardt, Der Jude mit dem Hakenkreuz. Meine deutsche Familie, Berlin 2015, hier S. 377.

216 Ebd., S. 377.

217 Ebd., S. 377. 
wobei er bereits 1933 NSDAP- und SS-Mitglied wurde und darüber hinaus für den Sicherheitsdienst des Reichsführers SS (Geheimdienst innerhalb der SS-Struktur) tätig war. ${ }^{218}$ Auszüge aus der Melitta Werkszeitung von 1938 sowie aus dem Melitta-Echo von 1940 bis 1944, wie die Werkszeitung ab 1939 genannt wurde, dokumentieren, wie dieses Veröffentlichungsorgan unter Bentz' Verantwortung Pogromhetze gegen die jüdische Bevölkerung verbreitete und die militärische Expansion Deutschlands unterstützte. ${ }^{219}$ So verwundert es kaum, dass Melitta 1941 als NS-Musterbetrieb ausgezeichnet wurde; Bentz, so berichtet Kossack, habe als Reaktion auf die Ehrung versprochen: „Der Betrieb und seine Arbeit gehören allezeit dem Führer.“"220 Dem MelittaUnternehmensleiter gelang es, während der NS-Zeit zu expandieren, obwohl die NS-Wirtschaft die Rüstungsindustrie gegenüber der Konsumgüterindustrie wie Melitta systematisch bevorzugte. Angesichts der aktiven Unterstützung des NS-Regimes und den resultierenden NS-Profiten, die Melitta für sich verbuchen konnte, verwundert es umso mehr, dass Bentz im Rahmen der Entnazifizierung schließlich nur als „Mitläufer“ eingestuft wurde. Ausschlaggebend dafür waren Persilscheine, die seine Rolle für das Regime und die Shoah verharmlosten und ihn gar als besonders

218 Vgl. Werner Dirks/Kristan Kossack, Ein „Musterbetrieb“?. Ehemaliger Melittachef Horst Bentz hatte mit Arbeitnehmerrechten nichts im Sinn [Manuskript], 2006, abgerufen am 20.8.2021 von http://www.zg-minden. de/ein__musterbetrieb__.html.

219 Vgl. Kristan Kossack, Melittawerke. Melitta - Dokument 1. Werkszeitung, 2004, abgerufen am 23.8.2021 von http://www.zg-minden.de/melittawerke. html; vgl. ders., Melittawerke. Melitta - Dokument 2. Feldpostbriefe aus Melitta-Echo, 2006, abgerufen am 23.8.2021 von http://www.zg-minden. de/melittawerke.html.

220 Horst Bentz gemäß einem im Mai 1941 erschienenen Artikel aus Westfälische Neuste Nachrichten zitiert nach Kristan Kossack, Entnazifizierungslegende. Der Fall des ehemaligen Melittachefs Horst Bentz, 2012, abgerufen am 23.8.2021 von http://www.zg-minden.de/entnazifizierungslegende.html. 
sozial gesinnten und unabkömmlichen Unternehmensführer darstellten. Diese glorifizierende Darstellung war derart überzeugend orchestriert, dass die Stadt Minden im Jahr 1964 Bentz für das Bundesverdienstkreuz vorschlug. ${ }^{221}$ Die Begründung umfasste eben die vermeintliche soziale Einstellung, die wirtschaftlichen Erfolge sowie Bentz' Rolle als Mäzen, der seine Heimatstadt Minden selbstlos unterstütze. ${ }^{222}$ Vom NS-Dokumentationszentrum in Berlin auf Bentz $z^{6}$ Mitgliedschaften in den diversen NS-Organen aufmerksam gemacht, wurde der Antrag zwar zurückgezogen, doch scheint die Stadt Minden im Gedenken an Bentz auch heute noch an dem Narrativ der weißen Weste festhalten zu wollen. Kritik an Bentz - und dem Familienunternehmen Melitta - sei in Minden oftmals ein Tabu, die Flecken in der weißen Weste würden geflissentlich übersehen, moniert Kossack. ${ }^{223}$

Lange Zeit präsentierte sich auch das Familienunternehmen Bahlsen unbescholten. Zwar war bekannt, dass in der NS-Zeit auch Zwangsarbeiterinnen und Zwangsarbeiter für das Unternehmen tätig gewesen waren. Doch sorgte dies nur für wenig Aufsehen, bis die 1993 geborene Unternehmenserbin Verena Bahlsen öffentlich zur Zwangsarbeit bei Bahlsen Stellung bezog: „Das war vor meiner Zeit und wir haben die Zwangsarbeiter genauso bezahlt wie die Deutschen und sie gut behandelt.“224 Diese Äußerung war nicht nur

221 Vgl. Dirks/Kossack, Musterbetrieb; vgl. Kossack, Entnazifizierungslegende.

222 Vgl. Stadtdirektor Dr. Krieg, Antrag der Stadt Minden auf Verleihung des Verdienstordens der Bundesrepublik Deutschland an Herrn Fabrikant Horst Bentz, Minden, Blumenstraße 25, Minden 17.3.1964, abgerufen am 23.8.2021 von http://www.zg-minden.de/HorstBentz-StadtMinden.pdf; vgl. Dirks/Kossack, Musterbetrieb; vgl. Kossack, Entnazifizierungslegende.

223 Vgl. Kossack, Entnazifizierungslegende.

224 Verena Bahlsen zitiert nach Max Czollek, Bahlsen und die Zwangsarbeit. Alternative Fakten über die NS-Zeit von der Erbin des Keks-Imperiums, Jüdische Allgemeine (15.05.2019), abgerufen am 23.8.2021 von https:// www.juedische-allgemeine.de/meinung/bahlsen-und-die-zwangsarbeit/. 
unbedarft und anmaßend, sondern auch faktisch unhaltbar (Zwangsarbeiterinnen und Zwangsarbeiter waren deutschen Angestellten nicht gleichgestellt) und zudem moralisch höchst fragwürdig: Im Falle von ererbtem Vermögen, das auf Entrechtung und Leiden anderer Menschen zurückzuführen ist, gibt es kein „Verfallsdatum“ der Schuld, nach dessen Ablauf die Erbin von einem verantwortungsvollen Umgang mit der Unternehmensgeschichte freigesprochen werden könnte. ${ }^{225}$

225 Die Einstellung, der zeitliche Abstand würde Unternehmenserbinnen und erben exkulpieren, ist auch bei anderen Unternehmen zu finden. Jüngst konterte Klaus-Michael Kühne, Unternehmenserbe von Kühne+Nagel Logistik und gegenwärtig drittreichster Deutscher, in einem Interview auf die Frage nach der NS-Vergangenheit der Firma (Transport von Einrichtungsgegenständen deportierter Jüdinnen und Juden aus Frankreich, Belgien, den Niederlanden und Luxemburg nach Deutschland zwecks Versteigerung), er selbst sei bei Kriegsende noch ein kleines Kind gewesen und eine systematische wissenschaftliche Auswertung der „Vorkommnisse“ sei ,nicht notwendig, denn mehr als das, was allgemein bekannt ist, wissen wir nicht“. Klaus-Michael Kühne, ,Jeder hat einen Makel“ (Interview: Marc Widmann), ZEIT ONLINE (27.10.2021), abgerufen am 1.11.2021 von https:// www.zeit.de/2021/44/klaus-michael-kuehne-milliardaer-unternehmerkuehne-nagel-pandemie. Kühne begründete die eingeschränkte Datenlage damit, die Unternehmensarchive seien im Krieg Bomben zum Opfer gefallen, wobei er unerwähnt lässt, dass der Historiker und Politologe Wolfgang Dreßen im Kölner Finanzamt umfangreiche Akten zur NS-Verstrickung der Möbeltransporte des Unternehmens auswerten konnte. Auch erwähnt Kühne nicht, dass der jüdische Anteilseigner Adolf Maass bis 1933 mit 45 Prozent Teilhaber des Familienunternehmens war, dann jedoch von KlausMichaels Vater und Onkel zum Ausscheiden gedrängt wurde. Maass, der von Kühne+Nagel nicht einmal seine vertragsmäßige Abfindung erhielt, wurde später im KZ ermordet. Unerwähnt lässt Klaus Michael Kühne auch, dass sein Vater und sein Onkel kurz nach Maass` Ausscheiden NSDAP-Mitglieder wurden und dass Kühne+Nagel mehrfach als NS-Musterbetrieb ausgezeichnet wurde. Nach Kriegsende durften Klaus-Michael Kühnes Vater und Onkel aufgrund ihrer NS-Belastung zunächst die Leitung der Firma nicht wieder übernehmen. Alfred Kühne, der Vater von Klaus-Michael Kühne, wurde 1948 jedoch auf Anordnung der CIA entnazifiziert - ein Hinweis auf die nicht zwangsläufig ehrenhafte Rolle, die den Siegermächten bei der Gestaltung der Nachkriegswirtschaft zukam. Vgl. Christian Kleinschmidt/Claus Leggewie, Die Abräumer. Kühne + Nagel profitierte von der Arisierung. Und schweigt, DIE ZEIT (14.7.2016), abgerufen am 1.11.2021 von https:// 
Bahlsen selbst scheint bewusst geworden $\mathrm{zu}$ sein, wie unpassend die Worte der Unternehmenserbin in den Ohren der Zuhörerinnen und Zuhörer klangen und veranlasste als Reaktion eine wissenschaftliche Untersuchung der Unternehmensgeschichte durch den Historiker Manfred Grieger, dersichbereits durch diewissenschaftliche Aufarbeitung der Zwangsarbeit bei Volkswagen einen Namen gemacht hatte - und eben diesen Konzern hatte verlassen müssen, nachdem er Kritik geübt hatte an der (mangelnden) Aufarbeitung durch die VW-Tochter Audi. ${ }^{226}$ Die wissenschaftliche Aufarbeitung von Bahlsens NS-Geschichte durch Grieger ist noch nicht abgeschlossen. In einem aktuellen Vortrag resümiert Grieger dennoch den gegenwärtigen Forschungsstand: Die Führungsriege des Familienunternehmens sei bereits früh der NSDAP beigetreten und habe die SS unterstützt. Anlass dafür sei nicht unbedingt eine empfundene Nähe zur NS-Ideologie gewesen, wohl aber wirtschaftliche Interessen. So sei es Bahlsen gelungen, sein Produktionsgewicht in der NS-Zeit zu verdreifachen; zudem habe das Unternehmen von der Besetzung Kiews profitiert, indem es eine dort ansässige Keksfabrik verwaltet habe. ${ }^{227}$

www.zeit.de/2016/30/kuehne-nagel-geschichte-nazi-zeit/komplettansicht; vgl. Henning Bleyl, Lasten der Vergangenheit, taz (31.3.2015), abgerufen am 1.11.2021 von https://taz.de/NS-Erbe-einer-Transportfirma/!5014561/; vgl. Henning Bleyl, Geschichtsschreibung bei Kühne+Nagel. Des Patriarchen alternative Fakten, taz (29.7.2018), abgerufen am 1.11.2021 von https://taz. de/Geschichtsschreibung-bei-KuehneNagel/!5520283/.

226 Vgl. Michael Verfürden, Deutsche Unternehmen in der NS-Zeit. Dieser Mann soll bei der Aufarbeitung helfen, Handelsblatt (21.10.2019), abgerufen am 24.8.2021 von https://www.handelsblatt.com/unternehmen/ handel-konsumgueter/manfred-grieger-deutsche-unternehmen-inder-ns-zeit-dieser-mann-soll-bei-der-aufarbeitung-helfen/25137482. html?ticket=ST-10965746-X3PfxWGcOhRxQFebeVOo-ap4.

227 Vgl. Manfred Grieger, Ein ganz anderes Unternehmen? Die Familienunternehmen Sartorius und Bahlsen im Nationalsozialismus und Nachkrieg, in: Lüdenscheider Gespräche des Instituts für Geschichte und Biographie der FernUniversität in Hagen (10.3.2021), abgerufen am 18.8.2021 von https://www.fernuni-hagen.de/videostreaming/archiv/ksw/ video/video_2021-10.shtml. 
Auch in den besetzten Niederlanden habe sich Bahlsen an der Übernahme von Backwarenindustrien interessiert gezeigt und wurde dabei von Rudolf Diels, dem ersten Chef der Gestapo, unterstützt. ${ }^{228}$ Wie von der Unternehmenserbin bereits eingeräumt, beschäftigte Bahlsen auch Zwangsarbeiterinnen und Zwangsarbeiter. Grieger kommentiert:

„Die unternehmerische Selbstverständlichkeit, mit der diese zumeist rechtlosen Menschen als verfügbare Ressource in den Betriebsalltag integriert wurden, ist ja doch recht viel bekannt im Allgemeinen und betraf natürlich nicht nur Familienunternehmen. Vielleicht der einzige Unterschied: Im Nachhinein taten Familienunternehmen besonders gern so, als wären sie besonders gut zu ihren Menschen gewesen." ${ }^{229}$

Die drei Bahlsen-Söhne, die während der NS-Zeit das Unternehmen geleitet hatten, überstanden die Entnazifizierung glimpflich und, ,[n]ach Ende der NS-Diktatur erhielt das Unternehmen als unverzichtbarer Nahrungsmittelproduzent rasch eine Produktionsgenehmigung und fand $\mathrm{zu}$ seiner Rolle und Bedeutung zurück" ${ }^{230}$ wobei womöglich gute Beziehungen zur britischen Besatzung eine Rolle gespielt haben könnten. ${ }^{231}$ Schließlich, so verkündet die unternehmenseigene Webseite, ,erlangte Bahlsen spätestens mit dem Wiedereinstieg Werner Bahlsens in die Politik 1957 Möglichkeiten zur umfassenden politischen und wirtschaftlichen Einflussnahme." 232

Dr. Oetker ist ein weiteres Familienunternehmen, das heute erfolgreicher Bestandteil der nationalen und

228 Vgl. Verfürden, Deutsche Unternehmen.

229 Grieger, Familienunternehmen, 36:42-37:13.

230 The Bahlsen Family, 1933-1945. Bahlsen während des NS-Zeit, 2021, abgerufen am 24.8.2021 von https://www.thebahlsenfamily.com/?id=558.

231 Vgl. Grieger, Familienunternehmen.

232 The Bahlsen Family, 1933-1945. 
internationalen Konsumgüterindustrie ist - und auf eine eindeutig NS-belastete Geschichte zurückblickt. Eine geschichtswissenschaftliche Untersuchung der Unternehmensgeschichte erfolgte 2009. ${ }^{233}$ Die Historiker Jürgen Finger, Sven Keller und Andreas Wirsching berichten von einer Verstrickung in das NS-Regime von beachtlichem Ausmaß: Richard Kaselowsky (1888-1944), der treuhänderisch das Unternehmen führte, bis sein Stiefsohn Rudolf-August Oetker (1916-2007) bereit war, die Leitung zu übernehmen, war ab 1933 NSDAPMitglied und schloss sich später auch der SS an; RudolfAugust Oetker war bereits in den 1930er Jahren Mitglied der Reiter-SA und trat 1942 der Waffen-SS bei. Jüdische Angestellte wurden entlassen; das Unternehmen wurde bereits 1937 als Musterbetrieb ausgezeichnet und profitierte von der NS-Wirtschaft durch die Versorgung der Truppen sowie der Zivilbevölkerung. Da Dr. Oetker 1942 als bedeutsam für die Kriegswirtschaft eingestuft wurde, hatte das Familienunternehmen weitaus weniger mit dem Problem der Rohstoffknappheit zu kämpfen als andere Unternehmen, deren Produkte für das NS-Regime von geringerem Interesse waren. Auf Zwangsarbeiterinnen und Zwangsarbeiter wurde vergleichsweise wenig zurückgegriffen, da das Unternehmen ohnehin vorwiegend junge Frauen beschäftigte, die nicht eingezogen wurden, sodass Dr. Oetker auch in Kriegszeiten keinen Arbeitskräftemangel hatte. Wohl aber spielten Arisierungen jüdischen Eigentums für Rudolf-August Oetker als Privatperson eine Rolle, der beim Erwerb einer Villa und eines Grundstückes mit Tennisplatz in Hamburg von der Notlage der jüdischen Verkaufenden profitierte. Darüber hinaus verweisen Finger et al. auf eine Reihe anderer Unternehmen jüdischen Ursprungs, an denen Dr. Oetker

233 Vgl. Jürgen Finger/Sven Keller/Andreas Wirsching, Dr. Oetker und der Nationalsozialismus: Geschichte eines Familienunternehmens 1933-1945, München 2013. 
indirekt durch Aktienbesitz beteiligt war; diese Anteile hatte Dr. Oetker über einen Mittelsmann erworben, sodass das Familienunternehmen nicht als direkter Initiator oder unmittelbarer Profiteur von Arisierungen in Erscheinung trat. In den Unternehmen, für die Dr. Oetker auf diese Weise Anteile erwarb, war die Beschäftigung von Zwangsarbeiterinnen und Zwangsarbeitern zur Tagesordnung. Abgesehen von dem wirtschaftlichen Schaden der Enteigneten und der Entrechtung der Zwangsarbeiterinnen und Zwangsarbeiter, die Dr. Oetker willentlich in Kauf nahm, um seine eigenen Profite zu steigern, ergeben sich aus dem Aktienbesitz des Unternehmens auch Verstrickungen in den Massenmord an der jüdischen Bevölkerung: Eklatantes Beispiel hierfür sind die Aktien des Schuhfabrikanten Salamander, der jüdische KZ-Häftlinge auf der Schuhprüfstrecke de facto zu Tode foltern ließ. Darüber hinaus war Dr. Oetker in die Shoah verstrickt, indem das Unternehmen 1943 gemeinsam mit den Hamburger Phrix-Werken und der SS die Hunsa-Forschungs-GmbH gründete. Hier sollten künstliche Nahrungsmittel entwickelt und vertrieben werden. Um den Arbeitskräftemangel der Phrix-Werke zu beheben, hatte sich Dr. Oetker im Vorfeld bei der SS für die Behebung dieses Mangels eingesetzt, woraufhin die bereits für Phrix tätigen Zwangsarbeiter durch bis zu $500 \mathrm{KZ}$-Häftlinge unterstützt wurden. Dabei hatte das Phrix-Werk Wittenberge sich schon 1942 einen Namen gemacht als eines der ,ersten rein privatwirtschaftlichen Unternehmungen, das über ein eigenes KZ-Außenlager verfügte“. ${ }^{234}$ Finger et al. bezweifeln, dass die Hunsa-Forschungs-GmbH jemals in das operative Geschäft eingestiegen ist; letztlich scheint sie als Ausdruck

234 Finger/Keller/Wirsching, Dr. Oetker, 317. 
einer geschäftlichen Beziehung zur SS einen gewissen Selbstwert für Dr. Oetker gehabt zu haben. ${ }^{235}$

Nach dem Ende des NS-Regimes wurde Rudolf-August Oetker zunächst von der britischen Besatzungsmacht verhaftet, kam jedoch nach acht Monaten wieder frei, unter anderem nachdem ,zehn Oetker-Mitarbeiter ein Freilassungsgesuch ein[gereicht hatten]; außerdem [waren] Unterschriften ehemaliger Konzentrationslagerhäftlinge in Bielefeld und Hamburg gesammelt [worden]“. ${ }^{236}$ Während Rudolf-August Oetker zunächst seine leitende Stellung nicht wieder ausfüllen durfte, wurde er schließlich in seinem Entnazifizierungsverfahren 1947 doch als ,unbelastet $^{\text {“ }}$ eingestuft. Dies sei, so Finger et al., möglich gewesen, indem die NS-Verstrickung des Familienunternehmens weitgehend dem 1944 bei einem Bombenangriff getöteten Kaselowsky angelastet wurde, weshalb Rudolf-August Oetker die Unternehmungsleitung wieder in vollem Umfang übernehmen durfte. ${ }^{237}$ Auch die verhängte treuhänderische Verwaltung des Firmenvermögens wurde 1947 aufgehoben, sodass Rudolf-August Oetker auch wirtschaftlich vollends rehabilitiert war. ${ }^{238}$

Deutlich geringer als bei Dr. Oetker wirkt die NS-Verstrickung des Familienunternehmens Vorwerk \& Co.: Das Familienunternehmen wurde um die Jahrtausendwende herum konfrontiert mit kritischen Fragen $\mathrm{zu}$ seiner NS-Vergangenheit, woraufhin die Unternehmensarchivarin Beate Battenfeld und der Historiker Florian Speer mit deren Erforschung beauftragt wurden. ${ }^{239}$ Ihre Untersuchung,

235 Vgl. Finger/Keller/Wirsching, Dr. Oetker.

236 Finger/Keller/Wirsching, Dr. Oetker, S. 377.

237 Vgl. Finger/Keller/Wirsching, Dr. Oetker.

238 Ebd.

239 Vgl. Beate Battenfeld/Florian Speer, Vorwerk \& Co. und seine Arbeiter im Zweiten Weltkrieg, Wuppertal 2000. 
herausgegeben vom unternehmenseigenen Verlag, bestätigte die Beschäftigung von bis zu 600 Zwangsarbeiterinnen und Zwangsarbeitern durch Vorwerk und räumt ein, dass das Unternehmen mit Kriegsbeginn seine Produktion auf Rüstungsgüter umstellte und zu diesem Zweck 1942 Teile der Produktion nach Lodz/Litzmannstadt verlagerte. Eine Beschäftigung jüdischer Zwangsarbeiterinnen und Zwangsarbeiter wird von dieser Publikation jedoch nicht bestätigt, ${ }^{240}$ wenn auch ein Rückgriff auf die im Ghetto Lodz eingepferchten Jüdinnen und Juden als Arbeitskräfte im Kontext der NS-Wirtschaft nicht unwahrscheinlich gewesen wäre. ${ }^{241}$ Die Unternehmerfamilie selbst scheint ideologisch dem NS-Regime nicht besonders verbunden gewesen zu sein: August Mittelsten Scheid (1871-1955) trat nicht der NSDAP bei, zog sich nach Machtergreifung der Nationalsozialisten aus Verbandsaktivitäten zurück und übergab seinen Söhnen Werner (1904-1953) und Erich (1907-1993) die Unternehmensführung, nachdem 1943 Teile des Unternehmens einem Bombenangriff zum Opfer gefallen waren. ${ }^{242}$ Allerdings wird Vorwerk nachgesagt, dass seine Staubsaugervertreter bis zur Einstellung des Direktvertriebs im Jahr 1943 letzteren auch genutzt haben sollen, um Propaganda-Bildserien zu verkaufen. ${ }^{243}$ Es ist

240 Vgl. Christian Schott, Familienunternehmen und „global player“. Vorwerk \& Co. und der Umgang mit der eigenen Vergangenheit (Interview mit Petra Mertins, Unternehmenssprecherin von Vorwerk \& Co.), in: Akkumulation, 12 (1999), S. 6-8, abgerufen am 28.8.2021 von https://www.kritischeunternehmensgeschichte.de/sites/default/files/Interview_Schott.pdf.

241 Vgl. Susanne Härtel, Das Ghetto Lodz/Litzmannstadt, in: Lebendiges Museum Online (Lemo), abgerufen am 29.8.2021 von https://www.dhm. de/lemo/kapitel/der-zweite-weltkrieg/voelkermord/ghetto-lodz.html.

242 Vgl. Beate Brüninghaus/August Mittelsten Scheid in: Neue Deutsche Biographie, 17 (1994), S. 580-581, abgerufen am 29.8.2021 von https:// www.deutsche-biographie.de/pnd138391653.html\#ndbcontent.

243 Vgl. Sebastian Schröder, Vom Staubsauger zur Flak - Steigerung des Profits mit allen Mitteln. Vorwerk \& Co. Wuppertal, in: Rallye „Spurensuche Verbrechen der Wirtschaft 1933-1945“ (2009), abgerufen am 29.8.2021 von http://www.verbrechen-der-wirtschaft.de/texte/0036_vorwerk.htm; 
folglich davon auszugehen, dass der Unternehmensleitung die Grundzüge der NS-Ideologie und ihrer völkermörderischen Konsequenzen direkt bekannt waren und sie diese womöglich im Rahmen ihrer unternehmerischen Aktivitäten im Direktvertrieb sogar unterstützten.

Der Direktvertrieb beziehungsweise später der Direktversand spielte auch bei der Vermarktung der Taschentücher der Marke Tempo eine Rolle, ${ }^{244}$ wenn auch hier keine Verknüpfung mit einem Verkauf von NS-Propagandamaterial bekannt ist. Vielmehr geht die Idee der Einmaltaschentücher aus Papier zurück auf den jüdischen Unternehmer Oskar Rosenfelder, für die dieser 1929 ein Patent anmeldete. Unmittelbar nach der Machtergreifung der Nationalsozialisten begann das NS-Regime, den jüdischen Unternehmer und seinen Bruder zu bedrohen. Sie flohen ins Ausland; ihr Unternehmen „Die Vereinigten Papierwerke“ fiel der Arisierung zum Opfer und ,ging für einen Bruchteil ihres tatsächlichen Wertes an einen der größten Opportunisten unter den deutschen Unternehmern in der NS-Zeit: Gustav Schickedanz", ${ }^{245}$ wie in einer Charakterisierung des Gründers des 1927 gegründeten Versandhauses Quelle berichtet wird.

Schickedanz war bereits 1932 in die NSDAP eingetreten und gilt als Profiteur von mindestens zehn arisierten Unternehmen und Grundstücken. ${ }^{246}$ Als sich abzeichnete, dass Deutschland den Krieg verlieren würde, überschrieb er sein Eigentum jedoch

vgl. Florian Rinke, Der Spaß am Spießertum, in: RP Online (22.3.2016), abgerufen am 29.8.2021 von https://rp-online.de/wirtschaft/unternehmen/ kobold-und-thermomix-der-spass-am-spiessertum_aid-18571953.

244 Vgl. Gregor Schöllgen, Gustav Schickedanz. Biographie eines Revolutionärs. Die QUELLE-Story, Berlin 2010.

245 Uwe Ritzer, „Tempo“. Eine deutsche Geschichte, in: Süddeutsche Zeitung (25.01.2019), abgerufen am 29.8.2021 von https://www.sueddeutsche.de/ politik/tempo-eine-deutsche-geschichte-1.4303294.

246 Vgl. Eckart Dietzfelbinger, Warum braune Flecken kein Makel blieben. Anmerkungen zum Fall Gustav Schickedanz in: transit nürnberg, 2 (2008), S. 31-36. 
seiner Frau und seiner Tochter, sodass sein Privatbesitz nach Kriegsende nur noch indirekt mit den Arisierungen der 1930er Jahre in Verbindung stand. ${ }^{247}$ Nach Ende des NS-Regimes wurde Schickedanz zunächst untersagt, seinen Beruf weiter auszuüben, und ein Entnazifizierungsverfahren wurde eingeleitet; darin wurde er 1949 jedoch lediglich als Mitläufer eingestuft und konnte bald seine Führungsposition im QuelleUnternehmen wieder einnehmen. Die Auseinandersetzung mit den ehemaligen jüdischen Eigentümern bzw. ihren Erbberechtigten endete 1947 in einem Vergleich, der eine Entschädigungszahlung in Höhe von 1,6 Millionen DM zugunsten letzterer festsetzte. Die Frage der Angemessenheit der Einstufung Schickedanz als Mitläufer sowie der Höhe der Entschädigungszahlung wird in Historikerkreisen unterschiedlich beurteilt. Gregor Schöllgen, Historiker und Autor verschiedener Politiker- und Unternehmerbiografien, hat den Nachlass des Quelle-Gründers ausgewertet und kommt in seiner Biografie von Gustav Schickedanz zu dem Schluss, dessen Entlastung sei absolut stichhaltig gewesen. ${ }^{248}$ Auf der Grundlage der eigens neu ausgewerteten Verfahrensakten zweifeln andere Historiker diese Einschätzung an: Eckart Dietzfelbinger geht von einer eindeutigen NS-Belastung Schickedanz aus, ${ }^{249}$ und Peter Zinke resümiert:

„Im Fall Schickedanz haben entweder die unterschiedlichen Belastungszeugen [u.a. wurde Schickedanz entlastet durch den Wirtschaftspolitiker und späteren Bundeskanzler Ludwig Erhard] durchweg gelogen oder es kristallisiert sich ein deutliches Verhaltensmuster heraus: Gustav Schickedanz hat hervorragende Beziehungen zur NSDAP-Gauleitung. Mit Hilfe dieser Machtinstanz

247 Vgl. Schöllgen, Schickedanz; vgl. Peter Zinke, „Er drohte wieder mit der Gauleitung“. Gustav Schickedanz und die „Arisierungen“, in: nurist Schwerpunktthema. Entrechtung und Enteignung (2008), S. 62-80.

248 Vgl. Schöllgen, Schickedanz.

249 Vgl. Dietzfelbinger, braune Flecken. 
wird auf die (meist) jüdischen Besitzer von lukrativen Immobilien Druck ausgeübt, der bis zur Inhaftierung und angedrohten Einweisung in ein $\mathrm{KZ}$ reicht. Die Drohungen führen dazu, dass die Haus- oder Fabrikbesitzer zum Verkauf genötigt werden. Dies hat Schickedanz über einen Zeitraum von mindestens fünf Jahren genutzt. Die Einschätzung der Spruch- und Wiedergutmachungskammer, er habe dies nicht gewollt oder nichts davon gewusst, sind nach Auswertung der Akten nur als abwegig zu bezeichnen." ${ }^{250}$

Zinke geht noch einen Schritt weiter, indem er die Schickedanz Einstufung im Entnazifizierungsverfahren als Symptom einer systemischen Insuffizienz in der Nachkriegsära sieht. Spruchkammerverfahren wie jenes, vor dem sich Schickedanz habe verantworten müssen, seien „Mitläuferfabriken“251 gewesen - so die vom Historiker Lutz Niethammer verwendete Terminologie - mit der „Funktion, Schickedanz, wie auch viele andere in seiner Position, ,weißzuwaschen', da er zu Beginn des Wirtschaftswunders als unverzichtbarer Faktor galt.“252

Die Tempo-Taschentücher selbst waren weit über das Wirtschaftswunder hinaus derartig erfolgreich, dass der Markenname im deutschen Sprachraum längst zum Synonym für die Produktidee geworden ist - und 1949, das heißt in demselben Jahr, in dem Schickedanz als Mitläufer entnazifiziert wurde, bezog sich auch der Werbeslogan der TempoTaschentücher auf die besondere Bedeutung der Reinheit im Nachkriegsdeutschland: „Die Hygiene eines Volkes, ein Gradmesser seiner Kultur“"253. Für braune Westen gab es im Wirtschaftswunder keinen Platz; Persilscheine sollten

250 Zinke, Schickedanz, S. 79f.

251 Vgl. Lutz Niethammer, Die Mitläuferfabrik. Die Entnazifizierung am Beispiel Bayerns, Bonn 1982.

252 Zinke, Schickedanz, S. 80.

253 Ritzer, „Tempo“. 
sie bleichen, damit der Gründungsmythos des modernen Deutschland in strahlendem Weiß erglänzen konnte.

In diesem Buch wurde am Beispiel der rheinischen Kleinstadt Unkel die deutsche Aufarbeitung der NS-Zeit und die Erinnerungspolitik kritisch porträtiert. Am Beispiel von Unkel lassen sich die Unzulänglichkeiten der Aufarbeitung im Lokalen aufzeigen, doch steht dahinter ein systemisches Problem, das weit über die Grenzen der Kleinstadt hinausgeht. Der deutsche Unternehmens- und Finanzsektor ist nach wie vor durchdrungen von NS-belasteten (Familien-) Unternehmen, deren Produkte, wie in vorstehender Szenenbeschreibung skizziert, im deutschen Alltag fortwährend präsent sind. Mehr noch verweist das institutionalisierte Mäzenatentum darauf, dass (lokal-)politische Entscheidungen oftmals in Zusammenhang stehen mit den Geldern eben dieser Unternehmen. Obwohl in Presse, wissenschaftlicher Debatte und öffentlicher Diskussion unterrepräsentiert, gibt es bis heute reale wirtschaftliche Auswirkungen der NS-Zeit. Wenn vom Wirtschaftswunder der Nachkriegsära die Rede ist, sollten wir dabei nicht außer Acht lassen, dass Familien wie Henkel, Dassler oder Quandt ihr während der NS-Zeit angehäuftes Vermögen von der internationalen Gemeinschaft nicht wieder weggenommen wurde. Ein Großteil des Kapitals, auf dem das moderne Deutschland aufgebaut ist, steht nach wie vor in Verbindung mit einem der ungeheuerlichsten Diebstähle sowohl von Vermögen als auch von Menschenleben, die die Welt je gesehen hat. ${ }^{254}$

254 Gemäß einer Schätzung des vormals für das US-Finanzministerium und die CIA tätigen Wirtschaftswissenschaftlers Sidney Zabludoff wurden weniger als 20 Prozent des von den Nazis und ihren Kollaborateuren gestohlenen jüdischen Vermögens zurückgezahlt. Die auf gesamteuropäischer Ebene ausstehende Summe beziffert Zabludoff auf 115 bis 175 Milliarden US-Dollar (gemäß der Preise von 2005). Bezogen auf das Gebiet des heutigen Deutschland beträgt der Anteil der Reparationszahlungen für die gestohlenen jüdischen 
Wie eingangs erläutert, liegt der Fokus dieses Buches auf der Analyse des Status quo, die hier durch nur kleine Hinweise auf mögliche best practices angereichert wird. Umfassendere Politikempfehlungen zur Erneuerung der deutschen Aufarbeitungsbemühungen $\mathrm{zu}$ entwickeln ist eine Herausforderung, die einen größeren Rahmen verlangt. Doch auch ohne Handlungsempfehlungen für die Politik wird deutlich, wie essenziell eine Diagnose des Zustandes der gegenwärtigen Aufarbeitung ist. Bliebe diese Problemdefinition aus, würde dadurch einem Fortbestehen der aktuellen Praxis Vorschub geleistet werden. Die gängige Aufarbeitungspraxis ist nicht nur unzureichend, insofern sie sich oft dem Thema eher halbherzig oder unbedarft nähert, anstatt sich tiefergehend mit der NS-Belastung der heutigen Gesellschaft auseinanderzusetzen. Darüber hinaus birgt der oberflächliche Charakter der gegenwärtigen Aufarbeitungskultur die Gefahr, sich in falscher Sicherheit zu wähnen: Jüdinnen und Juden wird suggeriert, Deutschland habe sich tiefgreifend und umfassend entnazifiziert, sodass Auschwitz „Nie wieder“ möglich sein könne; nicht-jüdischen Deutschen aber wird suggeriert, Deutschland habe

Vermögenswerte der NS-Zeit dagegen nur zehn Prozent. Vgl. Sidney Zabludoff, At issue. Restitution of Holocaust-era assets. Promises and reality, in: Jewish Political Studies Review 19 (2007), No. 1/2, S. 3-14. https://www. jstor.org/stable/25834718. - Selbst wenn in den vergangenen 15 Jahren weitere Rückzahlungen durch Deutschland bzw. deutsche Akteure erfolgt sind, so bleibt der Anteil der geleisteten Zahlungen doch beschämend gering. Das Gros der Vermögenswerte scheint nach Ende des Nationalsozialismus in der jeweiligen nationalen Wirtschaft verblieben zu sein. Im deutschen Kontext half es, die junge Bundesrepublik zu einer europäischen Wirtschaftsmacht heranwachsen zu lassen. Dies bedeutet unweigerlich, dass ein Lob des deutschen Wirtschaftswunders der Nachkriegsära in jüdischen Ohren wie blanker Hohn klingen muss: Gestohlene jüdische Vermögenswerte, deren Wert dem Gesamtvolumen des Marschallplans entspricht, verblieben in einer Wirtschaft, zu deren zentralen Akteuren nach wie NS-belastete (Familien-) Unternehmen zählen. Ausgerechnet Henkel, Dassler, Bahlsen, Quandt et cetera sind bis heute Nutznießer dieses „Wunders“. 
genug getan beziehungsweise das vergangene Leid lasse sich ohnehin nicht ungeschehen machen, sodass jegliches weitere Hinterfragen der NS-Belastung gesellschaftlicher Strukturen nicht nur unangenehm, sondern vor allem auch unnötig sei.

In diesem Sinne droht auch heute noch jeder Änderungswille „,sofort der überwältigenden Kraft des Bestehenden ausgesetzt [zu sein] und zur Ohnmacht verurteilt [zu] erscheinen“.255 Nichtsdestotrotz bleibt das ethische Mandat, sich für eine gerechtere Welt und ein ebensolches gesellschaftliches Miteinander einzusetzen. Hierfür aber ist es unumgänglich, über den Status quo der Aufarbeitung aufzuklären, auf einen mündigen Umgang mit der Geschichte hinzuwirken ${ }^{256}$ und schließlich dem Widerspruch und Widerstand gegenüber der systematischen NS-Belastung deutscher Strukturen durch ein empörtes gesellschaftliches Engagement ${ }^{257}$ Ausdruck zu verleihen.

„Wer in der Zukunft lesen will, muss in der Vergangenheit blättern.“258 Diese Formulierung des französischen Schriftstellers und Politikers André Malraux ist dem Vorwort der EDEKA-Geschichtsdokumentation vorangestellt. Doch in der Vergangenheit blättern genügt nicht, erlaubt dies doch, unangenehme Seiten zu überschlagen. Im Gegenteil: Wir müssen das Kleingedruckte lesen, Worte auf die Goldwaage legen und ausgehend von einer aufrichtigen Auseinandersetzung mit der Geschichte verantwortungsvoll die Zukunft gestalten.

255 Theodor W. Adorno, Erziehung zur Mündigkeit, in: Theodor W. Adorno (Gerd Kadelbach, Hrsg.), Erziehung zur Mündigkeit: Vorträge und Gespräche mit Helmut Becker 1959 bis 1969, Berlin (1969) 2013.

256 Vgl. ebd.

257 Vgl. Hessel, Empört Euch!.

258 Markus Mosa/Ralf Gerking/Jürgen Manegold, Vorwort, in: Holger Martens/Christine Lindner/Kai Rump, Dokumentation der Geschichte der EDEKA Zentralorganisation unter besonderer Berücksichtigung der EDEKABANK AG. 1907 bis 2012, Hamburg 2020, S. 5. 